\title{
ESTUDIO DE LA OBSERVACIÓN COMO ALTERNATIVA TERAPÉUTICA EN EL MELANOMA DE COROIDES
}

\author{
TESIS DOCTORAL
}

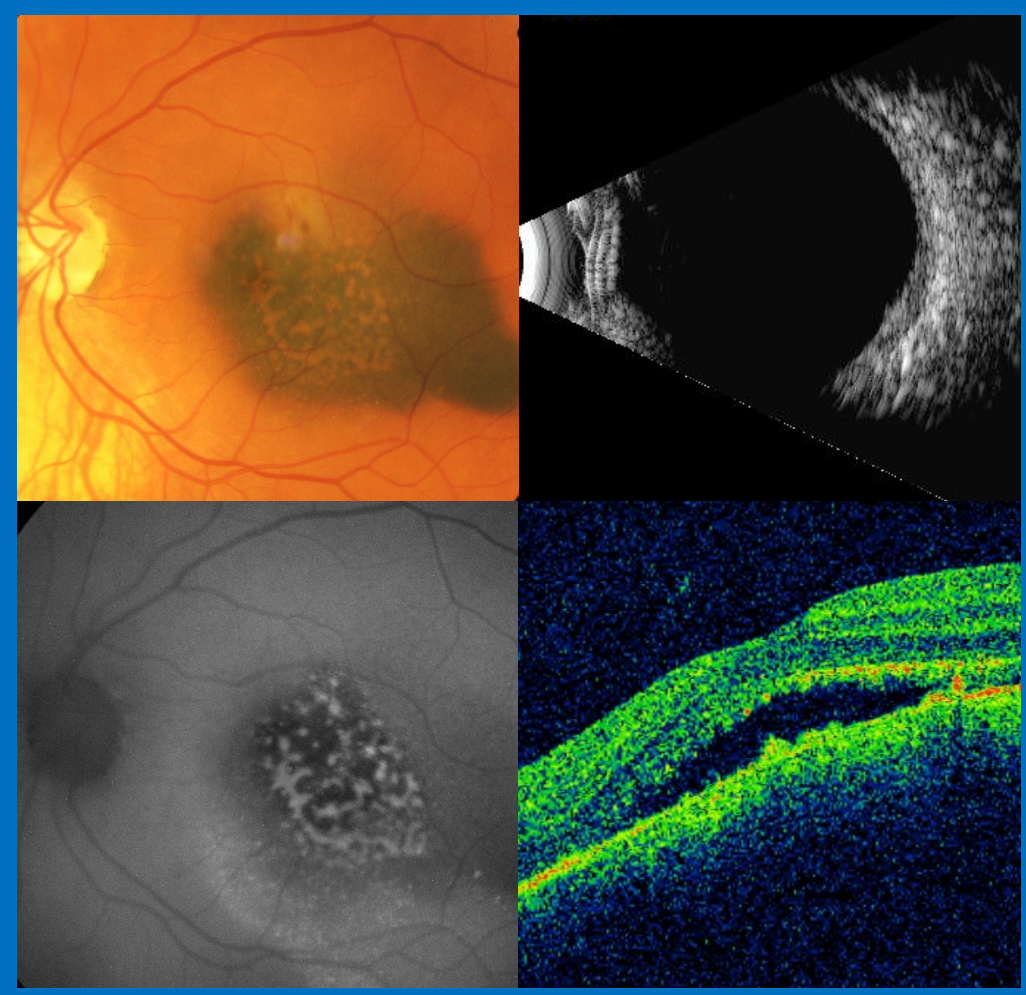

CIRO GARCÍA ÁLVAREZ 2012

UNIVERSIDAD DE VALLADOLID

FACULTAD DE MEDICINA 



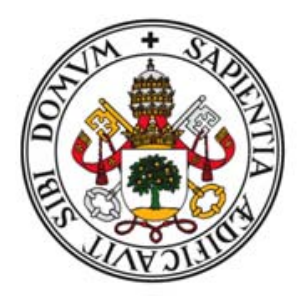

\section{UNIVERSIDAD DE VALLADOLID FACULTAD DE MEDICINA}

Departamento de Anatomia Patológica, Microbiologia, Medicina Preventiva y Salud Pública, Medicina Legal y Forense

\section{ESTUDIO DE LA OBSERVACIÓN COMO ALTERNATIVA TERAPÉUTICA EN EL MELANOMA DE COROIDES}

Trabajo de investigación que presenta

D. Ciro García Álvarez

para optar al grado de Doctor en Medicina

Directoras de Tesis:

Prof a . Dra. Dña. Ana Almaraz Gómez

Prof $^{a}$. Dra. Dña. Ma Antonia Saornil Álvarez

Valladolid, marzo de 2012 


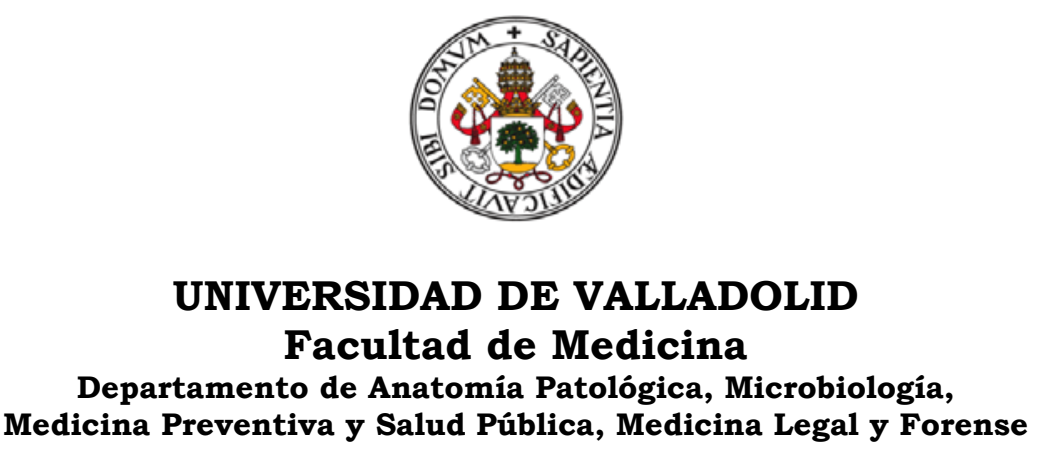

Dña. Ana Almaraz Gómez,

Doctora en Medicina y Catedrática de Medicina Preventiva y Salud Pública de la Universidad de Valladolid

$\mathrm{y}$

Dña. Ma Antonia Saornil Álvarez, Doctora en Medicina y Profesora Asociada de Oftalmología de la Universidad de Valladolid

\section{CERTIFICAN:}

Que el trabajo titulado "Estudio de la observación como alternativa terapéutica en el melanoma de coroides", ha sido realizado por D. Ciro García Álvarez bajo nuestra dirección, y cuenta con nuestra aprobación para su presentación como Tesis Doctoral.

Valladolid, 1 de marzo de 2012

Fdo.: Prof ${ }^{a}$. Dra. Dña. A. Almaraz Fdo.: Prof ${ }^{a}$. Dra. Dña. M ${ }^{a}$ A. Saornil 
A mi hermano Diego 
"Primum non nocere"

Hipócrates

"We can only see a short distance ahead, but we can see plenty there that needs to be done" Alan Turing

"Si hay algo en nosotros verdaderamente divino, es la voluntad. Por ella afirmamos la personalidad, templamos el carácter, desafiamos la adversidad, corregimos el cerebro y nos superamos diariamente" Santiago Ramón y Cajal

"You want to know how I did it?

This is how I did it:

I never saved anything for the return"

Vincent Freeman 


\section{AGRADECIMIENTOS}

En primer lugar, a los pacientes que forman parte de este estudio, pues ellos le dan sentido.

A la Dra. Saornil, por su ejemplo como médico, como investigador y como persona, por su paciencia infinita, sus consejos impagables, la generosidad de sus enseñanzas y su amistad sincera y desinteresada.

A la Dra. Almaraz por su dedicación, su tiempo, su interés y sus palabras de ánimo, y por regalarme el privilegio de su amistad.

Al Dr. Álvarez Recio, que con su ejemplo hizo nacer en mi el amor por la Medicina.

Al Dr. Galarreta, Dr. Blanco, Dra Carrasco, Prof. Maquet y la Dra. López-Gálvez por las molestias que se han tomado en mi formación.

A mis compañeros residentes Diego, Alejandro, Anna, Ester, Carmen e Yrbani, por su amistad, su apoyo y su estímulo.

A mi hermano Diego, por su ejemplo de responsabilidad, inteligencia, esfuerzo y honradez.

A mi abuela Luisa, mi madre y mi hermano Miguel, porque renunciaron a parte de sus sueños para que yo pudiera realizar los míos.

A Ignacio, Rafa, Mika, Came, Blanca, Raúl, Marta, Javier, Silvia y Amada, por ser mi otra familia. 


\section{FINANCIACIÓN}

\section{Sacyl}

El presente estudio ha sido financiado por los proyectos de investigación en biomedicina, biotecnología y ciencias de la salud de la Gerencia Regional de Salud de Castilla y León para el año 2008 con $18.500 €$. 


\section{ARTÍCULOS Y COMUNICACIONES}

El presente estudio ha dado lugar a las siguientes comunicaciones:

\section{Comunicaciones:}

- "Observation as Therapeutic Option of Uveal Melanoma: Review of 65 cases”. Comunicación Oral. Ocular Oncology Group Meeting. 2008. Lausanne, Suiza.

- "Observation as a therapeutic option in choroidal melanoma" Comunicación oral. International Society of Ocular Oncology Meeting. 2009. Cambridge, Reino Unido.

- "Controversia de la observación como actitud terapéutica en el melanoma de úvea". Comunicación oral. Jornada de Tumores Intraoculares de la Fundación Oftalmológica del Mediterráneo en Valencia. 2009.

- "Observation in choroidal melanomas" Comunicación oral. European Association for Vision and Eye Research. 2010. Hersonisos, Grecia.

- "Observation in small uveal melanoma in a Spanish population" Comunicación oral. Ocular Oncology Group Meeting. 2012. Paris, Francia. 


\section{SIGLAS Y UNIDADES}

AV: Agudeza visual

BMU: Biomicroscopía ultrasónica

COMS: Collaborative Ocular Melanoma Study

DMAE: Degeneración macular asociada a la edad

DT: Desviación típica

EPR: Epitelio pigmentario de la retina

Gy: Gray (unidad de medida de radiación absorbida)

HE: Hematoxilina-Eosina (tinción histológica)

Ki-67: Marcador inmunohistoquímico de proliferación celular

Max: Máximo

MHz: Megaherzio (unidad de medida de frecuencia)

Min: Mínimo

mm: Milimetros (unidad de medida de longitud)

NO: Nervio óptico

OCT: Tomografia de coherencia óptica

OD: Ojo derecho

OI: Ojo izquierdo

PAS: Ácido peryódico de Schiff (Tinción histológica)

PET: Tomografia por emisión de positrones

PIO: Presión intraocular

RNM: Resonancia magnética nuclear

TAC: Tomografia axial computerizada

TTT: Termoterapia transpupilar 


\section{ÍNDICE}

1.- JUSTIFICACIÓN ................................................ 23

2.- HIPÓTESIS .......................................................... 27

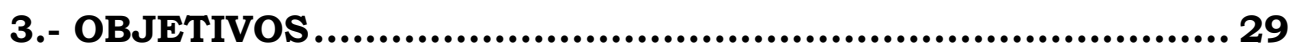

4.- ESTADO DEL TEMA................................................... 31

4.1.- Epidemiología ................................................... 31

4.2.- Patogenia y factores de riesgo...................................... 32

4.2.1.- Factores raciales ..................................... 32

4.2.2.- Nevus coroideos preexistentes..................... 32

4.2.3.- Factores genéticos ................................... 32

4.2.4.- Exposición solar ..................................... 34

4.2.5.- Factores ambientales .............................. 34

4.3.- Clasificación ......................................................... 34

4.3.1.- Clasificación del COMS ..............................34

4.3.2.- Clasificación TNM ..................................... 34

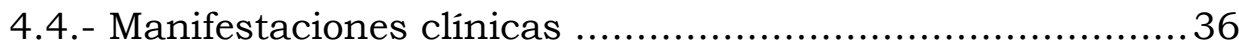

4.5.- Historia natural y metástasis ................................. 37

4.6.- Factores pronósticos ......................................... 37

4.6.1.- Factores clínicos .....................................37

4.6.2.- Factores histopatológicos ............................39

4.6.3.- Factores citogenéticos .............................. 42

4.7.- Diagnóstico..................................................... 44 
4.7.1.- Funduscopia......................................... 44

47.2.- Pruebas complementarias ............................ 45

4.8.- Diagnóstico diferencial......................................... 49

4.8.1.- Nevus coroideo......................................... 50

4.8.2.- Hemorragia coroidea .................................. 50

4.8.3.- Hemangioma coroideo ............................... 50

4.8.4.- Metástasis coroidea ...................................... 50

4.8.5.- Melanocitoma .............................................. 51

4.8.6.- Tumores del epitelio pigmentario de la retina ....51

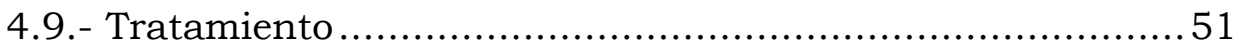

4.9.1.- Enucleación ........................................... 52

4.9.2.- Braquiterapia epiescleral............................ 52

4.9.3.- Radioterapia externa con protones ................. 54

4.9.4.- Radiocirugía .......................................... 55

4.9.5.- Resección transescleral .............................. 56

4.9.6.- Endoresección .......................................... 56

4.9.7.- Termoterapia transpupilar .......................... 56

4.9.8.- Observación........................................... 56

4.10.- Controversias en el tratamiento de los melanomas

pequeños ........................................................... 57

5.- METOdOLOGÍA ................................................. 61

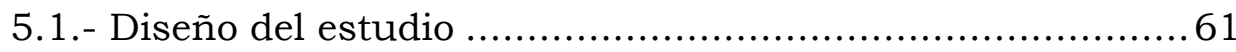

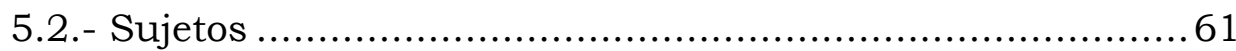

5.3.- Criterios de inclusión ........................................... 61

5.4.- Criterios de exclusión ..........................................63 63

5.5.- Variables a evaluar ............................................ 64

5.5.1.- Principales................................................ 64 
5.6.- Recogida de datos 66

5.6.1.- Primera exploración, tratamiento y datos generales .................................................. 66

5.6.2.- Seguimientos ....................................... 68

5.6.3.- Indicaciones de otros tratamientos en el curso del seguimiento ................................................. 69

5.7.- Análisis estadístico .............................................. 70

6.- RESULTADOS....................................................... 73

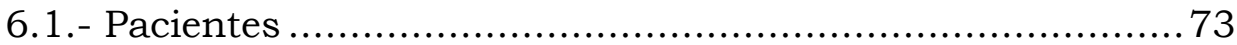

6.2.- Descripción general de la muestra..............................73

6.2.1.- Edad................................................... 73

6.2.2.- Sexo ........................................................ 73

6.2.3.- Seguimiento........................................ 75

6.2.4.- Diagnósticos por años ............................... 75

6.2.5.- Origen de los pacientes .............................. 76

6.3.- Características clínicas generales ............................77

6.3.1.- Antecedentes generales ........................... 77

6.3.2.- Tumores concomitantes ............................ 78

6.3.3.- Patología ocular concomitante.......................78

6.4.- Características oculares y tumorales..........................79

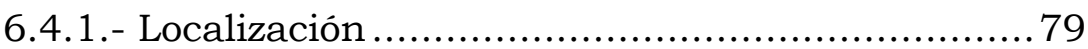

6.4.2.- Clasificación y tamaño .................................... 79

6.4.3.- Lateralidad ............................................. 80

6.4.4.- Color del iris ................................................ 80

6.4.5.- Motivo del diagnóstico................................ 81

6.4.6.- Forma del tumor ....................................... 81 
6.4.7.- Signos de actividad .82

6.4.8.- Agudeza visual en el momento del diagnóstico... 83

6.4.9.- Motivo de la observación 83

6.5.- Control tumoral 84

6.5.1.- Crecimiento tumoral ................................. 84

6.5.2.- Estimación del riesgo de crecimiento tumoral....85

6.6.- Evolución de la función visual. .89

6.7.- Supervivencia de los pacientes .89

6.7.1.- Supervivencia global 90

6.7.2.- Supervivencia específica .93

7.- DISCUSIÓN 97

7.1.-Limitaciones y fortalezas 98

7.2.- Discusión de la descripción general de la muestra........... 98

7.3.- Discusión de las características generales .................... 100

7.4.- Discusión de las características oculares y tumorales..... 101 7.4.1.- Características generales oculares y tumorales 101 7.4.2.- Signos de actividad .................................. 102 7.4.3.- Agudeza visual en el momento del diagnóstico. 104 7.4.9.- Motivo de la observación ............................... 104

7.5.- Discusión del control tumoral .................................. 105

7.5.1.- Crecimiento tumoral ............................... 105

7.5.2.- Estimación del riesgo de crecimiento tumoral.. 106

7.6.- Discusión de la evolución de la función visual ................ 106

7.7.- Discusión de la supervivencia de los pacientes ............. 108

7.8.- Algoritmo de manejo ........................................ 112

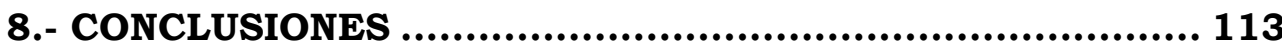

9.- TRABAJO FUTURO ........................................... 115 


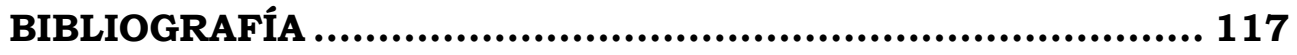

ANEXO I.......................................................... 127

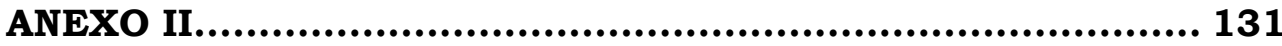




\section{JUSTIFICACIÓN}

El melanoma uveal es el tumor maligno primario ocular más frecuente en el adulto con una incidencia estimada de 4-6 casos nuevos por millón de habitantes y año. ${ }^{1}$ Es una neoplasia altamente agresiva, con una mortalidad a los 10-15 años del diagnóstico cercana al 50\%.2

Uno de los factores pronósticos más importantes es el tamaño del tumor,1,2 de forma que tumores pequeños (diámetro menor o igual a $16 \mathrm{~mm}$ o altura menor o igual a 2,5 mm) presentan una supervivencia a los 20 años del $78 \%$, mientras que en tumores medianos (diámetro hasta $16 \mathrm{~mm}$ y altura mayor de 2,5 $\mathrm{mm}$ y menor a $10 \mathrm{~mm}$ ) es del 55\% y en tumores grandes (diámetro mayor o igual a $16 \mathrm{~mm}$ o altura mayor o igual a $10 \mathrm{~mm}$ ) es del $30 \%{ }^{3}$ El melanoma uveal se considera una enfermedad sistémica desde el diagnóstico, al margen de su tamaño, puesto que se han observado metástasis en pacientes enucleados después de periodos superiores a los 10 años debido a la capacidad de algunos melanomas de producir metástasis subclinicas desde estadios muy precoces de la enfermedad. ${ }^{4}$

Las posibilidades terapéuticas van desde la observación periódica, pasando por las formas especializadas de radioterapia asociada o no a termoterapia transpupilar o resección quirúrgica, hasta la enucleación. ${ }^{1}$ Ninguna de las modalidades de tratamiento ha demostrado mejorar la supervivencia de los pacientes, considerándose que la enfermedad sistémica es independiente de la forma de tratamiento del tumor primario. ${ }^{5}$ 
Los objetivos de los tratamientos conservadores son el control del tumor (detener su crecimiento), conservar el globo ocular y preservar la máxima función visual. La enucleación es una opción mutiladora, reservada a tumores grandes $\sin$ expectativas de recuperación funcional, mientras que los tratamientos conservadores basados en la radioterapia especializada tienen gran éxito en el control del tumor pero asocian distintos efectos secundarios (como son la retinopatía y la neuropatía por radiación) que implican una importante disminución de la agudeza visual.

La observación se puede indicar en tumores pequeños e inactivos, pero existe una gran controversia en torno a esta opción, principalmente debida al temor de que el tiempo de observación pueda aumentar el riesgo de aparición de enfermedad sistémica; ${ }^{6}$ por otro lado existen razones que justifican esta actitud, como son la morbilidad de los tratamientos, que provocan una importante pérdida de la agudeza visual, la dificultad de establecer un diagnóstico definitivo entre nevus grande y melanoma pequeño inactivo clínicamente, ${ }^{7}$ la falta de conocimiento acerca de la historia natural de esta enfermedad, y estudios previos que demuestran que la proporción de tumores pequeños que crecen en cinco años oscila entre el $30-35 \%^{8}$ y la mortalidad específica de éstos del 1\% a los cinco años y del3,7\% a los 8 años. ${ }^{9}$

En este contexto, la vigilancia periódica se recomienda cuando los melanomas son pequeños y no se documentan signos de actividad. ${ }^{10}$ Los signos de actividad son de vital importancia en el seguimiento de los melanomas uveales en observación, puesto que su detección determina la aplicación de tratamiento. Estos signos son la presencia de fluido subretiniano, la presencia de pigmento naranja en la superficie tumoral, la presencia de sintomatología clínica, una altura superior a los dos milímetros y una distancia menor a 3 milímetros del nervio óptico'11 (en el año 2009 los autores agregaron dos nuevos factores de actividad: la presencia de sombra posterior en la ecografia y la ausencia de halo atrófico ${ }^{12}$ ). En este sentido, el estudio de las lesiones sospechosas con tomografia de coherencia óptica (OCT) y autofluorescencia puede ser de gran utilidad, puesto que esta tecnología tiene capacidad de poner de manifiesto el fluido subretiniano antes de que éste sea clínicamente detectable. 
Por otra parte las lesiones entre 1 a 3 milimetros de altura y entre 5 a 10 milímetros de base han sido denominadas por algunos autores como lesiones indeterminadas, existiendo controversia sobre su malignidad y sobre la conveniencia de ser tratadas. ${ }^{13}$

La observación periódica puede aplicarse también a melanomas medianos sin signos de actividad en pacientes de edad avanzada, con mal estado general, ojo contralateral con función visual seriamente comprometida o que rechazan el tratamiento.

Los investigadores del grupo de la Unidad de Tumores Intraoculares del Adulto del Hospital Clínico Universitario de Valladolid pertenecen a un equipo multidisciplinar, que es uno de los referentes en nuestro país en el tratamiento del melanoma de coroides y otros tumores oculares mediante braquiterapia epiescleral.

La Unidad de Oncología Ocular del Hospital Clínico Universitario de Valladolid comenzó como proyecto en 1992. Desde entonces se ha desarrollado una unidad referencial y multidisciplinar en la que colaboran oftalmólogos, Oncólogos radioterapeutas, radiofísicos hospitalarios y epidemiólogos clínicos. A lo largo de estos 15 años:

- Se han diagnosticado y tratado más de 1000 pacientes nuevos, de los cuales más de 400 son pacientes con melanoma de úvea.

- Se han puesto en marcha protocolos de diagnóstico, tratamiento y seguimiento para estos pacientes.

- Se han desarrollado terapias de tratamiento multidisciplinar (Braquiterapia epiescleral).

- Se ha convertido en una unidad de referencia nacional reconocida por el Ministerio de Sanidad para el diagnostico y tratamiento de estos pacientes.

- Se ha colaborado activamente con la Unidad de Apoyo a la Investigación del Hospital Clínico Universitario de Valladolid y con el Área de Medicina Preventiva y Salud Pública de la Facultad de Medicina de la Universidad de Valladolid.

A lo largo de estos años se ha observado que pacientes con tumores pequeños e inactivos que se trataban se acompañaban de efectos secundarios 
que comprometian seriamente la función visual y por otra parte una falta de consenso que hace que los criterios de tratamiento en estos tumores pequeños sean muy variables según los autores que se consulten.

En este contexto, el propósito del presente estudio es demostrar que en determinados tumores la observación periódica puede ser una alternativa terapéutica que puede cumplir los objetivos del tratamiento conservando la función visual y la calidad de vida de los pacientes sin ensombrecer el pronóstico.

Por último, son muy limitados los estudios que se han realizado sobre melanomas pequeños sometidos a observación, y casi inexistentes en el caso de melanomas medianos. El análisis de los datos recogidos durante los últimos 15 años en la unidad de oncología ocular del Hospital Clínico Universitario de Valladolid puede ser de gran utilidad para avanzar en el conocimiento de la historia natural de esta enfermedad. 


\section{HIPÓTESIS}

La observación periódica de pacientes seleccionados afectos de melanoma coroideo puede cumplir los objetivos terapéuticos con respecto al control tumoral, conservación de la agudeza visual y sin menoscabo en la supervivencia. 


\section{OBJETIVOS}

Los objetivos del presente estudio son:

1.- Estudiar la evolución de los pacientes diagnosticados de melanoma coroideo en la Unidad de Oncología Ocular del Hospital Clínico Universitario de Valladolid sometidos a observación respecto a control tumoral, agudeza visual y supervivencia.

2.- Comparar la supervivencia, el control tumoral y la agudeza visual de los pacientes en observación clasificados según su tamaño.

3.- Identificar los signos predictivos de crecimiento tumoral y mortalidad en los pacientes objeto del estudio. 


\section{ESTADO DEL TEMA}

El melanoma uveal es el tumor maligno primario más frecuente del ojo en los adultos, ${ }^{1}$ y se origina por la transformación maligna de los melanocitos de la úvea.

\section{1.- EPIDEMIOLOGÍA}

Los melanomas oculares suponen el 5\% del total de los melanomas, ${ }^{14}$ originándose el $85 \%$ en la úvea (los melanomas de conjuntiva y órbita son raros) y de éstos el 90\% aparecen en la coroides. ${ }^{15}$

La incidencia del melanoma uveal varía entre los 4,3 a los 10,9 casos por millón de habitantes y año en función de las poblaciones estudiadas. ${ }^{15} \mathrm{E} 1$ Programa SEER (Surveillance and Epidemiology and End Result) del Instituto Nacional de Salud de los Estados Unidos es hoy por hoy la fuente más fiable respecto a la incidencia de esta enfermedad ${ }^{16}$, que es estimada en 4,9 casos por millón de habitantes y año en Estados Unidos para los hombres y de 3,7 en el caso de las mujeres. La comparación de estudios, no obstante, indica que la incidencia es muy similar en Estados Unidos, Europa y Australia. ${ }^{17}$ En España se encuentra catalogado dentro del sistema de enfermedades raras (SIERE) aunque no hay datos epidemiológicos. La incidencia aumenta con la edad, estando el pico en la década de los 70 para los hombres ${ }^{15}$ y en la de los 60 para las mujeres. ${ }^{18}$ A diferencia del melanoma cutáneo, la incidencia del melanoma de úvea ha permanecido estable a lo largo del tiempo ${ }^{19}$. 


\section{2.- PATOGENIA Y FACTORES DE RIESGO}

No se han aclarado por completo los factores que influyen en la génesis del melanoma de úvea. ${ }^{20}$ Los que siguen son los que han demostrado tener relación, sin que las bases etiopatogénicas estén aclaradas.

\subsection{1.- Factores raciales}

Son los más significativos. El melanoma uveal es 150 veces más frecuente en las personas de raza blanca que en los de raza negra. ${ }^{20}$ Se ha observado menor incidencia entre los hispanos ${ }^{21}$ y los asiáticos ${ }^{22}$ que en la raza blanca. Si bien se han citado clásicamente la piel clara el pelo rubio y los ojos azules como factores de riesgo, en nuestro país se ha visto mayor incidencia de la enfermedad en personas de ojos oscuros. ${ }^{23}$

\subsection{2.- Nevus coroideos preexistentes}

Existe la evidencia clínica e histopatológica de que los melanomas uveales pueden aparecer a partir de nevus coroideos preexistentes ${ }^{24}$ o bien de novo ${ }^{25}$. La tasa de transformación de nevus a melanomas en la úvea es de aproximadamente 1 de cada 8500.26

\subsection{3.- Factores genéticos}

No se han encontrado factores genéticos relacionados y la mayoría de Los melanomas uveales suelen ser esporádicos ${ }^{20}$ pero existen excepciones que indican predisposición hereditaria:

1.- Melanoma uveal familiar: supone el $0,6 \%$ de los melanomas uveales. ${ }^{27}$

2.- Melanoma uveal en individuos jóvenes: Sólo el 1\% de los melanomas uveales aparecen en individuos por debajo de los 20 años de edad. ${ }^{28}$ Estos tumores suelen estar asociados con la melanosis oculodérmica. ${ }^{29}$

3.- Melanoma uveal bilateral: es muy poco frecuente. ${ }^{30}$ No se ha podido relacionar con predisposición genética a padecer otros tumores. ${ }^{31}$ 


\section{4.- Asociaciones fenotípicas:}

a.- Melanocitosis oculodérmica (Nevus de Ota): Es una hiperpigmentación congénita de la piel periocular, la epiesclera, la úvea, la órbita y las meninges. 1 de cada 400 pacientes tienen melanoma de coroides. ${ }^{32,33}$

b.- Sindrome del nevus displásico familiar y melanoma: Se define como la concurrencia de más de 50 nevus cutáneos y presencia de melanomas cutáneos en familiares de $1^{\circ}$ o $2^{\circ}$ orden. Se ha observado que en las series de pacientes con melanoma uveal que la incidencia de este sindrome es mucho mayor que en la población general ${ }^{34}$ Sin embargo no se ha encontrado una mayor incidencia de melanomas uveales en las series de pacientes afectos de esta entidad. ${ }^{35}$ Por otro lado la mutación CDKN2A que aparece en el 50\% de los pacientes afectos del Síndrome del nevus displásico familiar, no se ha encontrado en los pacientes afectos de melanoma uveal. ${ }^{36}$

c.- Neurofibromatosis tipo I: Es una facomatosis condicionada por una alteración de las células de la cresta neural. No se ha logrado asociar de forma específica con el melanoma uveal. ${ }^{37}$

d.- Sindrome de Li-Fraumeni: Es una predisposición genética y poco frecuente a padecer cánceres múltiples causada por una mutación del gen p53 y que se hereda de forma autosómica dominante. Todavía no se ha demostrado que en este sindrome aumente la frecuencia del melanoma uveal. ${ }^{38}$

e.- Segundos tumores malignos en pacientes con melanoma uveal: Los resultados de los estudios caso-control son dispares, encontrándose en unos un aumento de la incidencia de segundos tumores 39,40 y en otros no. 41 


\subsection{4.- Exposición solar}

A diferencia de los melanomas cutáneos, no ha sido establecida una relación causal entre la exposición solar y los melanomas uveales. ${ }^{42,43}$

\subsection{5.- Factores ambientales}

No se ha encontrado asociación entre factores ambientales profesionales y la génesis del melanoma úvea. 44

\section{3.- CLASIFICACIÓN}

Los melanomas de úvea se clasifican desde el punto de vista clínico fundamentalmente en función de su tamaño, empleándose dos clasificaciones, la del COMS (Collaborative Ocular Melanoma Study) y la TNM.

\subsection{1.- Clasificación del COMS:}

Se basa en las medidas ecográficas del tumor. ${ }^{45}$

A.- Pequeños: aquellos tumores que tienen una altura maxima menor o igual a 2,5 $\mathrm{mm}$ y una base máxima menor o igual a $16 \mathrm{~mm}$.

B.- Medianos: aquellos que tienen una altura máxima mayor de 2,5 $\mathrm{mm}$ y menor o igual a $10 \mathrm{~mm}$ y una base máxima menor o igual a 16 $\mathrm{mm}$.

C.- Grandes: aquellos que tienen una altura máxima mayor de $10 \mathrm{~mm}$ o una base máxima mayor de $16 \mathrm{~mm}$

\subsection{2.- Clasificación TNM:}

Se basa en la afectación anatómica (T), la presencia de extensión linfática $(\mathrm{N})$ y en la presencia de metástasis $(\mathrm{M}) .{ }^{46}$

En la tabla número 1 se presenta dicha clasificación. 
Tabla 1 Estadificación del melanoma de úvea

(Tomado de AJCC Cancer Staging Manual. $7^{\circ}$ Edición. Ed. Springer. Nueva York)

IRIS

\begin{tabular}{|c|c|}
\hline $\begin{array}{l}\text { T1 } \\
\text { T1a } \\
\text { T1b } \\
\text { T1c }\end{array}$ & $\begin{array}{l}\text { Tumor limitado al iris } \\
\text { Tumor limitado al iris que no afecta más de } 3 \text { husos horarios } \\
\text { Tumor limitado al iris que afecta más de } 3 \text { husos horarios } \\
\text { Tumor limitado al iris con glaucoma } 2^{\circ}\end{array}$ \\
\hline $\begin{array}{l}\mathrm{T} 2 \\
\mathrm{~T} 2 \mathrm{a}\end{array}$ & $\begin{array}{l}\text { Afectación de iris con invasión de cuerpo ciliar y/o coroides } \\
\text { Invasión de cuerpo ciliar (CC) y/o coroides con } 2^{\circ}\end{array}$ \\
\hline $\begin{array}{l}\text { T3 } \\
\text { T3a }\end{array}$ & $\begin{array}{l}\text { Invasión de cuerpo ciliar y/o coroides con extensión escleral } \\
\text { Invasión de cuerpo ciliar y/o coroides con extensión escleral y glaucoma } 2^{\circ}\end{array}$ \\
\hline $\begin{array}{l}\text { T4 } \\
\text { T4a } \\
\text { T4b }\end{array}$ & $\begin{array}{l}\text { Extensión extraescleral } \\
\text { Extensión extraescleral menor o igual de } 5 \mathrm{~mm} \text { de diámetro } \\
\text { Extensión extraescleral mayor de } 5 \mathrm{~mm} \text { de diámetro }\end{array}$ \\
\hline
\end{tabular}

CUERPO CILIAR Y COROIDES

Según las medidas del tumor, este se organiza en 4 categorias representadas en el siguiente diagrama:

\begin{tabular}{|c|c|c|c|c|c|c|c|}
\hline$>15.0$ & & & & & 4 & 4 & 4 \\
\hline $12.1-15.0$ & & & & 3 & 3 & 4 & 4 \\
\hline $9.1-12.0$ & & 3 & 3 & 3 & 3 & 3 & 4 \\
\hline $6.1-9.0$ & 2 & 2 & 2 & 2 & 3 & 3 & 4 \\
\hline $3.1-6.0$ & 1 & 1 & 1 & 2 & 2 & 3 & 4 \\
\hline$\leq 3.0$ & 1 & 1 & 1 & 1 & 2 & 2 & 4 \\
\hline & $\leq 3.0$ & $3.1-6.0$ & $6.1-9.0$ & $9.1-12.0$ & $12.1-15.0$ & $15.1-18.0$ & $>18.0$ \\
\hline
\end{tabular}

T1 Tumor con tamaño categoria 1

T1a Tumor con tamaño categoría 1 sin invasión del CC ni extensión extraocular

T1b Tumor con tamaño categoría 1 con invasión del CC

T1c Tumor con tamaño categoría 1 sin invasión del CC y con extensión extraocular $\leq 5 \mathrm{~mm}$

T1d Tumor con tamaño categoría 1 con invasión del CC y con extensión extraocular $\leq 5 \mathrm{~mm}$

T2 Tumor con tamaño categoría 2

T2a Tumor con tamaño categoría 2 sin invasión del CC ni extensión extraocular

$\mathrm{T} 2 \mathrm{~b}$ Tumor con tamaño categoría 2 con invasión del $\mathrm{CC}$

T2c Tumor con tamaño categoría 2 sin invasión del CC y con extensión extraocular $\leq 5 \mathrm{~mm}$

T2d Tumor con tamaño categoría 2 con invasión del CC y con extensión extraocular $\leq 5 \mathrm{~mm}$

T3 Tumor con tamaño categoría 3

T3a Tumor con tamaño categoría 3 sin invasión del CC ni extensión extraocular

T3b Tumor con tamaño categoría 3 con invasión del CC

T3c Tumor con tamaño categoría 3 sin invasión del CC y con extensión extraocular $\leq 5 \mathrm{~mm}$

T3d Tumor con tamaño categoría 3 con invasión del CC y con extensión extraocular $\leq 5 \mathrm{~mm}$

T4 Tumor con tamaño categoría 4

T4a Tumor con tamaño categoría 4 sin invasión del CC ni extensión extraocular

T4b Tumor con tamaño categoría 4 con invasión del CC

T4c Tumor con tamaño categoría 4 sin invasión del CC y con extensión extraocular $\leq 5 \mathrm{~mm}$

T4d Tumor con tamaño categoría 4 con invasión del CC y con extensión extraocular $\leq 5 \mathrm{~mm}$

T4e Cualquier tamaño con extensión extraocular $\geq 5 \mathrm{~mm}$ 


\section{4.- MANIFESTACIONES CLÍNICAS}

Las manifestaciones clínicas dependen fundamentalmente de la localización dentro del globo ocular y del tamaño del tumor. ${ }^{1}$ Los tumores pequeños y alejados de la mácula son asintomáticos, y se diagnostican en exploraciones rutinarias de fondo de ojo. Cuando el tumor crece, o se localiza cerca de papila o mácula origina disminución de agudeza visual y/o defectos en el campo visual. Los tumores de mayor tamaño pueden causar dolor por inflamación o glaucoma. La esclera constituye una barrera en el crecimiento del tumor, la membrana de Bruch en cambio es más débil, y con el tiempo se va estrechando y puede llegar a romperse y el tumor, que hasta entonces tenía forma discoide, crece en el espacio subretiniano adquiriendo una configuración en botón de camisa o imagen en champiñón. La retina suprayacente puede desprenderse o ser invadida por el tumor.

El melanoma de coroides suele crecer durante largo tiempo dentro del globo y finalmente se disemina por los canales emisarios de las venas vorticosas y de los nervios y arterias ciliares. Puede diseminarse también por el canal óptico y ocasionalmente en el interior de las venas vorticosas. Más raramente puede necrosar la esclera cuando el tumor está muy evolucionado o la esclera está debilitada por cirugía previa. El tumor con extensión extraocular puede ocasionar proptosis, la aparición de una masa subconjuntival visible o sintomatología inflamatoria orbitaria, y tiene mucho peor pronóstico que aquel que se mantiene confinado al interior del globo. 47

Existe una variante de tumor difuso en la que el tumor crece más en superficie que en altura. Son tumores más agresivos con mayor tendencia a extenderse extraocularmente y a producir gran afectación orbitaria precozmente. 48

Los tumores que se originan en el cuerpo ciliar son menos frecuentes y de peor pronóstico que los originados en la coroides; pueden crecer hacia el segmento anterior invadiendo las estructuras del ángulo, el iris y la cámara anterior, y es frecuente encontrar una catarata o vasos tortuosos y dilatados en la conjuntiva suprayacente, denominados vasos centinela. 


\section{5.- HISTORIA NATURAL Y METÁSTASIS}

Los melanomas uveales metastatizan por vía hematógena y lo hacen al hígado principalmente, aunque también pueden extenderse al pulmón, los huesos, el riñón y el cerebro. ${ }^{49,50}$ Aunque no son tan agresivos como los cutáneos, existe un importante riesgo de metástasis a partir del diagnóstico. ${ }^{51}$ La mortalidad debida al melanoma uveal aumenta proporcionalmente con el tamaño y el tiempo en todas las series publicadas, aunque las cifras difieren según el tamaño de la muestra, y el tiempo de seguimiento de los pacientes. Según Kujala en un estudio a largo plazo el riesgo de desarrollar metástasis es del $31 \%$ a los 5 años, $45 \%$ a los 15 años, 49\% a los 25 años y $52 \%$ a los 35 años. ${ }^{52}$ Una vez que aparecen las metástasis la supervivencia media es de tan solo 7 meses, ${ }^{53}$ no existiendo en la actualidad ningún tratamiento efectivo para la enfermedad diseminada. ${ }^{54}$

\section{6.- FACTORES PRONÓSTICOS}

El pronóstico de los pacientes que son diagnosticados de melanoma uveal está condicionado por la diseminación sistémica de la enfermedad y el desarrollo de metástasis. La enfermedad metastasica hoy por hoy no tiene tratamiento efectivo y la supervivencia es muy pobre. A continuación se exponen los factores que se han relacionado un peor pronóstico vital de los pacientes afectos por la enfermedad.

\subsection{1.- Factores clinicos:}

1.- Diámetro basal máximo: Se considera la característica clínica más consistente relacionada con el pronóstico: a mayor diámetro basal peor pronóstico. ${ }^{55}$ Puede estimarse mediante oftalmoscopia indirecta, ecografia o retinografia.

2.- Altura máxima: Se considera también una característica relacionada con el pronóstico, aunque menos que la anterior. ${ }^{55}$ 
3.- Localización o invasión del cuerpo ciliar: Los tumores que asientan en el cuerpo ciliar tienen peor pronóstico (figura 1). ${ }^{56}$

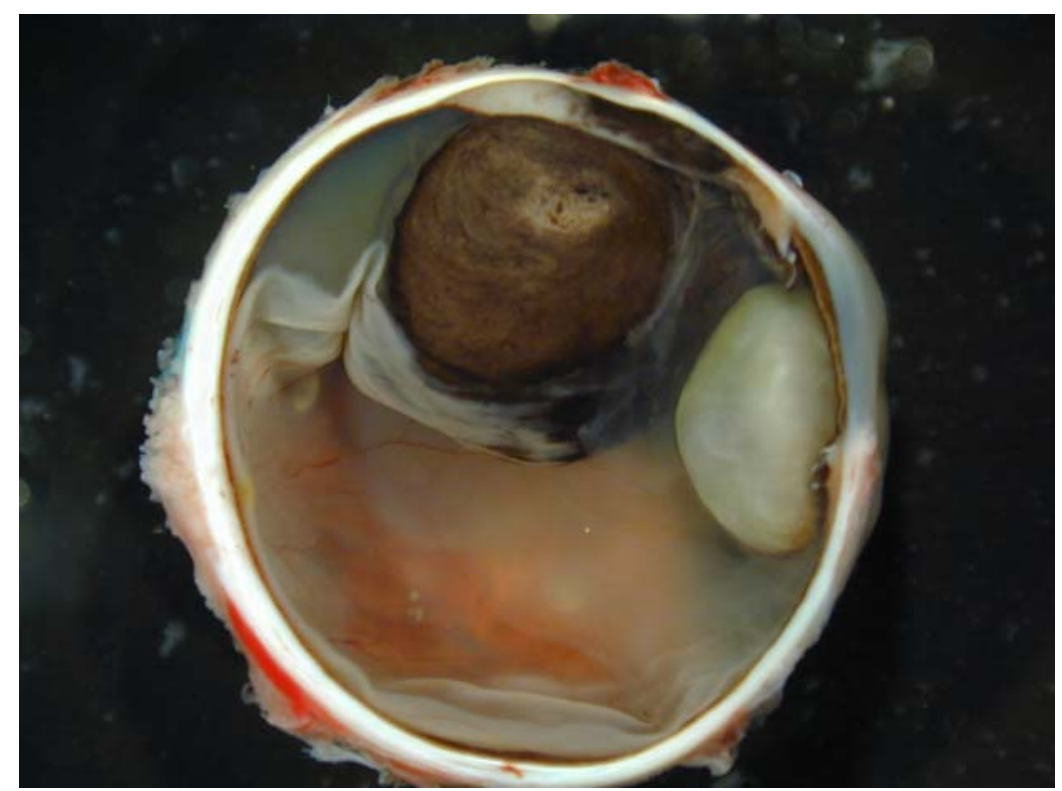

Figura 1: fotografia de una pieza de enucleación de un ojo afecto de un melanoma que asienta en el cuerpo ciliar.

4.- Extensión extraescleral: La infiltración por las células tumorales de la esclera con la consiguiente extensión extraocular (figura 2). ${ }^{55}$

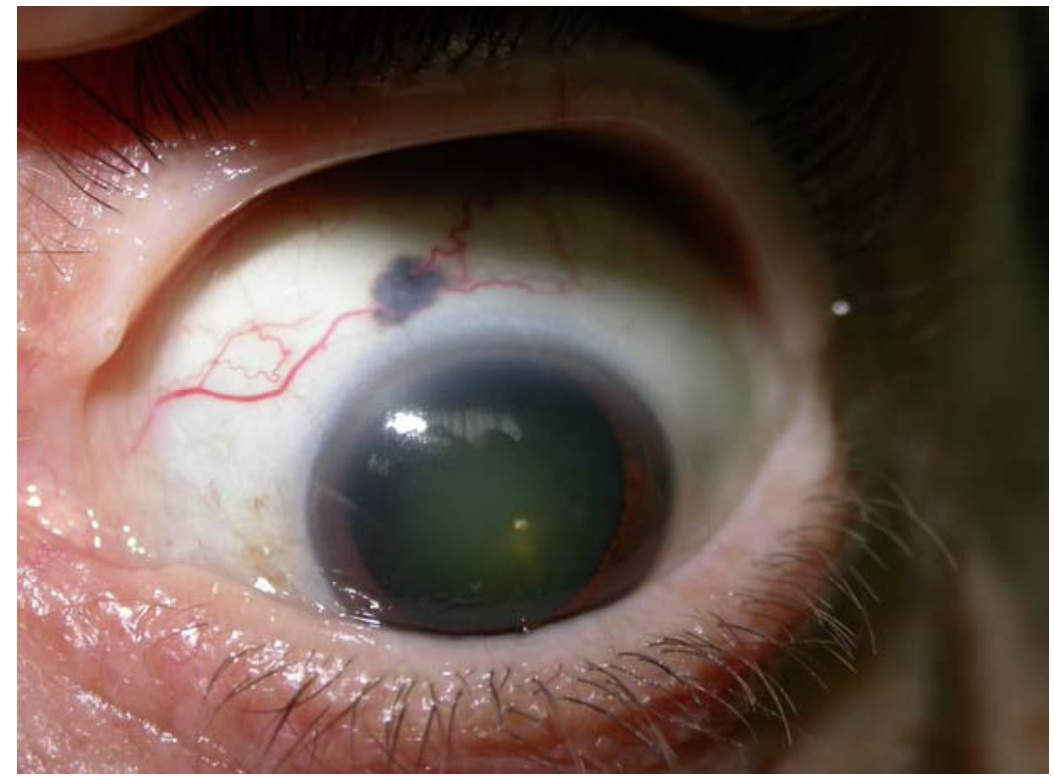

Figura 2: fotografia de una extensión extraocular a través de la esclera en un paciente afecto de un melanoma de úvea. 
5.- Melanomas difusos: Los melanomas de tipo difuso, aquellos que en lugar de tender a la formación de nódulos por crecimiento vertical, tienden al crecimiento horizontal invadiendo difusamente la coroides (figura 3). ${ }^{56}$

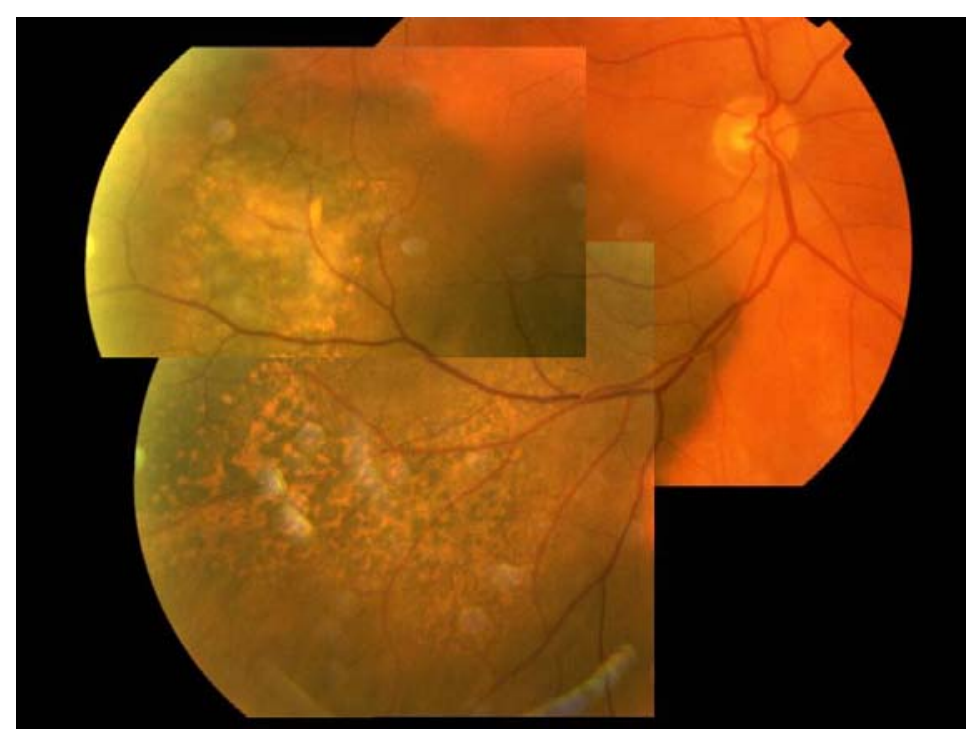

Figura 3: retinografia de un melanoma uveal infiltrativo difuso.

6.- Velocidad de crecimiento: cuanto mayor es la velocidad de crecimiento del tumor peor pronóstico. 57

7.- Regresión rápida de la masa tumoral: Una pérdida superior al $10 \%$ de la altura total del tumor cada mes tras el tratamiento supone un empeoramiento significativo de la supervivencia. ${ }^{58}$

\subsection{2.- Factores histopatológicos}

1.- Tamaño: se ha demostrado que cuanto mayor es el tamaño peor es la supervivencia del paciente, sea cual fuere la forma de clasificarlo. ${ }^{2}$

2.- Localización: El origen o la invasión del cuerpo ciliar es un factor fuertemente relacionado con el pronóstico del paciente. ${ }^{2,56}$

3.- Existencia de extensión extraocular: Aunque clínicamente esta extensión no se manifieste, en el análisis histopatológico puede observarse invasión y salida de células tumorales a través de la pared escleral (figura 4).59 


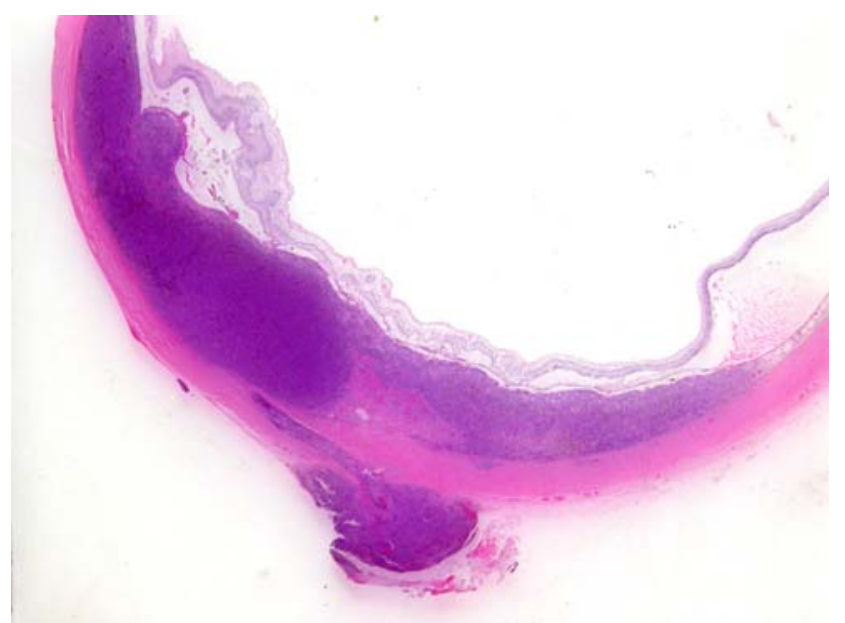

Figura 4: fotografia de una preparación histológica de melanoma uveal teñida con hematoxilina-eosina, donde se observa una extensión a través de la esclera.

4.- Patrón de crecimiento: la existencia de un patrón de crecimiento difuso hace que el tumor tienda a invadir la esclera y alcanzar tejidos orbitarios empeorando el pronóstico. 59

5.- Tipo celular: según la clasificación de Callender60 o su modificación ${ }^{61}$ los tipos celulares de los melanomas de úvea se pueden clasificar como fusiformes A, fusiformes B o epitelioides, pudiendo aparecer mezcla de éstas en un tumor. La presencia de células epitelioides se relaciona con un peor pronóstico (figuras 5 y 6).
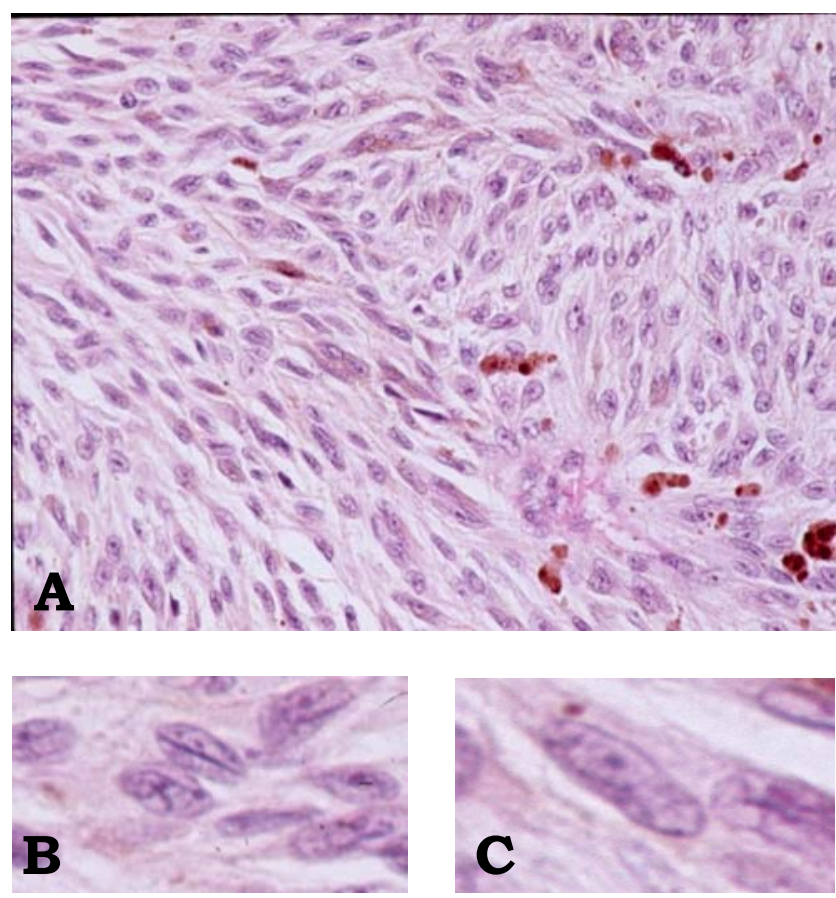

Figura 5: microscopía óptica de melanoma uveal (hematoxilina-eosina (HE) 40x) (A). Se presentan ampliados ejemplos de células fusiformes de tipo A (B) y de tipo B (C). 


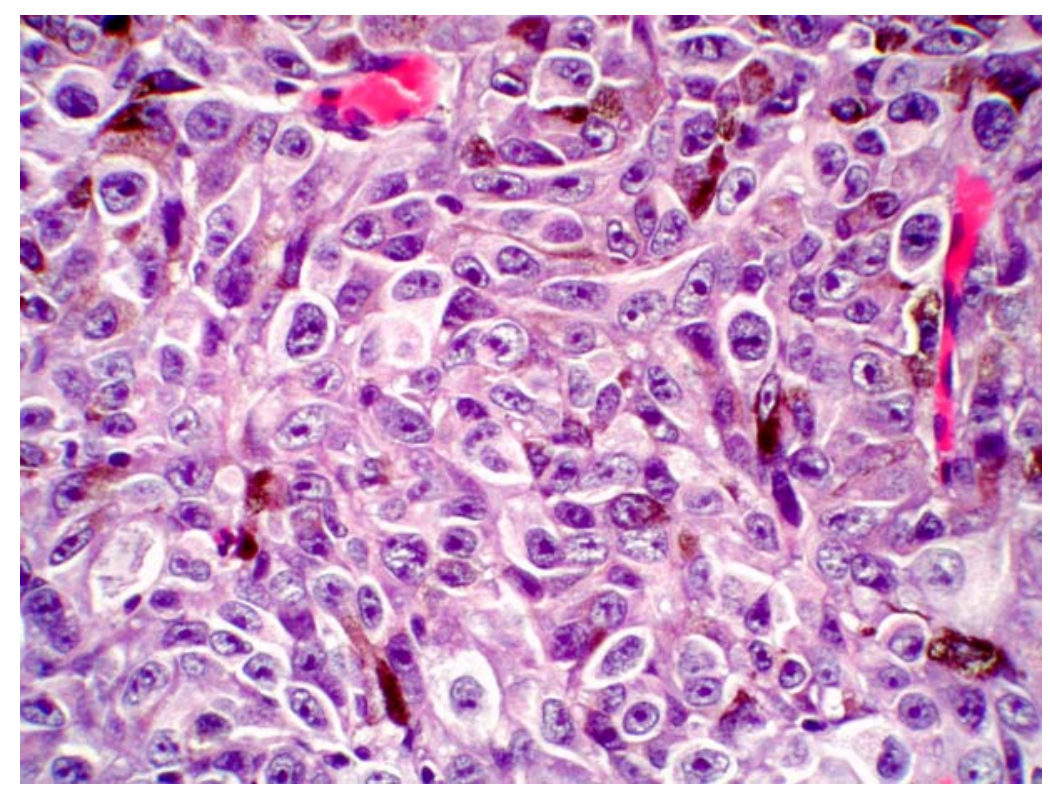

Figura 6: microscopía óptica de melanoma uveal (HE 40x) donde se observan células tumorales del tipo epitelioide.

6.- Índice de proliferación: entendido como el número de figuras mitóticas por cada campo de cuarenta aumentos (hoy en día se emplean marcadores de proliferación como el Ki-67 que facilitan el cálculo). Un indice de proliferación alto se relaciona con un peor pronóstico (figura 7). ${ }^{62}$

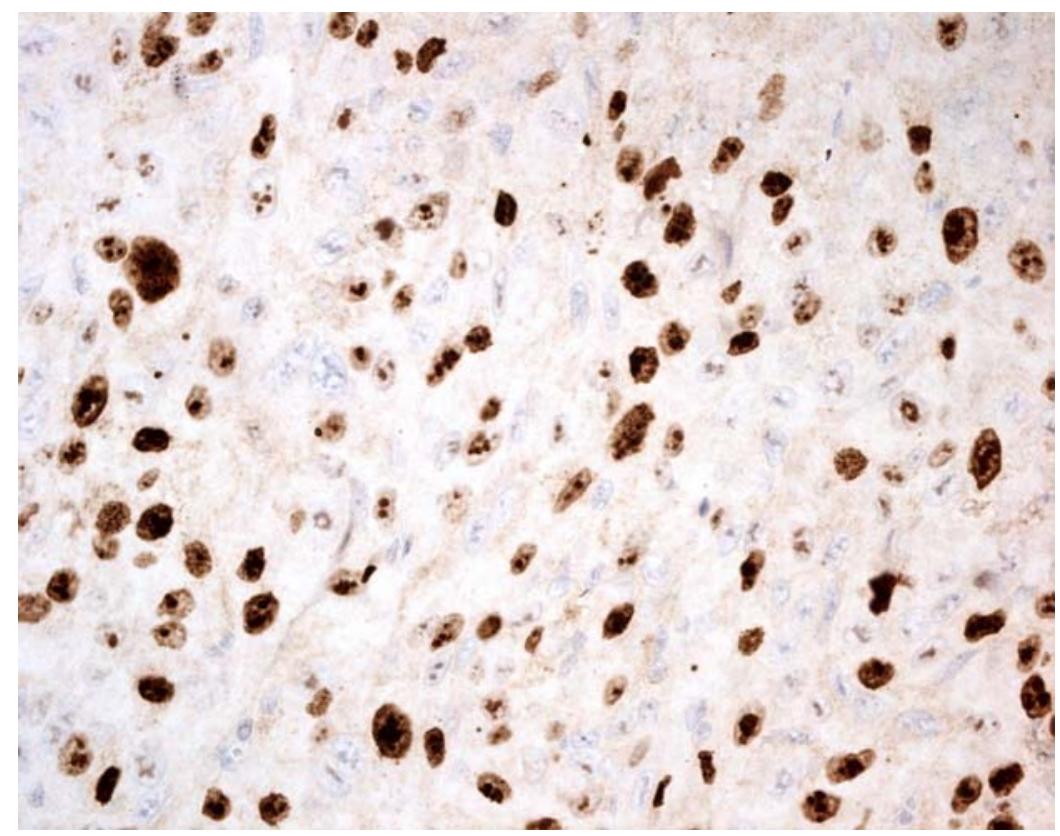

Figura 7: microscopía óptica de melanoma uveal (Ki-67 40x) donde se observan marcadas las células en fase de mitosis. 
7.- Infiltración linfocitaria: aunque en el melanoma cutáneo se ha observado que la presencia de linfocitos infiltrando el tumor es un signo de buen pronóstico, en el melanoma uveal, la presencia de éstos se ha relacionado con un peor pronóstico. 63

8.- Patrones vasculares: Se han descrito varios patrones vasculares en el estudio histológico de los melanomas de úvea. De ellos, los patrones en asas o "loops" cerrados y redes (tres "loops" agrupados) han sido relacionados con un peor pronóstico (figura 8). ${ }^{64}$

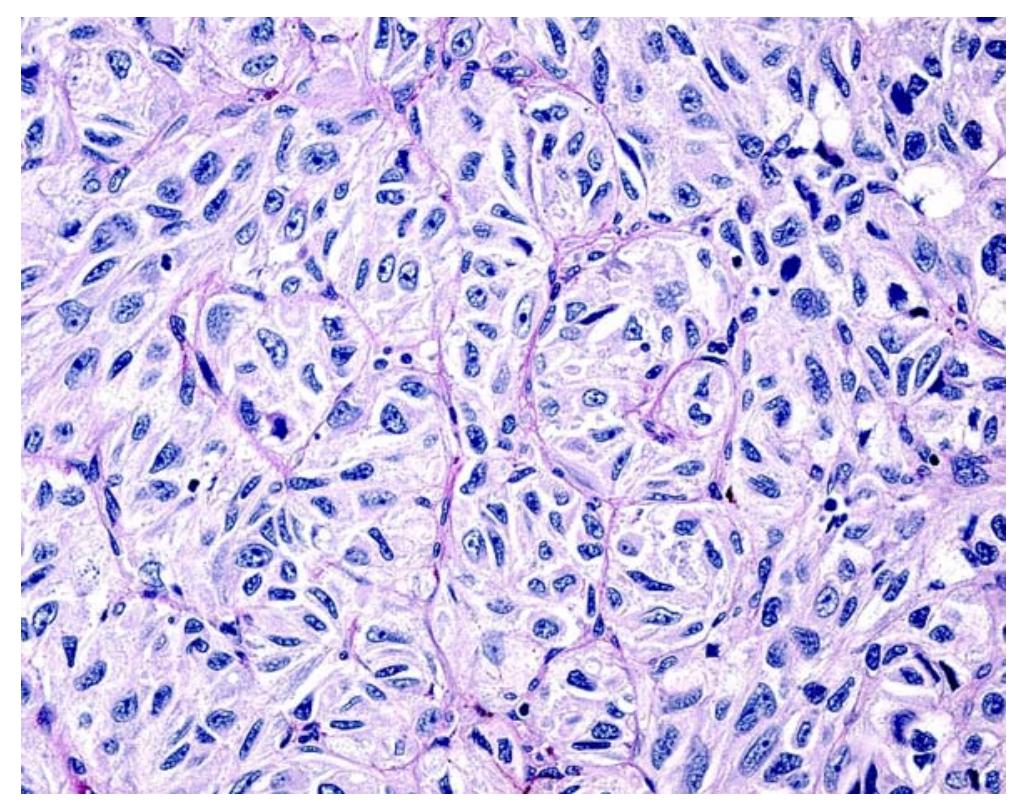

Figura 8: microscopía óptica de melanoma uveal (PAS 40x) donde se observan patrones vasculares en asas o "loops" cerrados formando redes.

\subsection{3.- Factores citogenéticos}

En los últimos años se han buscado alteraciones citogenéticas que se relacionen con el pronóstico de los melanomas uveales. ${ }^{38}$ Hasta la fecha las únicas alteraciones que se han relacionado claramente con la agresividad del tumor son alteraciones en el cariograma de las células tumorales. En concreto la monosomía del cromosoma 3 y la polisomía del cromosoma 8.65 Distintos estudios han relacionado un mayor riesgo de desarrollo de enfermedad diseminada en los pacientes que presentan tumores con una de las dos alteraciones cromosómicas, especialmente si portan la monosomía del cromosoma tres o ambas alteraciones combinadas (figura 9).65 


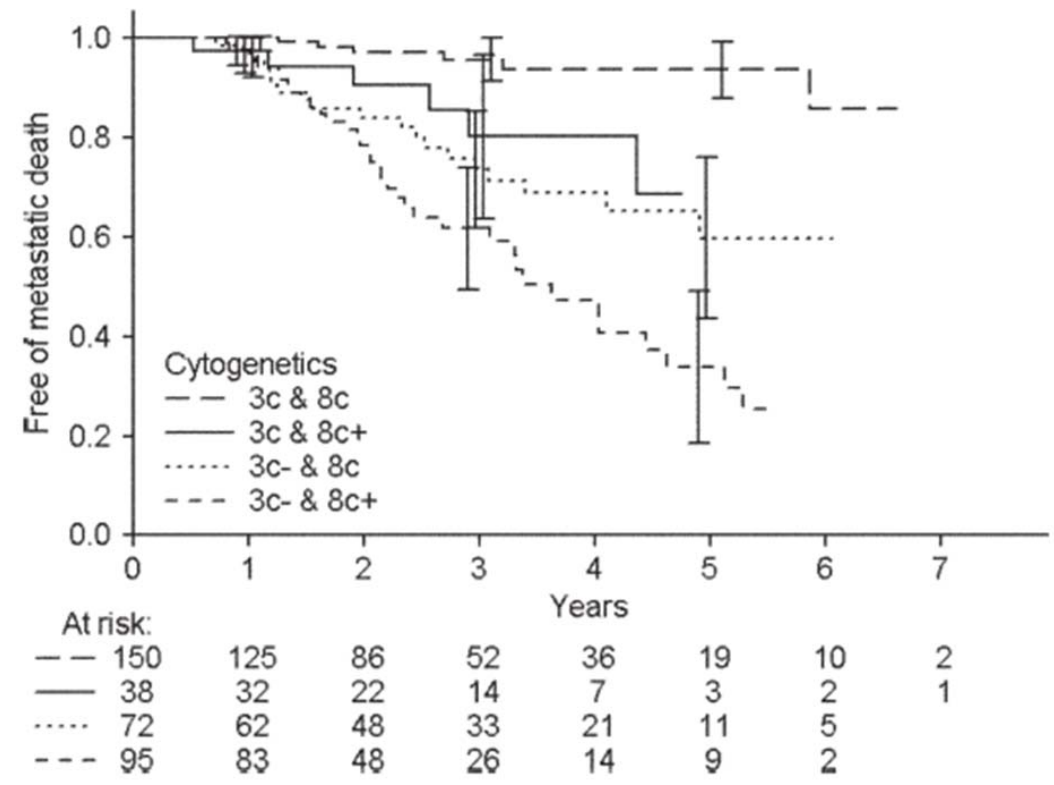

Figura 9: Gráfica que representa la supervivencia de pacientes afectos de melanoma uveal en función de de la ausencia o presencia de la monosomía del cromosoma 3, la trisomía del cromosoma 8, o la combinación de ambas (tomado de: Damato et al; Cytogenetics of uveal melanoma: a 7-year clinical experience. Ophthalmology. 2007 Oct;114(10):1925-3)1.

Si bien en un principio se dio un gran valor pronóstico a estas alteraciones citogenéticas, actualmente se interpretan con más cautela, asociándolas a los factores clínicos e histopatológicos. 66

Se han enumerado los factores más importantes. En la literatura pueden encontrarse muchos más (microdensidad vascular, macrófagos infiltrando el tumor, expresión de citoqueratinas...).

Ningún factor es independiente. Lo más frecuente es encontrar los factores de mal pronóstico agrupados de forma que los tumores grandes que crecen rápidamente, afectan al CC, tienen un índice de proliferación alto, células epitelioides etc. ${ }^{2}$

Usando análisis multivariantes los factores más importantes son el mayor diámetro tumoral, el tipo celular y la afectación del cuerpo ciliar. Con asociación estadística más débil se encuentran la invasión escleral y la actividad mitótica. ${ }^{2}$ 


\section{7.- DIAGNÓSTICO}

El diagnóstico de la lesión es preferentemente clínico. Ante la sospecha clínica se debe hacer una historia clínica completa, comenzando con una anamnesis pormenorizada. En función de la localización de la masa se realiza funduscopia si la lesión es postecuatorial, y en caso de que se encuentre en cuerpo ciliar o iris es necesario el empleo de lentes para visualización de periferia extrema o incluso transiluminación.

\subsection{1.- Funduscopia}

La exploración mediante funduscopia es el primer paso en el diagnóstico del melanoma uveal. Es una exploración rutinaria y de fácil acceso para cualquier oftalmólogo.

Debe realizarse en condiciones de midriasis farmacológica de forma que pueda explorarse el mayor área intraocular posible.

El uso del oftalmoscopio de imagen invertida permite una observación general del interior del ojo aportando información sobre la localización y extensión de la tumoración así como la existencia de desprendimiento de retina.

La exploración con la lámpara de hendidura permite completar el estudio de la lesión obteniendo detalles de ésta, como la presencia en la superficie de pigmento naranja, de drusas, hemorragias, exudados duros, ruptura de la membrana de Bruch, fibrosis subretiniana, dispersión de pigmento en la cámara vítrea, etc (figura 10). La presencia de hemorragia vítrea densa impide una correcta visualización del interior del ojo y limita esta técnica.

Si bien, en manos expertas, puede sugerir el diagnóstico casi con certeza,67 dicha exploración debe completarse con las técnicas complementarias que a continuación se detallan. 


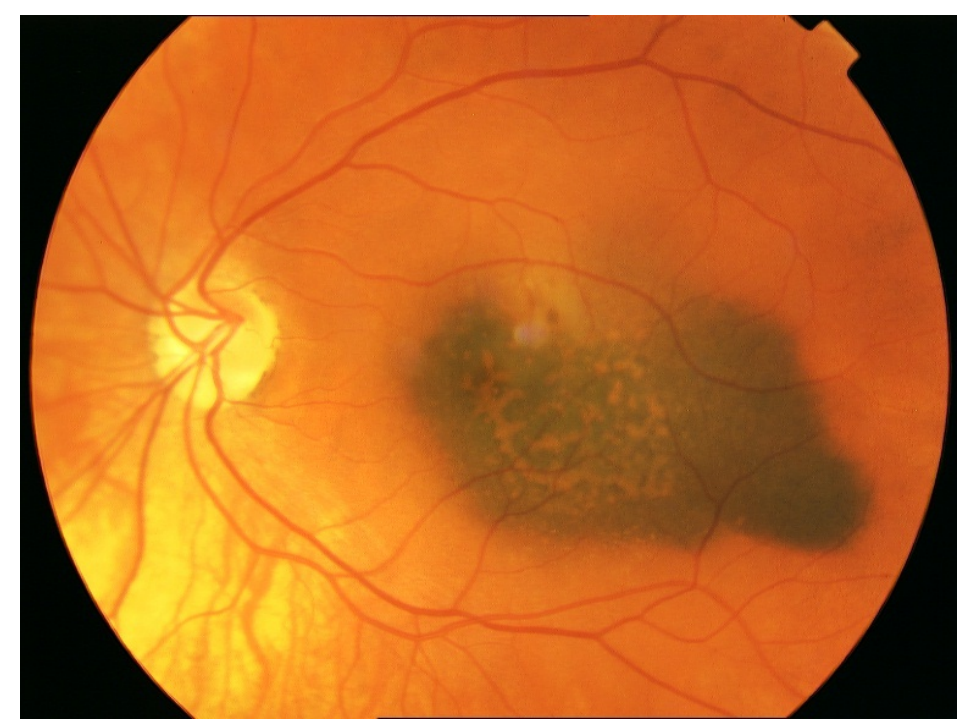

Figura 10: Retinografia donde puede verse, en el polo posterior de un ojo izquierdo, una tumoración melanótica coroidea con abundante pigmento naranja en su superficie.

\subsection{2.- Pruebas complementarias}

1.- Ecografia ocular: es la prueba más útil para el diagnóstico del melanoma uveal.68 E1 tumor se presenta como una masa hiperecogénica, con excavación coroidea, y sombra ecogénica posterior (figura 11). 68

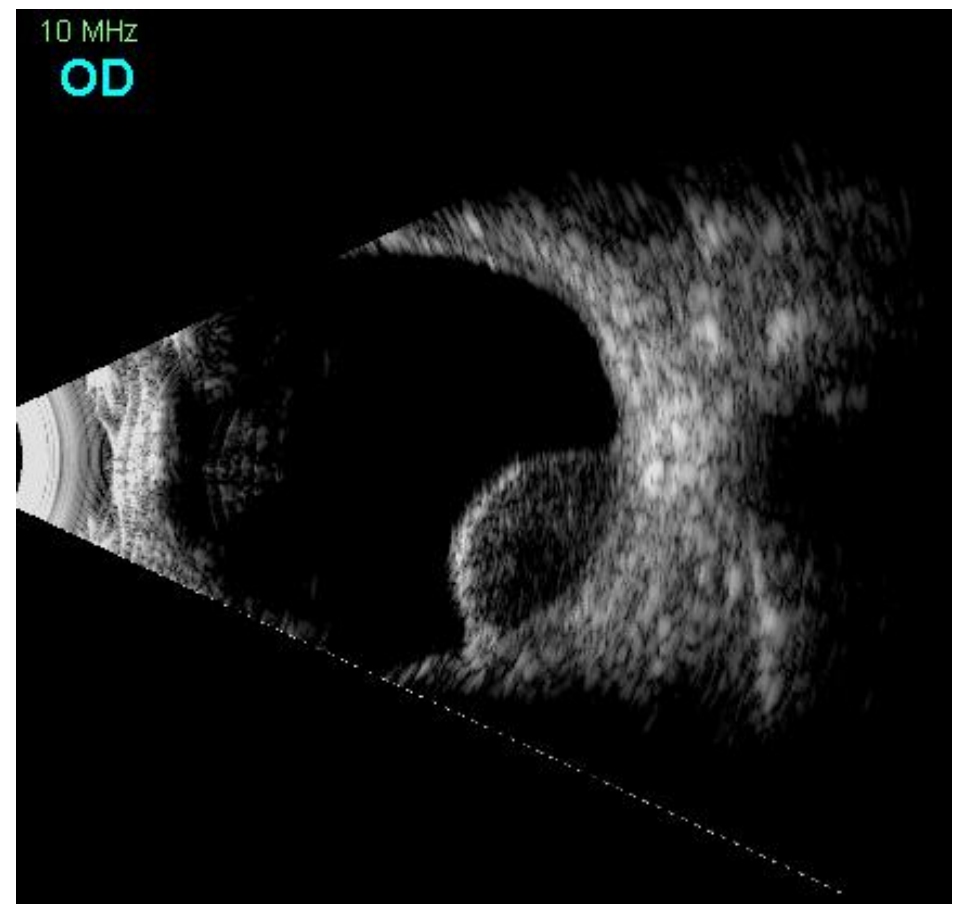

Figura 11: Ecografia de un melanoma uveal. Se pueden observar el vacio ecogénico de la masa, la excavación coroidea y la sombra ecogénica posterior. 
A veces adopta forma de "champiñón" por romper la membrana de Bruch, siendo esta imagen patognomónica. ${ }^{69}$ Es muy característico que en el vector A el tumor presente un pico en la superficie anterior para decrecer y volver a aumentar. Este comportamiento se denomina “ángulo kappa" (figura 12). ${ }^{70}$
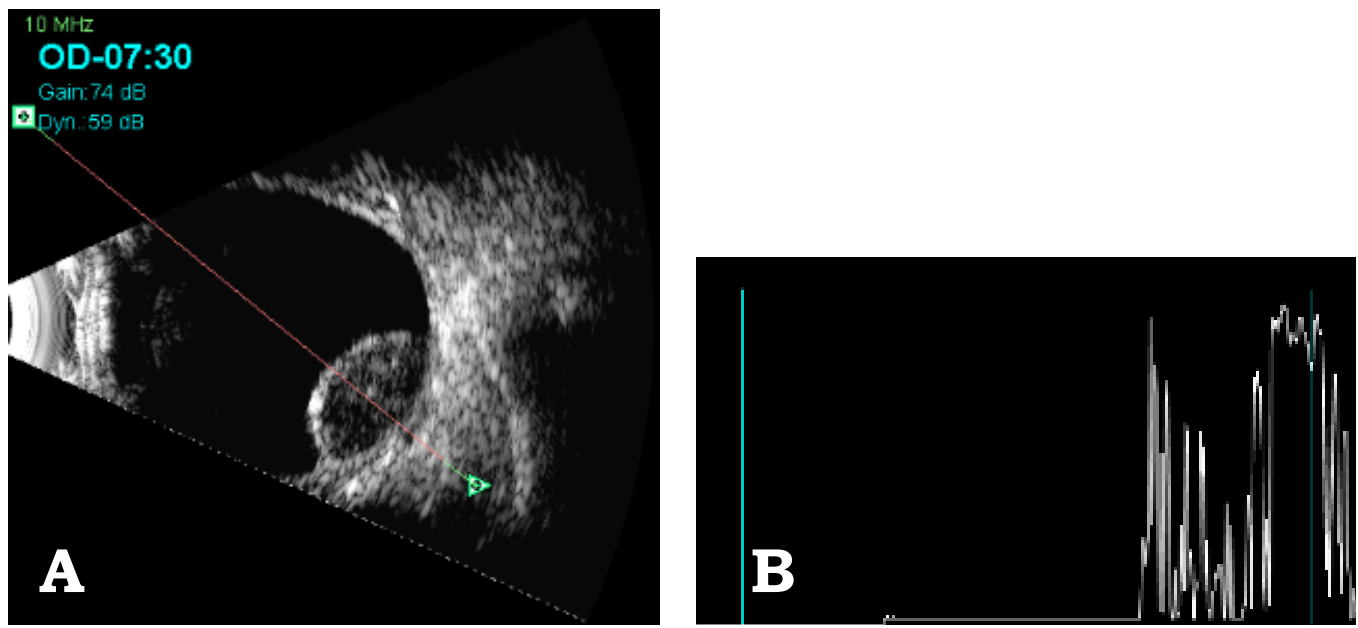

Figura 12: Ecografia de un melanoma uveal. Se observa el corte del vector A (A) y la señal característica que produce: angulo kappa (B).

La ecografia ha demostrado ser, además, superior al TAC y la RNM en la detección de extensión extraocular. ${ }^{69} \mathrm{El}$ rendimiento diagnóstico, sin embargo, disminuye mucho cuando se trata de lesiones pequeñas, siendo muy complicado establecer el diagnóstico diferencial con nevus. 68

2.- Doppler: permite estudiar la circulación intrínseca de los tumores coroideos. Si bien existen lesiones distintas del melanoma que pueden simular la circulación de éste, por lo que no permite un diagnóstico de certeza, si puede ser una prueba más para apoyar el diagnóstico. ${ }^{71}$

3.- Biomicroscopia ultrasónica (BMU): Permite el estudio de masas localizadas en el iris o el cuerpo ciliar. Sus características son asimilables a las presentadas para la ecografia ocular. ${ }^{72}$

4.- Angiografia con fluoresceína: su utilidad es muy limitada en los melanomas uveales. ${ }^{73}$ Las alteraciones que más frecuentemente se observan son la "doble circulación" y el "patrón moteado", que es la 
representación de la circulación intrínseca del tumor, los "hot spots", que se deben a alteraciones puntuales del epitelio pigmentario de la retina, y fuga tardía de fluoresceína.

5.- Angiografia con verde de indocianina: permite una mejor visualización de la vascularización tumoral que la anterior técnica. ${ }^{74}$ No existen patrones patognomónicos por lo que los hallazgos que resultan de esta prueba deben ser puestos en común con el resto de exploraciones. ${ }^{75}$

6.- Tomografia de coherencia óptica (OCT): Permite detectar fluido subretiniano, poniendo de manifiesto alteraciones del EPR (figura 13). ${ }^{76}$

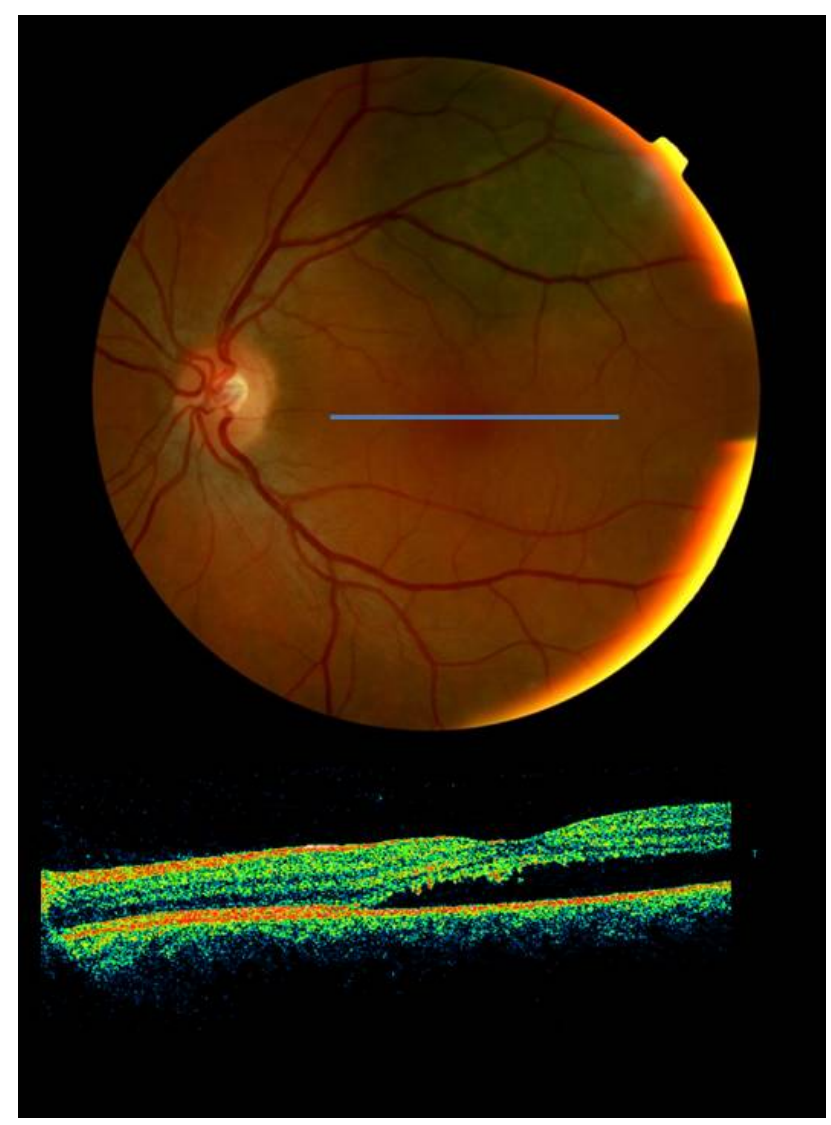

Figura 13: OCT macular en paciente con lesión melanocitica donde se puede apreciar la presencia de fluido subretiniano.

7.- Autofluorescencia: Permite la detección del pigmento naranja con mayor precisión que otras técnicas y además pone de manifiesto la presencia de fluido subretiniano, siendo muy útil para el seguimiento y vigilancia de lesiones sospechosas (figura 14). ${ }^{77}$ 

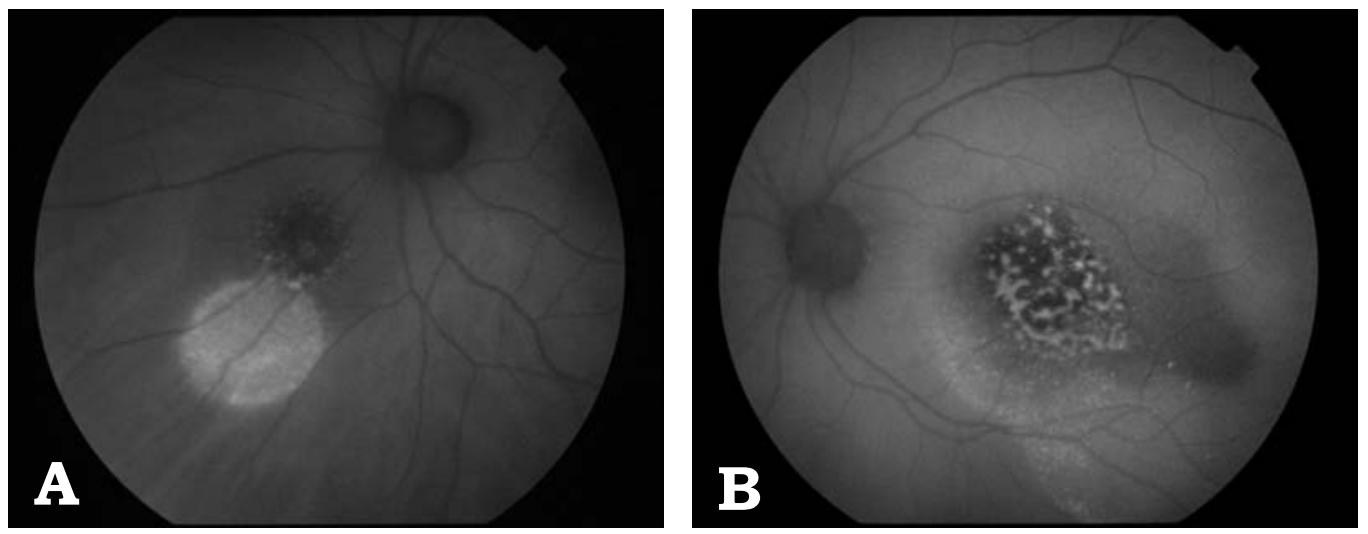

Figura 14: Imágenes de autofluoresncencia donde pueden observarse la presencia de fluido subretiniano (A) y de pigmento naranja (B)

8.- Tomografia axial computerizada (TAC): los melanomas uveales aparecen como masas hiperdensas que re realzan moderadamente con contraste. Los tumores de menos de $2 \mathrm{~mm}$ de altura son dificilmente detectables con esta técnica. ${ }^{78}$

9.- Resonancia magnética nuclear (RNM): los melanomas aparecen hiperintensos en T1 e hipointensos en T2 (figura 15). ${ }^{79}$

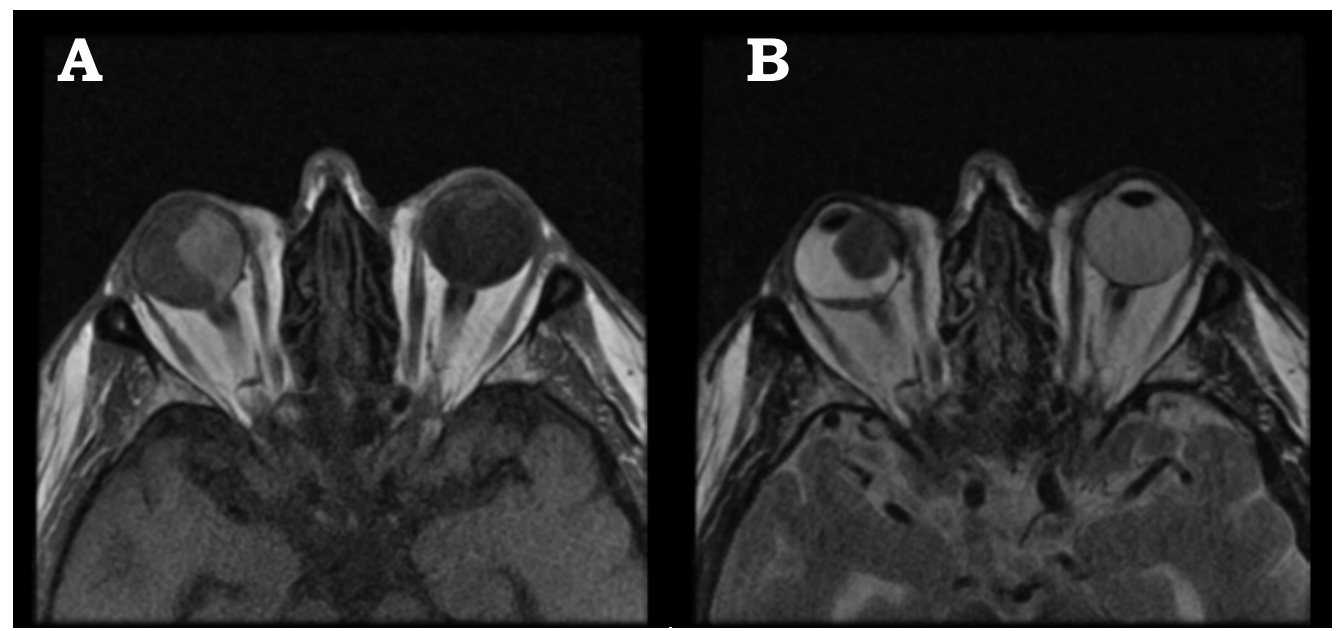

Figura 15: Imágenes de resonancia nuclear de un melanoma de la úvea. Puede observarse la hiperintensidad de la lesión en T1 (A) y la hipointensidad en T2 (B).

10.- Tomografia por emisión de positrones (PET): Se ha empleado en estudios piloto para analizar alteraciones metabólicas, pero hoy en día no se ha establecido su utilidad en el diagnóstico de esta enfermedad. ${ }^{80}$ 
Una vez realizado el diagnóstico de melanoma se debe realizar un estudio de extensión encaminadas a detectar alteraciones hepáticas. El hígado constituye el objetivo principal en la búsqueda de metástasis debido a la selecta predilección del melanoma uveal por este órgano, ya que la enfermedad metastásica se diagnostica inicialmente en el hígado en el $85 \%$ de los casos y en el $55 \%$ es el único órgano afectado. ${ }^{81}$

\section{8.- DIAGNÓSTICO DIFERENCIAL}

La precisión del diagnóstico del melanoma de la úvea ha mejorado en los últimos años, debido a la experiencia adquirida en el manejo de estos tumores, al desarrollo del conocimiento de los factores de riesgo y a la mejora de los medios diagnósticos, especialmente la ecografia ocular. En los años 70 alrededor del $20 \%$ de los ojos enucleados por sospecha de melanoma uveal tenían lesiones benignas. ${ }^{82}$ Esta tasa de error ha bajado hasta el $0,48 \%$ en la actualidad.67,83 Sin embargo es todavía muy alto para lesiones iridianas o ciliares (hasta el 40\%). ${ }^{73,84}$

Existen una serie de características que pueden ayudar en el diagnóstico del melanoma de coroides. En la anamnesis son importantes la edad (por debajo de 20 años debemos dudar del diagnóstico), personas de raza no blanca, antecedentes de cirugía ocular (que puedan haber condicionado hemorragias coroideas), procesos inflamatorios oculares (escleritis) o historia de procesos oncológicos sistémicos (metástasis).

La exploración ocular puede darnos también valiosa información. Es importante tener en cuenta que hasta el 30\% de los melanomas coroideos pueden ser amelanóticos $\mathrm{y}$ que es muy raro encontrar un melanoma completamente negro (una lesión negra es más sugestiva de hemorragia, proliferación del epitelio pigmentario de la retina o un melanocitoma). ${ }^{85}$ Las lesiones múltiples y/o bilaterales son más sugestivas de metástasis o patología inflamatoria. La forma de "champiñón" que aparece cuando el tumor rompe la membrana de Bruch es muy típica de los melanomas. La hemorragia vitrea es muy rara en asociación con melanomas de coroides. 
Existen sin embargo múltiples procesos que pueden simular un melanoma coroideo, los más importantes son:

\subsection{1.- Nevus coroideo:}

Es muy dificil distinguir un melanoma pequeño de un nevus atípico. Los nevus coroideos son característicamente planos, de menos de $6 \mathrm{~mm}$ de diámetro y suelen tener drusas en su superficie y atrofia alrededor. Para lesiones de $1,5 \mathrm{~mm}$ a $3 \mathrm{~mm}$ de altura y menos de $10 \mathrm{~mm}$ de base, el diagnóstico diferencial es más complicado y se discute más adelante.

\subsection{2.- Hemorragia coroidea/subretiniana:}

Diversos procesos hemorrágicos intraoculares pueden simular un melanoma, entre ellos, la degeneración macular asociada a la edad (DMAE), hemorragias subretinianos y macroaneurismas arteriales. ${ }^{86} \mathrm{El}$ aspecto oftalmoscópico y ecográfico pueden simular un melanoma; sin embargo su evolución natural es hacia la reabsorción en poco tiempo, lo que facilita el diagnóstico diferencial.

\subsection{3.- Hemangioma coroideo:}

Es una lesión benigna que puede simular ser un melanoma de coroides.67 Son lesiones rojo-anaranjadas que frecuentemente asocian desprendimiento de retina. La angiografía con fluoresceína y verde de indocianina es característica, apareciendo fluorescencia temprana y fenómeno de "wash-out". En la ecografia tiene aspecto nodular con alta reflectividad interna. ${ }^{73}$

\subsection{4.- Metástasis coroideas:}

Pueden aparecer antes que el primario entre el 10\% y el $90 \%$ de los casos dependiendo de la histologia. ${ }^{87}$ Suelen asentar en el polo posterior y suelen ser múltiples. Son amelanóticas y sus características ecográficas son 
diferentes de las del melanoma (no presentan angulo kappa, vacio ecogénico ni excavación coroidea. ${ }^{88}$

\subsection{5.- Melanocitoma:}

Debido a su aspecto melanótico pueden confundirse con un melanoma. Sin embargo son más pigmentados, con los límites mucho más netos y suelen ocultar la vascularización retiniana al crecer las células melanocíticas alrededor de los vasos. Por lo demás su comportamiento en la ecografia también es muy similar al de los melanomas. ${ }^{89}$

\subsection{6.- Tumores del epitelio pigmentario de la retina}

Las hipertrofias congénitas del EPR cuando son muy periféricas pueden simular melanomas debido a que son dificiles de explorar. Los adenomas y adenocarcinomas del EPR son tumores muy raros que también pueden simular melanomas. Se caracterizan por tener limites muy netos, pigmentación más oscura que los melanomas y por tener un comportamiento ecográfico diferente de éstos.

\section{9.- TRATAMIENTO}

Los objetivos del tratamiento son:

1.- Destruir el tumor: El melanoma de coroides es una neoplasia agresiva que sin tratamiento tiende a crecer destruyendo las estructuras oculares, invadiendo las estructuras vecinas y a diseminarse vía hematógena produciendo metástasis. El primer objetivo del tratamiento debe ser detener la progresión de la enfermedad destruyendo el tumor.

2.- Conservar el órgano y la función visual: Tanto el melanoma como los tratamientos para erradicarlo suponen una agresión para las estructuras oculares y por la tanto para su función. Los tratamientos actuales tienden a tratar el tumor minimizando los daños sobre las estructuras oculares sanas. 
3.- Mejorar la supervivencia: Hasta la fecha ningún tratamiento ha demostrado ser superior a los demás en cuanto a mejora de la supervivencia. El diagnóstico precoz es la única herramienta eficaz en la mejora de la supervivencia, puesto que el pronóstico está fuertemente influido por el tamaño del tumor. ${ }^{2}$

Hoy en día existen múltiples alternativas terapéuticas para el tratamiento del melanoma de la úvea. Hasta hace unos años el único tratamiento posible era la enucleación, sin embargo en las últimas décadas se han desarrollado tratamientos conservadores que permiten controlar la enfermedad preservando en mayor o menor medida la función visual, quedando la enucleación relegada a los casos más avanzados.

\subsection{1.- Enucleación}

Debido al desarrollo de tratamientos conservadores, la enucleación queda reservada para ojos ciegos o con dolor, y en tumores grandes, no susceptibles de ser tratados con terapias conservadoras. 90 Los ojos con extensión extraescleral en el diagnóstico se tratan también mediante enucleación, puesto que no parece que cirugias más amplias mejoren el pronóstico. La asociación de terapias adyuvantes como la radioterapia externa previa y/o postcirugía es otra opción en estos casos. ${ }^{91}$

La enucleación como tratamiento primario del melanoma uveal no ha estado exenta de polémica. En los años setenta del pasado siglo, Zimmerman, McLean y Foster, pusieron en duda los beneficios de la enucleación sobre el pronóstico vital de los pacientes afectos de melanoma uveal, presentando resultados que apuntaban a que este tratamiento aumentaba la incidencia de metástasis. ${ }^{92}$ Hoy en día se ha demostrado que la enucleación no presenta diferencias frente a los tratamientos conservadores en cuanto a supervivencia aplicada a tumores de características similares. ${ }^{5}$

\subsection{2.- Braquiterapia epiescleral}

La braquiterapia epiescleral con isotopos radiactivos es uno de los métodos más empleados en la actualidad para el tratamiento de los 
melanomas uveales. Desde que esta técnica comenzó en los años 30 con el uso del radón por Moore, ${ }^{93}$ diversos isótopos como el cobalto $\left({ }^{60} \mathrm{Co}\right)$, el rutenio (106 Ru), el iridio (192 Ir), el estroncio ( $\left.{ }^{90} \mathrm{Sr}\right)$, el paladio $\left({ }^{103} \mathrm{Pd}\right)$ y el yodo (125I) se han empleado, siendo en la actualidad el yodo (figura 16) el más utilizado junto con el rutenio. La técnica se basa en la colocación de una placa cargada con alguno de estos isótopos sobre la proyección escleral externa del tumor. Dicha placa se sutura para inmovilizarla y el tumor sea expuesto a la dosis programada de radiación. Esta técnica garantiza una adecuada irradiación del tumor puesto que la placa se desplaza junto con el ojo.94 Actualmente se considera que la dosis terapéutica en el ápex tumoral debe ser de 85 Gy. ${ }^{95}$

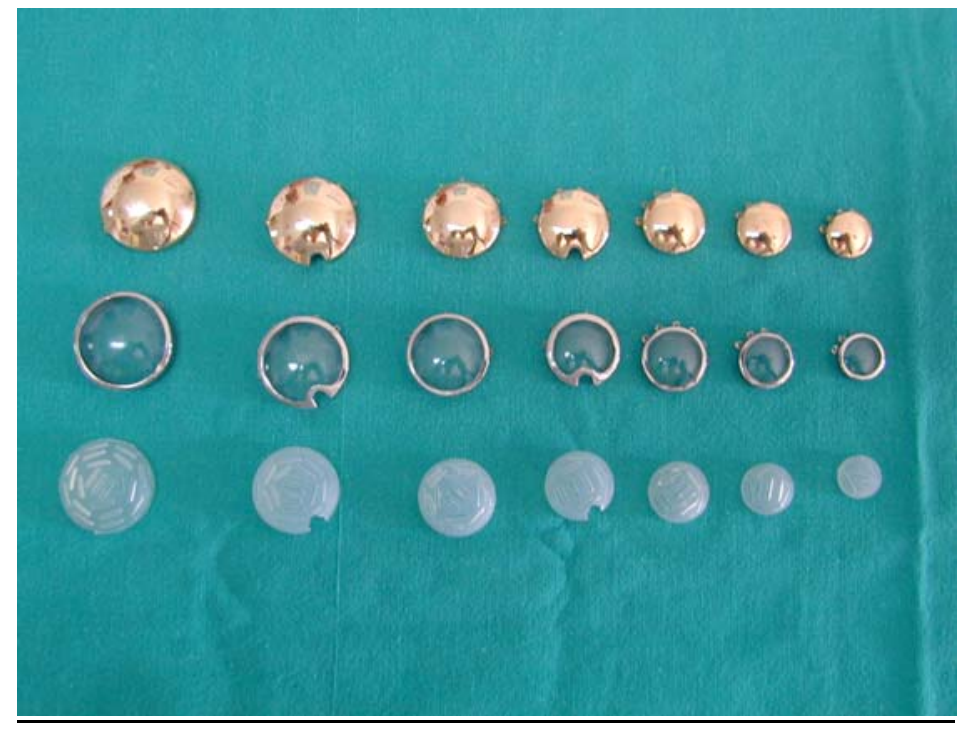

Figura 16: Placas de braquiterapia epiescleral tipo COMS para yodo 125

El COMS (Collaborative Ocular Melanoma Study), un ensayo clínico múlticentrico realizado es Estados Unidos para estudiar la eficacia del tratamiento de la braquiterapia con yodo en el melanoma de úvea, ha demostrado que este tratamiento es tan eficaz en cuanto al control de la enfermedad y la supervivencia como la enucleación para melanomas medianos ${ }^{96}$ y grandes. ${ }^{97}$ La tasa de control local es superior al 90\%, 98 pero de manera asociada la irradiación de los tejidos circundantes al tumor trae consigo el desarrollo de efectos secundarios entre los que destacan la formación de cataratas, la retinopatía y la neuropatía por radiación, que comprometen de manera reversible en el primer caso e irreversible en los dos últimos la función visual del paciente (figura 17). ${ }^{99}$ 


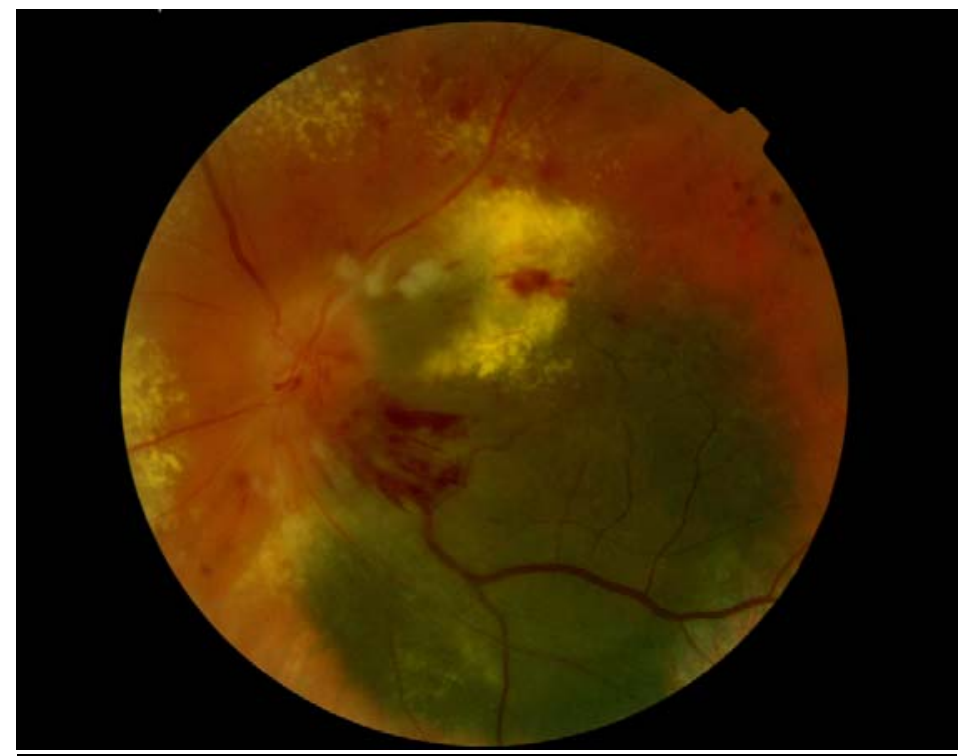

Figura 17: Ejemplo de neuroretinopatia por radiación.

\subsection{3.- Radioterapia externa con protones}

Otra alternativa conservadora para el tratamiento de los melanomas de la úvea es el uso de radiación externa con protones. Se basa en el bombardeo del tumor con protones o núcleos de helio que son acelerados mediante un ciclotrón (figura 18). Es un tratamiento menos empleado debido a la escasez de equipos, puesto que los aceleradores tienen un elevadísimo coste de construcción y mantenimiento lo que restringe mucho su uso. Su eficacia en cuanto a control tumoral, supervivencia y tasa de efectos secundarios es similar a la de la braquiterapia epiescleral. ${ }^{100}$

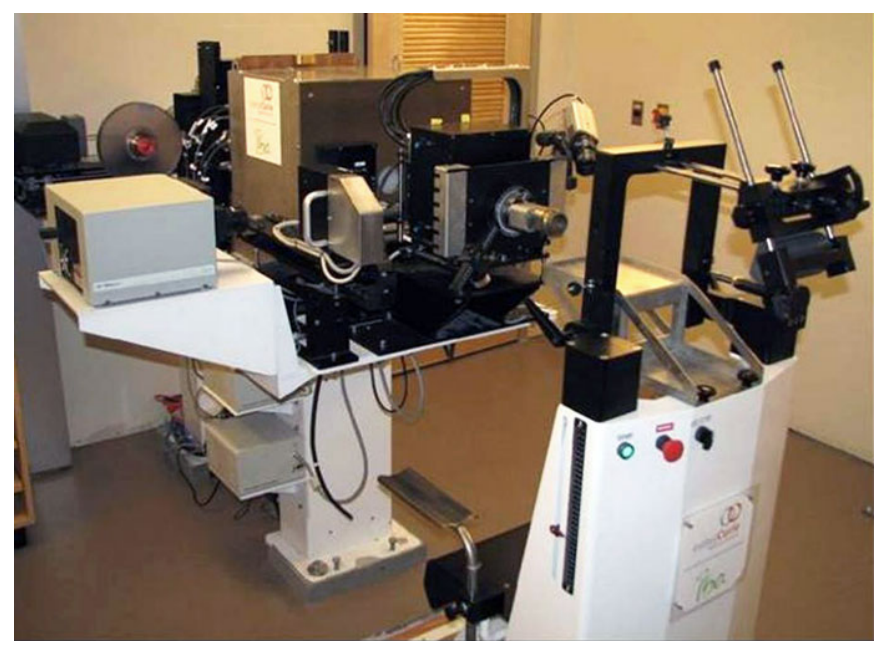

Figura 18: Dispositivo para tratamientos oculares de un ciclotrón de uso clínico 


\subsection{4.- Radiocirugia}

La radiocirugía es otra modalidad de tratamiento con radiación. Hoy en día existen distintos sistemas como son el gammaknife (consiste en un dispositivo con múltiples fuente de cobalto $\left({ }^{60} \mathrm{Co}\right)$ colocadas en una estructura hemisférica que hace que la emisión de rayos $\gamma$ converja en el tumor), el ciberknife (es un acelerador lineal de electrones colocado en un brazo robótico con múltiples grados de movimiento que permite irradiar el tumor en múltiples planos espaciales que convergen en éste), la tomoterapia (consiste en un acelerador lineal de electrones montado junto con un sistema de tomografia axial computerizada que permite recalcular la dosis suministrada en función de la información que en tiempo real se recoge mediante el sistema de tomografia) o la radioterapia estereoatáxica (consiste en un acelerador de electrones que varia la dosis de radiación suministrada según realiza un movimiento circular con centro en el tumor) (Figura 19). No existe experiencia en el tratamiento del melanoma uveal con dispositivos de tomoterapia, y con el cyberkife hay muy poca. ${ }^{101} \mathrm{Si}$ bien el gammaknife ${ }^{102}$ y la radioterapia estereoatáxica103 han demostrado una eficacia comparable a la de la braquiterapia epiescleral presentan el inconveniente de la necesidad de una fijación temporal del globo ocular mientras se aplica el tratamiento. ${ }^{104}$

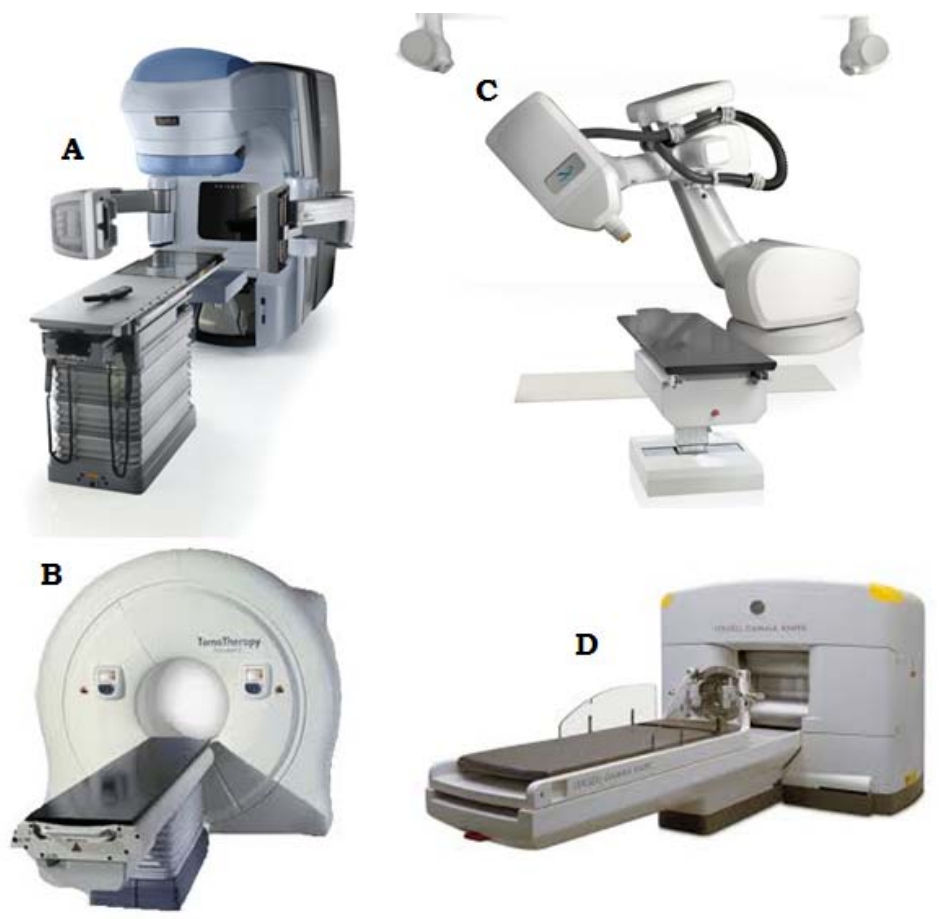

Figura 19: Distintos dispositivos de radiocirugía: A: Radioterapia estereoatáxica. B: Tomoterapia. C: Cyberknife. D: Gammaknife. 


\subsection{5.- Resección transescleral}

La resección de los melanomas uveales a través de la esclera es una técnica muy controvertida. Consiste en la extirpación del tumor desde su proyección escleral. De gran complejidad técnica, presenta como principal problema la necesidad de respetar parte de la integridad de la pared escleral para conservar la integridad del globo ocular, y no puede descartarse la presencia de invasión de esta pared por células tumorales. ${ }^{105}$ Hoy en día su indicación se restringe a tumores intratables mediante radioterapia (en este caso debe radiarse la proyección escleral del tumor en un segundo tiempo) ${ }^{106} \mathrm{o}$ bien como complemento a la radiación para disminuir los efectos secundarios de ésta (desprendimientos de retina exudativos extensos o glaucoma neovascular). ${ }^{107}$

\subsection{6.- Endoresección}

Consiste en la eliminación del tumor a través de la retina mediante vitrectomía. Al igual que la anterior, esta es una técnica muy controvertida, puesto que no se ha demostrado que no aumente el riesgo de diseminación o de recidiva tras el tratamiento. ${ }^{108}$ La realización de la endorresección después de haber tratado el tumor mediante radioterapia si ha demostrado por el contrario una mejora en la tasas de complicaciones debidas al tratamiento. ${ }^{109}$

\subsection{7.-Termoterapia transpupilar}

Consiste en calentar mediante láser diodo el tumor. Dado que es una técnica relativamente accesible y sencilla, se ha difundido mucho en los últimos años como tratamiento aislado, sin embargo los estudios publicados indican que es una técnica no efectiva con una tasa inadmisible de recurrencias. ${ }^{110} \mathrm{Si}$ puede, sin embargo, utilizarse combinada con la braquiterapia epiescleral. ${ }^{111}$

\subsection{8.- Observación}

El tratamiento de las lesiones catalogadas como melanomas pequeños inactivos o lesiones sospechosas es controvertido. Muchas de estas lesiones 
catalogadas como melanomas probablemente no lo son, no se ha demostrado que el tratamiento precoz de los melanomas pequeños mejore la supervivencia, y los tratamientos no son inocuos para la función visual. ${ }^{13}$ Puesto que esta modalidad terapéutica es el objeto del presente trabajo se desarrolla en el apartado siguiente.

\subsection{0.- CONTROVERSIAS EN EL TRATAMIENTO DE LOS MELANOMAS PEQUEÑOS}

No existe consenso a la hora de trazar el límite que separa las lesiones melanóticas coroideas benignas de las malignas. ${ }^{13}$ Se consideran nevus las lesiones de menos de un $\mathrm{mm}$ de altura y cinco de base, y melanomas pequeños aquellas que tienen más de tres $\mathrm{mm}$ de altura y diez de base. ${ }^{8}$

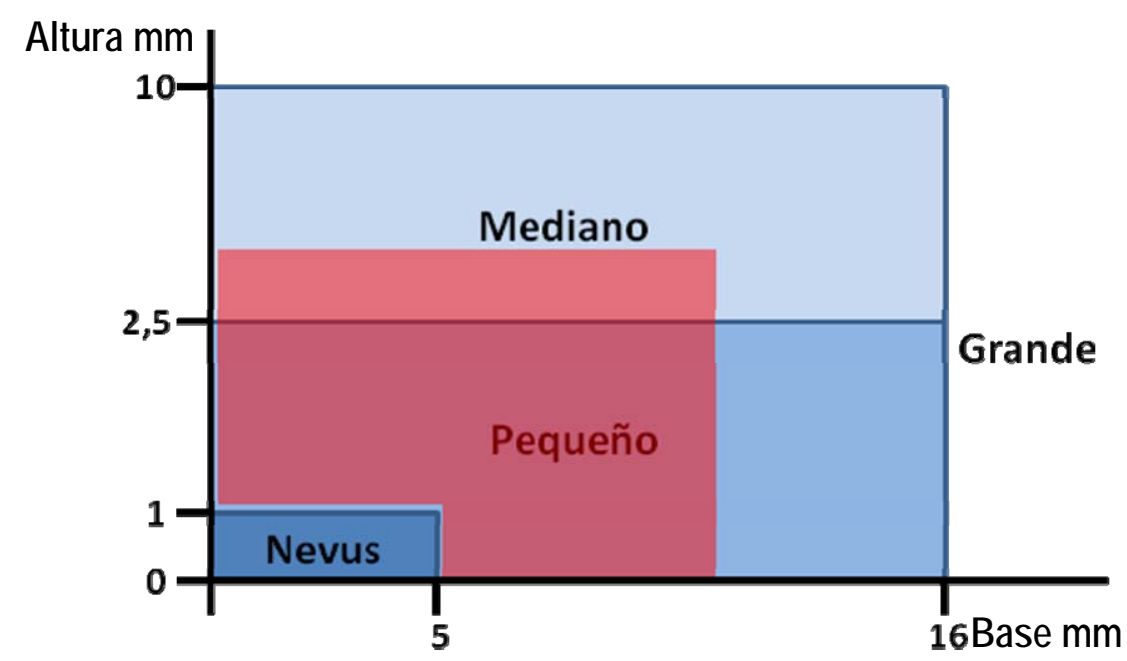

Figura 20: Esquema donde sobre las medidas que emplea el COMS para clasificar los melanomas coroideos según su tamaño se representa (en rojo) el área que ocupan las lesiones que se consideran sospechosas sin ser melanomas (modificado de Singh et al en Ocular Oncology Ed. Saunders 2008).

Las lesiones que se encuentran entre un milimetro y tres de altura, y entre cinco y diez milimetros de base, son consideradas lesiones sospechosas. ${ }^{13}$ Estos tumores son denominados en la literatura como nevus sospechosos, 112 supuestos melanomas pequeños ${ }^{13} \mathrm{u}$ otras denominaciones (figura 20).

Se ha observado que las lesiones melanociticas sospechosas, tienen potencial metastásico (mayor del 3\% en las series publicadas). ${ }^{11}$ La aparición 
de metástasis se ha relacionado con la altura del tumor (mayor de $2 \mathrm{~mm}$ ), la presencia de síntomas, el contacto con el nervio óptico y el crecimiento tumoral en el seguimiento. ${ }^{11}$

El crecimiento es el único factor que puede ser controlado por el oftalmólogo, puesto que los otros tres vienen impuestos por la propia naturaleza de la lesión y están presentes en el momento del diagnóstico.

En un intento por tratar las lesiones sospechosas antes de que crezcan, Shields y cols, ${ }^{113}$ han analizado y descrito una serie de factores, estudiando lesiones en 1287 pacientes (con un seguimiento medio de 51 meses (rango 1277 meses), que asociados, son indicadores de riesgo de crecimiento y por lo tanto de aumento de la incidencia de metástasis.

Estos factores son:

- La presencia de pigmento naranja.

- La presencia de fluido subretiniano.

- La presencia de síntomas visuales.

- La cercanía al nervio óptico (menos de un milimetro).

- Una altura mayor de 2 milímetros.

Cada factor tiene un peso específico, siendo los más importantes la presencia de fluido subretiniano, la altura superior a dos milímetros y el contacto con el nervio óptico. La asociación de dos o más factores tiene un efecto acumulativo que varía en función de los factores asociados, de forma que un paciente que presente tres o más factores de riesgo asociados tiene más del $50 \%$ de posibilidades de que su lesión crezca en los siguientes 5 años. Más tarde, en 2009, se añadieron otros dos factores más al ampliar la serie; 2514 pacientes seguidos durante 53 meses de media (rango 6-434 meses). Estos nuevos factores son el vacio ecogénico y la ausencia de halo de atrofia peritumoral. ${ }^{12}$

Singh y colaboradores han descrito como factor protector de crecimiento la presencia en la superficie del tumor de drusas. ${ }^{114}$ 
La detección precoz de estos signos de crecimiento puede mejorarse con el uso de métodos diagnósticos complementarios. El uso de la tomografía de coherencia óptica mejora la detección del fluido subretiniano. ${ }^{76}$ Por otra parte, la introducción de las técnicas de estudio de la autofluorescencia del epitelio pigmentario de la retina, han mejorado el diagnóstico de alteraciones en esta estructura. ${ }^{115}$

Obviamente, el único diagnóstico certero de malignidad o benignidad sólo puede obtenerse a través del estudio anatomopatológico. Puesto que la escisión de estas lesiones no es asequible desde el punto de vista clínico, ya que comportaría gravísimas e irreversibles alteraciones de la función visual, se ha postulado la utilidad de su estudio a través de la toma de muestras mediante técnicas de punción-aspiración con aguja fina, encontrándose en la literatura desiguales resultados en cuanto a fiabilidad diagnóstica $\mathrm{y}$ complicaciones. ${ }^{84}$

Con respecto al manejo de las lesiones indeterminadas, actualmente no existe consenso entre los distintos autores. Por un lado, la posibilidad de crecimiento y por tanto de desarrollo de metástasis inclinan la balanza hacia un tratamiento muy precoz de estas lesiones, pero no se ha demostrado que este tratamiento precoz revierta en una mejora del pronóstico a largo plazo. ${ }^{6}$ Por otro lado, el tratamiento no está exento de efectos secundarios que de forma irreversible menoscaban la agudeza visual del paciente.

En este contexto, el objeto del presente trabajo es estudiar el comportamiento de las lesiones indeterminadas diagnosticadas y seguidas en la Unidad de Tumores Intraoculares del Adulto del Servicio de Oftalmología del Hospital Universitario de Valladolid, con el objeto de determinar el impacto que sobre el pronóstico tiene la observación frente al tratamiento e identificar a los pacientes con mayor riesgo de crecimiento susceptibles de ser sometidos a tratamiento. 


\section{METODOLOGÍA}

\section{1.- DISEÑO DEL ESTUDIO}

El presente estudio se corresponde con un estudio histórico de cohorte única.

\section{2.- SUJETOS}

Pacientes que fueron diagnosticados de melanoma de coroides en la unidad de oncología ocular del Hospital Clínico Universitario de Valladolid desde enero de 1992 hasta febrero de 2010 .

\section{3.- CRITERIOS DE INCLUSIÓN}

1. Pacientes diagnósticados de melanoma de coroides que se clasificaron por su tamaño ecográfico según la clasificación COMS. 45

El diagnóstico de melanoma de coroides se realizó atendiendo a las características oftalmoscópicas (masa coroidea melanótica o amelanótica que puede asociar la presencia de pigmento naranja (lipofucsina) en su superficie, desprendimiento de retina exudativo o fluido subretiniano y drusas en su superficie) y características ecográficas cómo son el ángulo kappa (pico en el vector A seguido de una caida progresiva de la reflectividad), vacio ecogénico central, excavación coroidea y sombra posterior. 
Según las medidas ecográficas, los melanomas de coroides se clasificaron como:

A.- Pequeños: aquellos tumores que tenían una altura maxima menor o igual a $2,5 \mathrm{~mm}$ y una base máxima menor o igual a $16 \mathrm{~mm}$.

B.- Medianos: aquellos que tenian una altura máxima mayor de 2,5 $\mathrm{mm}$ y menor o igual a $10 \mathrm{~mm}$ y una base máxima menor o igual a $16 \mathrm{~mm}$.

C.- Grandes: aquellos que teían una altura máxima mayor de $10 \mathrm{~mm}$ o una base máxima mayor de $16 \mathrm{~mm}$

En un principio la diferencia entre pequeños y grandes se estableción en $3 \mathrm{~mm}$, pero en 1990 se modificó a 2,5 mm. Las lesiones menores de $5 \mathrm{~mm}$ de base y de $1 \mathrm{~mm}$ de altura se consideraron nevus (figura 21).

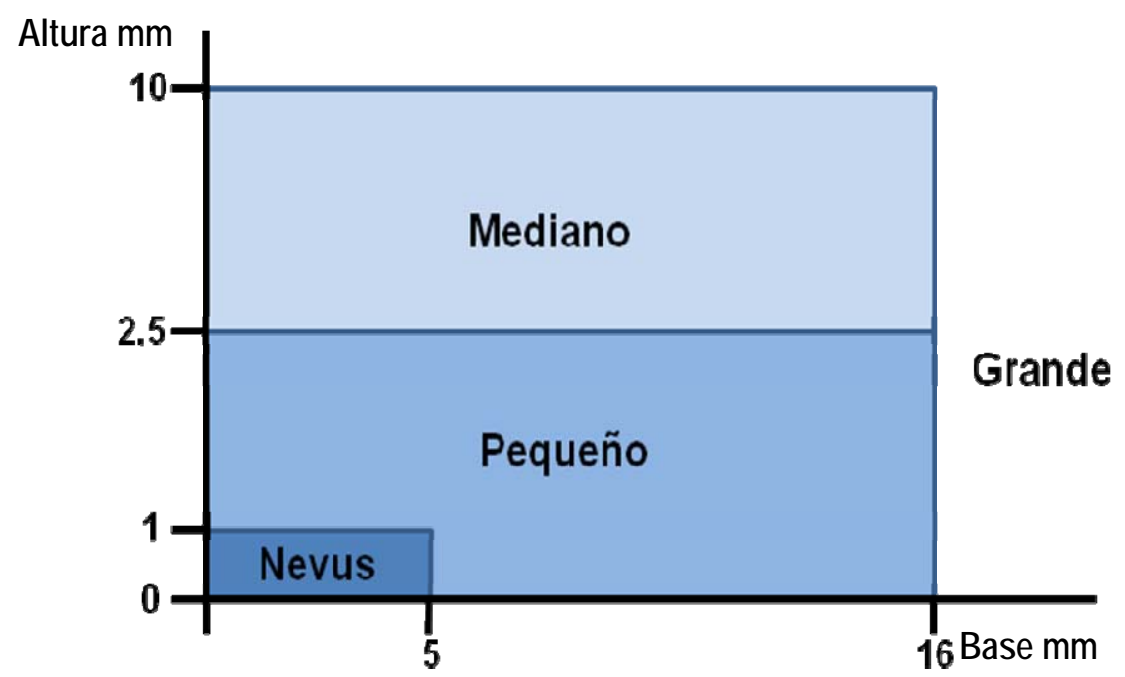

Figura 21: Clasificación de los melanomas de coroides según el COMS por tamaños en $\mathrm{mm}$.

2. El paciente debió ser sometido a observación como primera intención terapeútica, pudiendo recibir en el devenir del proceso 
tumoral otros tratamientos, ya fueran braquiterapia epiescleral con 125I o ${ }^{106} \mathrm{Ru}$ o enucleación.

Se consideraron indicaciones de observación:

- Pacientes con tumores pequeños:

o que presentaban dos o menos signos de actividad y en los que no se demostraba crecimiento.

- Pacientes con tumores medianos o grandes:

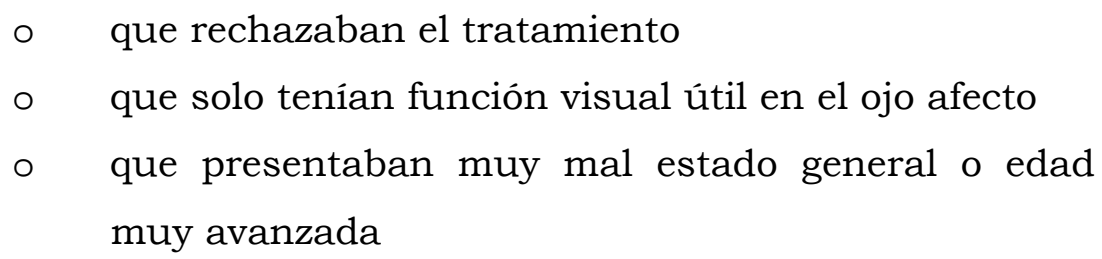

3. El paciente debía ser mayor de edad.

4. El paciente debía haber firmado el pertinente consentimiento informado. (De acuerdo a la Ley Orgánica 15/1999 de 13 de diciembre sobre protección de datos de carácter personal) (Anexo I).

5. El paciente debía ser absolutamente competente.

6. El paciente debía estar dispuesto y capacitado para el seguimiento.

\section{4.- CRITERIOS DE EXCLUSIÓN}

1. Presencia de extensión extraocular en el momento del diagnóstico. Se determinó mediante la realización de ecografia ocular asociada a tomografia axial computerizada y/o resonacia magnética nuclear de la órbita.

2. Presencia de metástasis en el momento del diagnóstico. Se determinó mediante la asociación de estudio bioquímico sanguineo 
con pruebas de función hepática y pruebas de imagen (tomografía axial computerizada toraco-abdominal y/o ecografia hepática).

3. Pacientes que presentaron tumores originados en el cuerpo ciliar o en el iris.

\section{5.- VARIABLES A EVALUAR}

\subsection{1.- Principales}

1. Tamaño del tumor: se clasificaron según los criterios publicados por el "Collaborative Ocular Melanoma Study" (Descritos en los criterios de inclusión). El tamaño del tumor se determinó mediante ecografia ocular con sonda B de $10 \mathrm{MHz}$ (equipo OTI-Scan 2000®). Se realizaron dos cortes de la tumoración, longitudinal y transversal, y se midieron los diámetros basales y la altura. Mediante sonda A de $10 \mathrm{MHz}$ se determinó la presencia de ángulo Kappa.

2. Agudeza visual: se entiende por agudeza visual al límite espacial de discriminación. Se determinó mediante el uso de optotipos. En este estudio se emplearon los proyectores de optotipos de Topcon ${ }^{\circledR}$ modelos: CC-100P y ACP-8.

3. Supervivencia: se entendió que el paciente continua vivo si acudió a las revisiones programadas o en caso de que no le fuera posible si se contactó con éste telefónicamente. $\mathrm{Si}$ el paciente no se hubo presentado en un año a consulta ni fue posible ponerse en contacto con él por via telefónica, ni se pudo constatar su defunción, se dió por perdido. Se calculó como la diferencia en meses entre la fecha de diagnóstico y la fecha de defunción o de última revisión.

4. Crecimiento tumoral: entendido como aumentos en el tamaño tumoral entre revisiones que indicaran actividad de la lesión. 
5.5.2.- Secundarias (Signos de actividad o crecimiento) ${ }^{12}$ :

1. Sintomatología visual atribuible al tumor: entendida como sintomas oculares: fotopsias (visualización de formas luminosas), metamorfopsias (visión de las líneas rectas torcidas), discromatopsia (alteración en la visión de los colores), alteraciones campimétricas o disminución de la agudeza visual referidas por el paciente.

2. Presencia de pigmento naranja: entendido como acumulos de lipofucsina en la superficie del tumor observada mediante funduscopia (se realizaócon oftalmoscopio de imagen invertida Heine ${ }^{\circledR}$ modelo Omega 200) o retinografia (realizada mediante cámara funduscópica no midriática Topcon ${ }^{\circledR}$ modelo TRC-NW8) y confirmada mediante autofluorescencia (realizada mediante retinógrafo Topcon ${ }^{\circledR}$ modelo TRC 50DX provisto de filtros especiales para esta técnica).

3. Altura ecográfica superior a $2 \mathrm{~mm}$ : en el momento del diagnóstico, medida de forma objetiva mediante ecografia.

4. Presencia de fluido subretiniano: determinado de forma objetiva mediante tomografia de coherencia óptica(OCT)(Se usó el dispositivo Topcon ${ }^{\circledR}$ modelo 3D OCT-1000), o mediante autofluorescencia (con el dispositivo antes mencionado para esta técnica).

5. Localización yuxtapapilar: definida como distancia del borde más próximo del tumor al nervio óptico menor o igual a 1 milimetro, y determinada mediante funduscopia o retinografia

6. Presencia de drusas: acúmulos blanquecinos amarillentos redondeados situados en la membrana de Bruch sobre la lesión tumoral y observados mediante funduscopia o retinografia. 


\section{6.- RECOGIDA DE LOS DATOS}

\subsection{1.- Primera exploración, tratamiento y datos generales}

En todos los pacientes se realizó una exploración ocular completa que se recogió en un formulario diseñado al efecto dividido en los siguientes apartados (El cuestionario completo se presenta en el anexo II):

Datos del paciente: número de protocolo, número de historia clínica, nombre y apellidos, fecha de nacimiento, sexo, dirección y teléfono.

Antecedentes generales: exposición solar (se clasificó a los pacientes según exposiciones mayores o menores del 50\% de las horas de luz), presencia de cáncer cutáneo, otros cánceres, inmunosupresión, depresión, antecedentes familiares de melanoma y hábito tabáquico.

Antecedentes oftalmológicos que afectaban a la agudea visual en el ojo afecto y en el contralateral: ambliopía, degeneración macular asociada a la edad, glaucoma, catarata, retinopatía diabética u otros.

Datos clínicos: fecha de inicio de los síntomas, fecha de diagnóstico, motivo del diagnóstico (revisión rutinaria o sintomatología visual), tumor recidivado y tratamiento previo.

Exploración ocular: lateralidad, agudeza visual de ambos ojos, presión intraocular de ambos ojos, biomicroscopia del polo posterior (color del iris, invasión del iris, rubeosis, afectación del cristalino, hemovitreo u otras), gonioscopia (invasión del ángulo), localización y tamaño (base máxima ecográfica y funduscópica, base a $90^{\circ}$ ecográfica y funduscópica, altura máxima ecográfica y funduscópica, localizacion del borde anterior y del borde posterior, localización temporal o nasal, afectación macular y forma del tumor (nodular, champiñón o difuso)). 
Signos de actividad: drusas, desprendimiento de retina, pigmento naranja, tumor yuxtapapilar, crecimiento demostrado, fluido subretiniano comprobado mediante tomografia de coherencia óptica o forma de champiñón.

Causas de disminución de la agudeza visual por melanoma: catarata, glaucoma, hemovitreo, desprendimiento de retina, hemorragia subretiniana, edema macular o tumor macular.

Tomografia de coherencia óptica (OCT): presencia de edema macular y medida en micrómetros.

Pruebas de extensión extraocular: tomografia axial computerizada y/o resonacian magnética nuclear.

Pruebas de extensión sistémica: ecografia hepática alterada, perfil bioquímico analítico hepático o presencia de metástasis.

Clasificación del melanoma: tamaño (pequeño, mediano o grande) localización (coroides, cuerpo ciliar o iris), actividad, extensión extraocular, extensión sistémica, aspecto melanótico y clasificación TNM.

Tratamientos: braquiterapia (fecha de implante y retirada, dosis en Gy en apex nervio óptico y fovea, isótopo empleado, tamaño de la placa y forma de la placa), radioterapia externa con protones (fecha), termoterapia transpupilar (número de sesiones, fecha, $\mathrm{n}^{\circ}$ de spots, tamaño del espot y potencia), resección quirúrgica (fecha), enucleación (fecha, con o sin radioterapia o en centro de origen) y observación (fecha y motivo: pequeño inactivo, rechazo de tratamiento, edad avanzada, ojo unico o mal estado general).

Recidiva: fecha en la que se presentan signos evidenciables de actividad del tumor después de haber sido tratado.

Enuclación secundaria: fecha de la intervención y motivo (efectos secundarios del primer tratamientoconservador aplicado o bien recidiva despues de haber sido tratado). 
Metástasis: fecha en la que se objetiva la diseminación sistémica de la enfermedad.

Defunción: fecha y motivo (melanoma u otros)

\subsection{2.- Seguimientos}

Una vez diagnosticado el paciente y tratado en función de los hallazgos obtenidos, se le revisó al mes, a los tres, seis, nueve y doce meses durante el primer año, de forma semestral los primeros cinco años y de forma anual a partir del quinto año. En las visitas de revisión los datos de la exploración se codificaron en un cuestionario diseñado al efecto (este cuestionario se presenta en el Anexo II) en el que se incluyeron los siguentes datos: número de revisión, tiempo de seguimiento, fecha de revisión, nombre y apellidos, número de registro, número de historia clínica, tratamiento realizado, agudeza visual del ojo afecto y el contralateral, presión intraocular del ojo afecto y el contralateral, tamaño ecográfico (base máxima, a 90 grados y altura máxima), pruebas de extensión sistémica (ecografia hepatica o TAC toracoabdominal y analitica sanguinea), complicaciones del tratamiento (ptosis, necrosis escleral, dolor, catarata, diplopia, desprendimiento de retina, retinopatía por radiación, neuropatía por radiación, hemorragia vítrea, glaucoma neovascular, membrana epirretiniana, exposición del implante en el caso de enucleados u otros), espesor macular medido mediante OCT, recidiva si la hay, metástasis si las hay y fecha de defunción.

Las pruebas de extensión se realizan de forma anual a lo largo del seguimiento.

El encargado de recoger los datos en los cuestionarios fue un oftalmólogo (adjunto, residente o alumno master) perteneciente a la unidad. Una vez completado el cuestionario, se codificó en una base de datos diseñada en Microsoft ${ }^{\circledR}$ Acces ${ }^{\circledR}$ (figura 22) previo consentimiento informado del paciente.

Se consideró pérdida de seguimiento aquel sujeto del estudio que no acudió a revisión en los 365 días previos al 1 de febrero de 2010. 


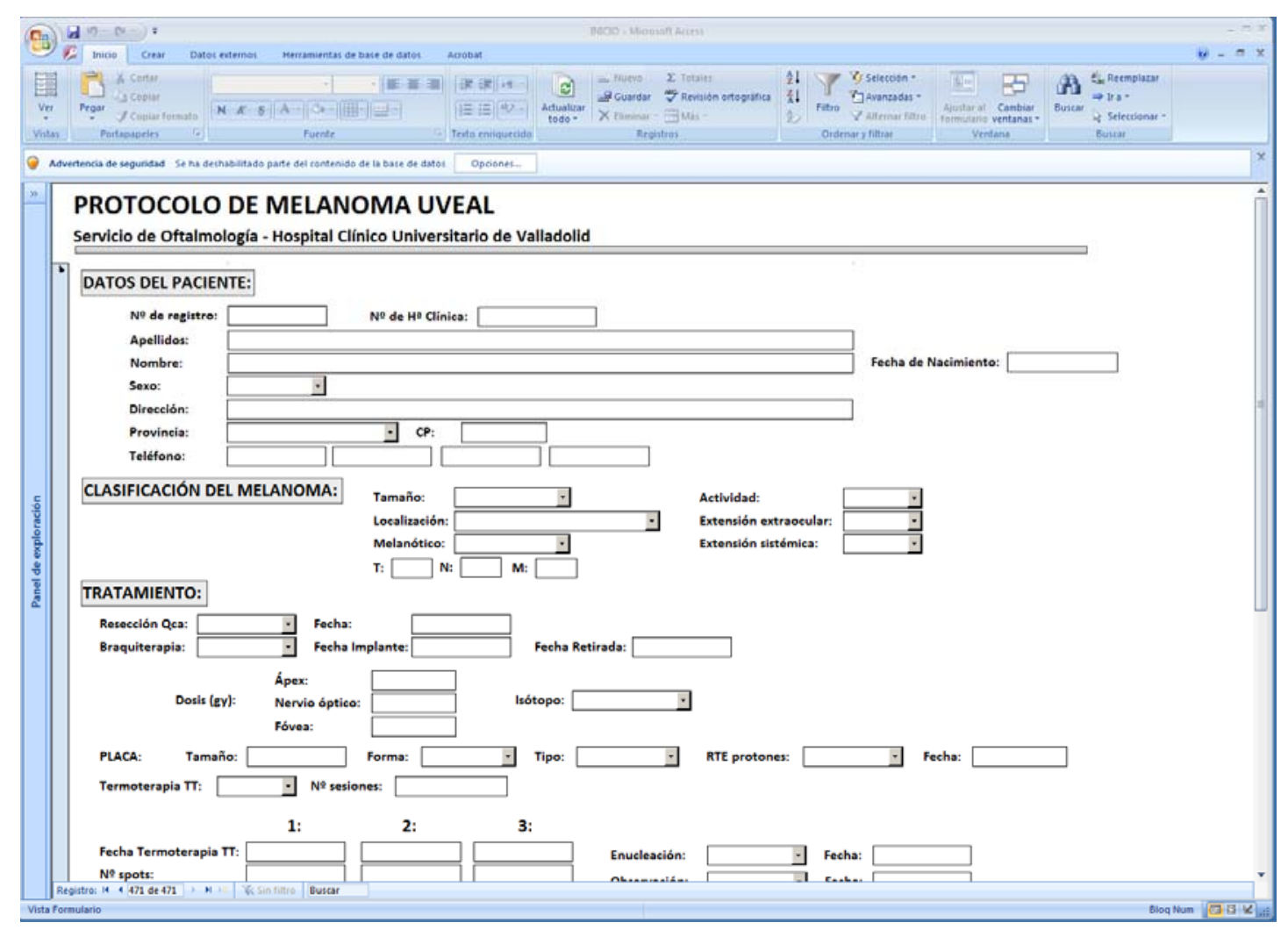

Figura 22: Base de datos del protocolo de melanoma uveal del Hospital Clinico Universitario de Valladolid.

\subsection{3.- Indicaciones de otros tratamientos en el curso del seguimiento}

En caso de observarse actividad y/o crecimiento del tumor se reevalúa al paciente, y tras informarle se aplica el tratamiento más adecuado según el caso.

Se somete a braquiterapia a aquellos pacientes con tumores medianos o con tumores pequeños que en el devenir del seguimiento aumentan de tamaño (entendiendose por crecimiento un aumento de tamaño claramente objetivable, o un cambio de forma en la ecografia o retinografias) o presentan 3 o más signos de actividad.

Se somete a enucleación a aquellos pacientes con tumores grandes que continuan creciendo o medianos o pequeños que presenten invasión del nervio óptico o que tras tratamiento conservador presenten recidiva. 


\section{7.- ANÁLISIS ESTADÍSTICO}

La información utilizada en el presente trabajo procede de la base de datos de la Unidad de Tumores Intraoculares, elaborada en su primera versión en el año 1992.

Los datos relevantes para el presente estudio fueron exportados para su análisis a SPSS (Statistical Package for Social Sciences) versión 15.0.

El análisis descriptivo de las variables se presenta en forma de distribución de frecuencias para las variables cualitativas y de medidas (desviación típica) para las cuantitativas.

La asociación entre dos variables cualitativas se ha evaluado mediante el test de $\chi^{2}$ y test exacto de Fisher.

La comparación de medias entre categorias de una variable cualitativa se ha realizado mediante la t de student en el caso de variables dicotómicas o ANOVA en el caso de las politómicas. Para la evolución de la agudeza visual se emple una T de Student para datos pareados

Las dos variables resultado más relevantes del presente estudio son la mortalidad y el crecimiento del tumor. Éstas se han analizado tanto en términos de incidencia acumulada (proporción) como de tiempo transcurrido hasta la aparición del evento de interés (muerte o crecimiento). Para este último objetivo se ha utilizado un análisis de supervivencia mediante el método de Kaplan Meier. Las fechas utilizadas para el cálculo de los tiempos han sido: fecha del diagnóstico, fecha de última revisión, fecha de defunción y fecha de detección del crecimiento del tumor. La comparación de funciones de supervivencia se ha realizado mediante el test de log-rank.

Con el fin de identificar los factores pronósticos que determinan el crecimeitno tumoral y la supervivencia del paciente, se ha realizado un análisis multivariante ajustando un modelo de riesgos proporcionales de Cox para las variables "crecimiento tumoral” y "defunción” respectivamente. 
En todos los casos se ha utilizado un nivel de significación estadística de 0.05 . 


\section{RESULTADOS}

\section{1.- PACIENTES}

Se incluyeron 118 pacientes diagnosticados de melanoma de coroides y sometidos como primera opción terapéutica a observación, de entre los 377 pacientes diagnosticados de melanoma uveal entre enero de 1992 y febrero de 2010 en la Unidad de Tumores Intraoculares del Adulto del Servicio de Oftalmología del Hospital Clínico Universitario de Valladolid.

\section{2.- DESCRIPCIÓN GENERAL DE LA MUESTRA}

\subsection{1.- Edad}

La edad media de los pacientes en el momento del diagnóstico fue de 66,41 años, presentando una distribución bimodal con un primer pico de incidencia en torno a los 40 años y un segundo pico en torno a los 70 años (gráfico 1).

La edad media se presenta estratificada por tamaño tumoral en la tabla número 2 observándose que la de los tumores pequeños es significativamente menor que la de medianos y grandes $(p=0,028)$. 


\begin{tabular}{|c|c|c|c|}
\hline \multicolumn{5}{|c|}{ Tabla 2 Edad media al diagnóstico } \\
\hline & $\mathrm{N}$ & Edad media & $\begin{array}{c}\text { Desviación } \\
\text { estándar }\end{array}$ \\
\hline Pequeños & 91 & 64,42 & 13,84 \\
\hline Medianos & 22 & 72,44 & 14,67 \\
\hline Grandes & 5 & 74,45 & 15,36 \\
\hline Total & 114 & 66,41 & 14,39 \\
\hline \multicolumn{4}{|c|}{$\mathrm{p}=0,028$} \\
\hline
\end{tabular}

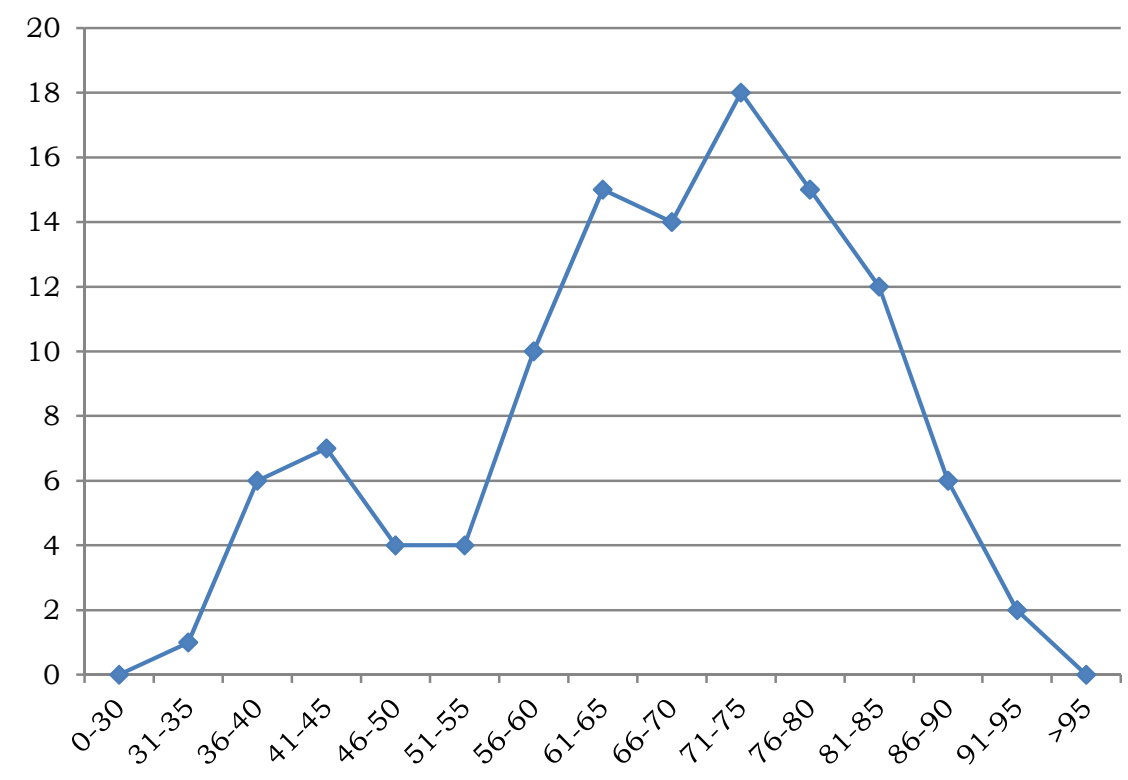

Gráfico 1: pacientes por rango de edad

\subsection{2.- Sexo}

La distribución según sexo de los pacientes estratificada por tamaño tumoral se presenta en la tabla 3 donde puede observarse predominio de mujeres estadísticamente significativo $(\mathrm{p}=0,009)$ para el grupo de pequeños y medianos. En el grupo de los tumores grandes todos los pacientes fueron varones. 


\begin{tabular}{|c|c|c|c|}
\hline \multicolumn{5}{|c|}{ Tabla 3 Sexo } \\
\hline & Varón & Mujer & Total \\
\hline Pequeños & $30(32,97 \%)$ & $61(67,03 \%)$ & 91 \\
\hline Medianos & $7(31,82 \%)$ & $15(68,18 \%)$ & 22 \\
\hline Grandes & $5(100,0 \%)$ & 0 & 118 \\
\hline Total & $42(35,59 \%)$ & $76(64,41 \%)$ & 5 \\
\hline \multicolumn{2}{|c|}{$\mathrm{p}=0,009$} \\
\hline
\end{tabular}

\subsection{3.- Seguimiento}

El seguimiento medio de los pacientes fue de 51,15 meses (DS 49,9; Mínimo 0 meses; Máximo 179 meses). En la tabla 4 se presenta el seguimiento estratificado por años. El 52,54\% de los pacientes incluidos en el estudio tuvieron un seguimiento de tres o más años.

\begin{tabular}{|c|c|}
\hline \multicolumn{2}{|c|}{ Tabla 4 Seguimiento por años } \\
\hline Años & $\mathbf{N}$ \\
\hline Un año o más & $86(72,88 \%)$ \\
\hline 3 años o más & $62(52,54 \%)$ \\
\hline 5 años o más & $43(36,44 \%)$ \\
\hline
\end{tabular}

Se contabilizaron 6 pérdidas de seguimiento lo que supone el $0.05 \%$ del total de la muestra.

\subsection{4.- Diagnósticos por años}

En el gráfico 2 se pueden observar el número de pacientes diagnosticados por año. En el año 2009 la Unidad de Tumores Intraoculares del Adulto del Hospital Clínico Universitario de Valladolid es designada como centro de referencia nacional por el Ministerio de Sanidad. Téngase en cuenta que el periodo de inclusión finaliza en febrero de 2010. 


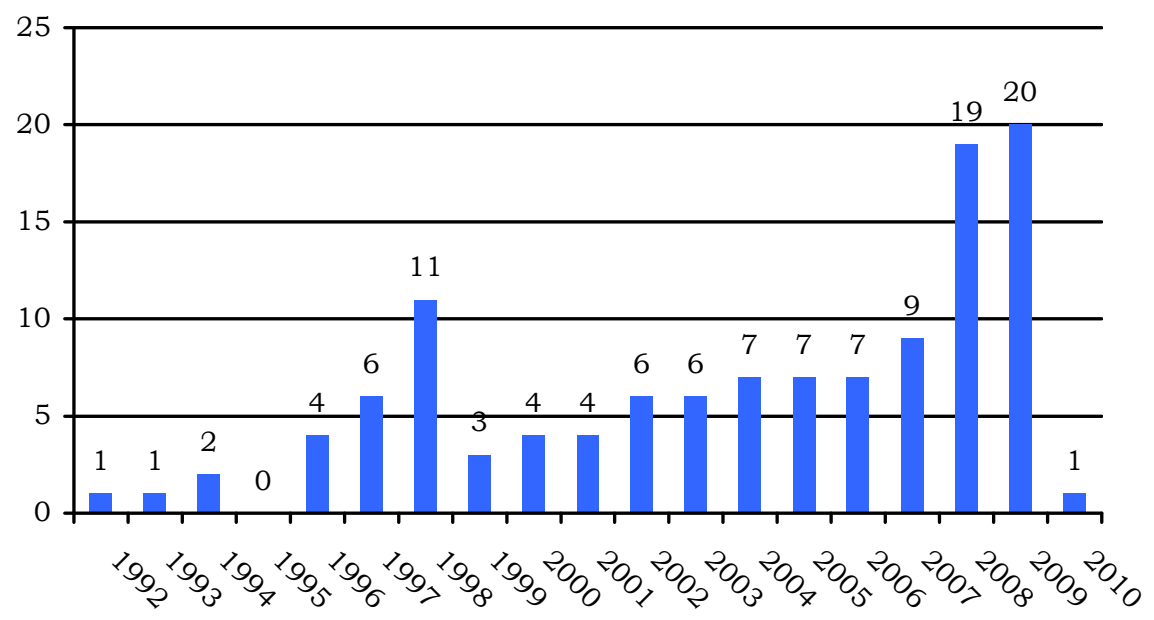

Gráfico 2: Pacientes diagnosticados por año

\subsection{5.- Origen de los pacientes}

En la tabla 5 se muestra el origen de los pacientes incluidos en la muestra, siendo Valladolid la provincia con más pacientes diagnosticados, seguida de las provincias limitrofes y pertenecientes a la comunidad autónoma de Castilla y León.

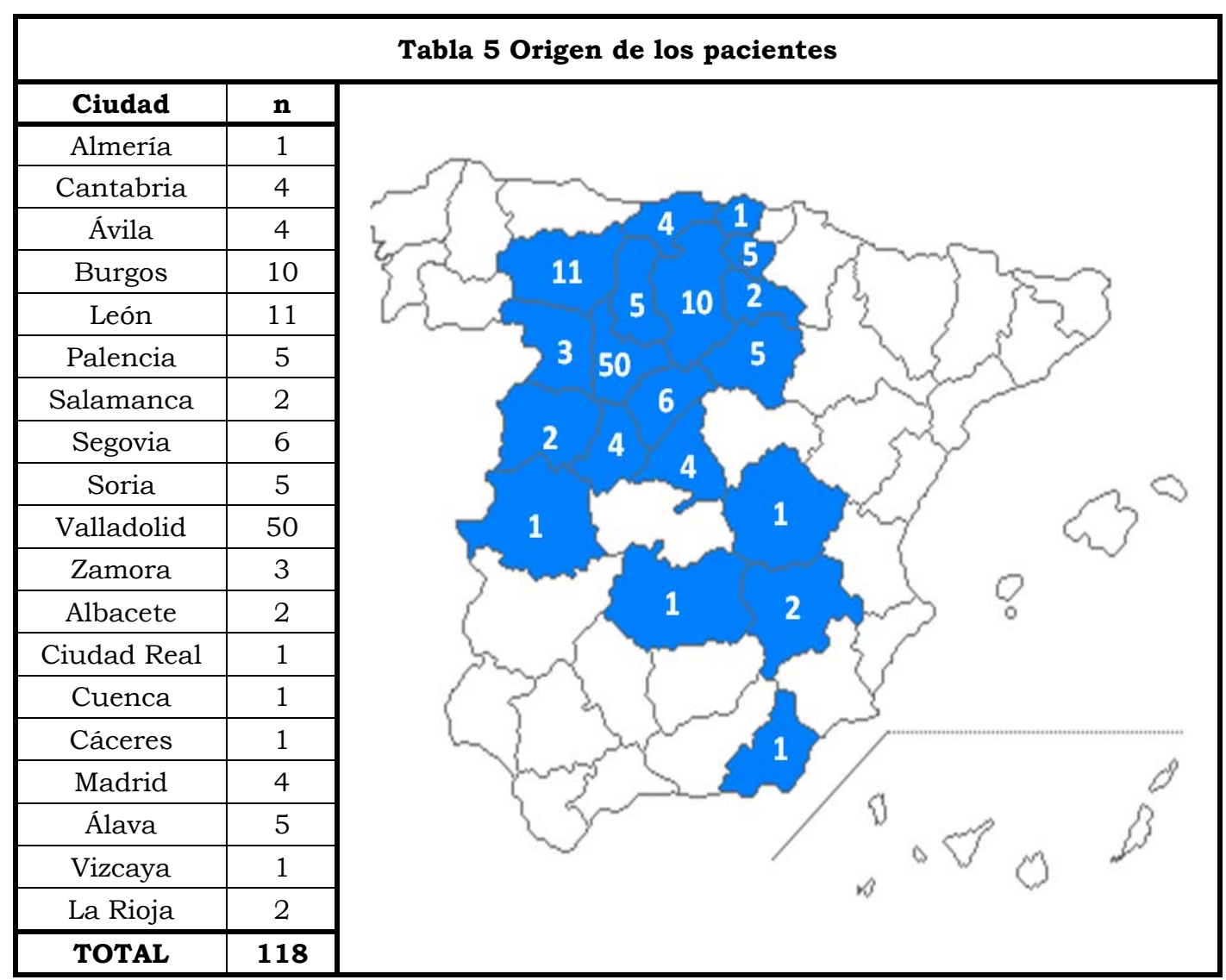




\section{3.- CARACTERÍSTICAS CLÍNICAS GENERALES}

\subsection{1.- Antecedentes generales}

Treinta y cuatro de los pacientes incluidos tuvieron una exposición solar mayor al $50 \%$ de las horas de actividad cotidiana. Cuatro pacientes (3,38\%) estaban inmunodeprimidos y 15 (12,71\%) padecían depresión. En 4 casos había antecedentes familiares de melanoma. Respecto del consumo de tabaco, 9 pacientes eran fumadores y 14 exfumadores (Tabla 6).

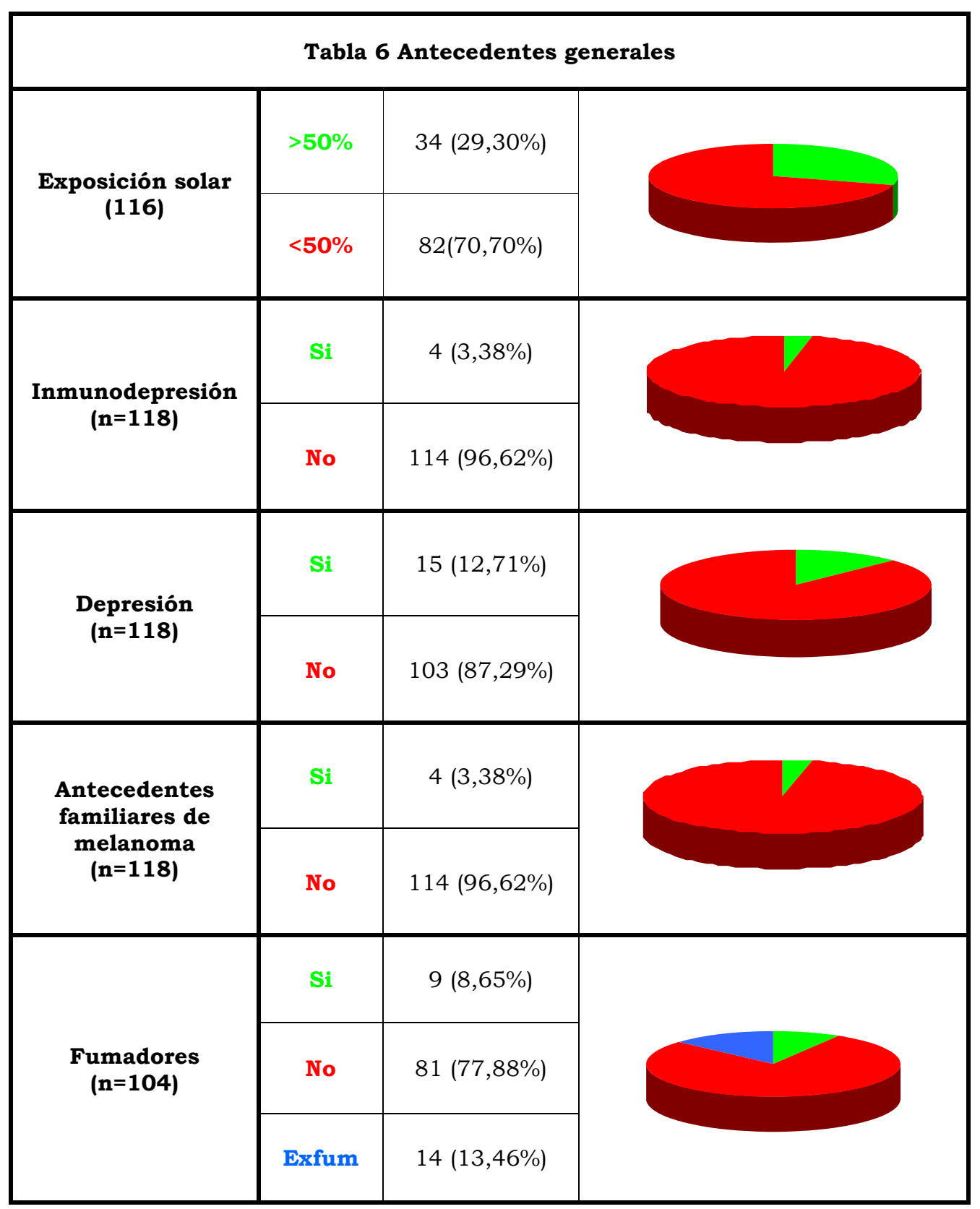




\subsection{2.- Tumores concomitantes}

Tres pacientes habian sufrido algún tipo de tumor maligno cutáneo y tres presentaban otras neoplasias no cutáneas que se describen en la tabla 7.

\begin{tabular}{|c|c|}
\hline \multicolumn{2}{|c|}{ Tabla 7 Tumores concomitantes } \\
\hline Mama & $1(0,84 \%)$ \\
\hline Próstata & $1(0,84 \%)$ \\
\hline Útero & $1(0,84 \%)$ \\
\hline Piel & $3(2,54 \%)$ \\
\hline
\end{tabular}

\subsection{3.- Patologia ocular concomitante}

En la tabla 8 se presentan los datos referidos a las patologías oculares detectadas en los pacientes incluidos en el estudio que pueden afectar a la agudeza visual en el ojo afecto o el contralateral. La alteración más prevalente tanto en los ojos afectados como en los no afectados fue la catarata, que se presentó en 42 de los 118 pacientes (35,59\%). La ambliopia, el glaucoma, la DMAE y la retinopatía diabética fueron muy poco prevalentes.

\begin{tabular}{|c|c|c|}
\hline \multicolumn{2}{|c|}{ Tabla 8 Patologia ocular concomitante } \\
\hline \multirow{2}{*}{$\begin{array}{c}\text { Ambliopia } \\
\text { (n=118) }\end{array}$} & Afecto & $2(1,69 \%)$ \\
\cline { 2 - 3 } & Contralateral & $4(3,38 \%)$ \\
\hline $\begin{array}{c}\text { DMAE } \\
\text { (n=118) }\end{array}$ & Afecto & $4(3,38 \%)$ \\
\hline \multirow{2}{*}{$\begin{array}{c}\text { Glaucoma } \\
\text { (n=118) }\end{array}$} & Contralateral & $4(3,38 \%)$ \\
\cline { 2 - 3 } & Afecto & $3(2,54 \%)$ \\
\hline $\begin{array}{c}\text { Catarata } \\
\text { (n=118) }\end{array}$ & Contralateral & $3(2,54 \%)$ \\
\hline \multirow{2}{*}{$\begin{array}{c}\text { Retinopatia } \\
\text { diabética } \\
\text { (n=118) }\end{array}$} & Afecto & $42(35,59 \%)$ \\
\hline
\end{tabular}




\section{4.- CARACTERÍSTICAS OCULARES Y TUMORALES}

\subsection{1.- Localización}

Todos los pacientes incluidos en el estudio tenian melanomas localizados en la coroides (los pacientes con melanomas asentados en el iris o en el cuerpo ciliar no fueron incluidos).

\subsection{2.- Clasificación y tamaño}

Según su tamaño los tumores diagnosticados se clasificaron en pequeños, medianos y grandes (la clasificación se detalla en el apartado sobre la metodología del estudio). El $77,12 \%$ de los tumores incluidos fueron de tamaño pequeño (tabla 9).

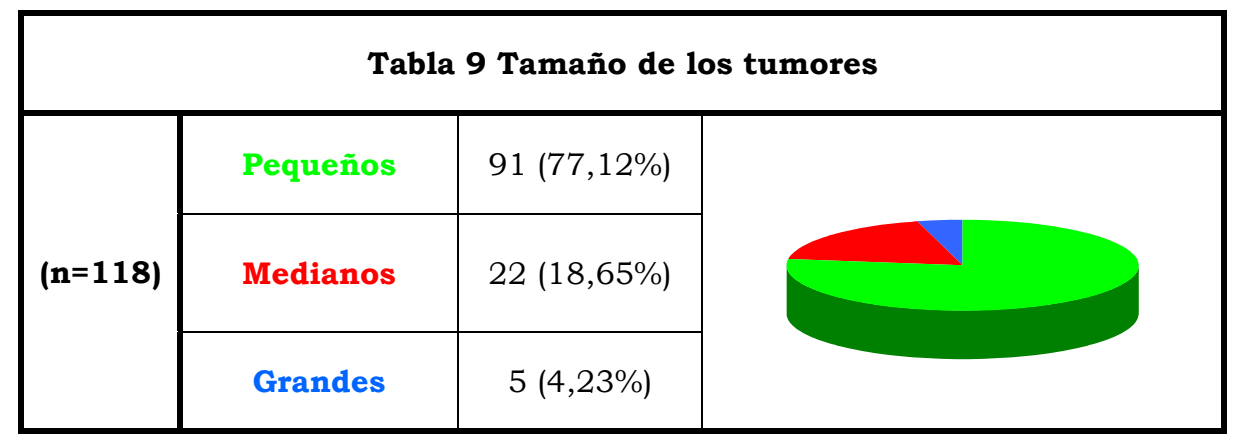

En la tabla 10 se representa las medias de la altura máxima y la base máxima ecográfica de los tumores en función de su tamaño.

\begin{tabular}{|c|c|c|c|c|c|c|}
\hline \multicolumn{7}{|c|}{ Tabla 10 Tamaño medio de las alturas y bases ecográficas (en mm) } \\
\hline \multirow{2}{*}{ Pequeños } & $\mathrm{N}$ & Medida ecográfica & Minimo & Máximo & Media & $\begin{array}{c}\text { Desviación } \\
\text { estándar }\end{array}$ \\
\hline \multirow{2}{*}{ Medianos } & 21 & Base máxima & 2,78 & 10 & 6,89 & 1,66 \\
\cline { 2 - 7 } & 22 & Altura máxima & 1 & 2,5 & 2,12 & 0,73 \\
\hline \multirow{2}{*}{ Grandes } & 5 & Base máxima & 4,50 & 13 & 9,54 & 1,76 \\
\cline { 3 - 7 } & & Altura máxima & 1 & 8 & 4,24 & 1,49 \\
\hline
\end{tabular}




\subsection{3.- Lateralidad}

La lateralidad de los tumores estudiados se presenta en la tabla número

11. No se observaron diferencias estadísticamente significativas $(p=0,66)$.

\begin{tabular}{|c|c|c|c|}
\hline \multicolumn{4}{|c|}{ Tabla 11 Lateralidad } \\
\hline & OD & OI & Total \\
\hline Pequeños & $36(39,56 \%)$ & $55(60,43 \%)$ & 91 \\
\hline Medianos & $9(40,90 \%)$ & $13(59,09 \%)$ & 22 \\
\hline Grandes & $3(60,00 \%)$ & $2(40,00 \%)$ & 5 \\
\hline Total & $48(40,68 \%)$ & $70(59,32 \%)$ & 118 \\
\hline \multicolumn{4}{|c|}{$\mathrm{p}=0,66$} \\
\hline
\end{tabular}

\subsection{4.- Color del iris}

Respecto al color del iris, el marrón fue el más frecuente en todos los grupos (Tabla 12, gráfico 3), no observándose diferencias estadísticamente significativas $(p=0,48)$ entre los grupos.

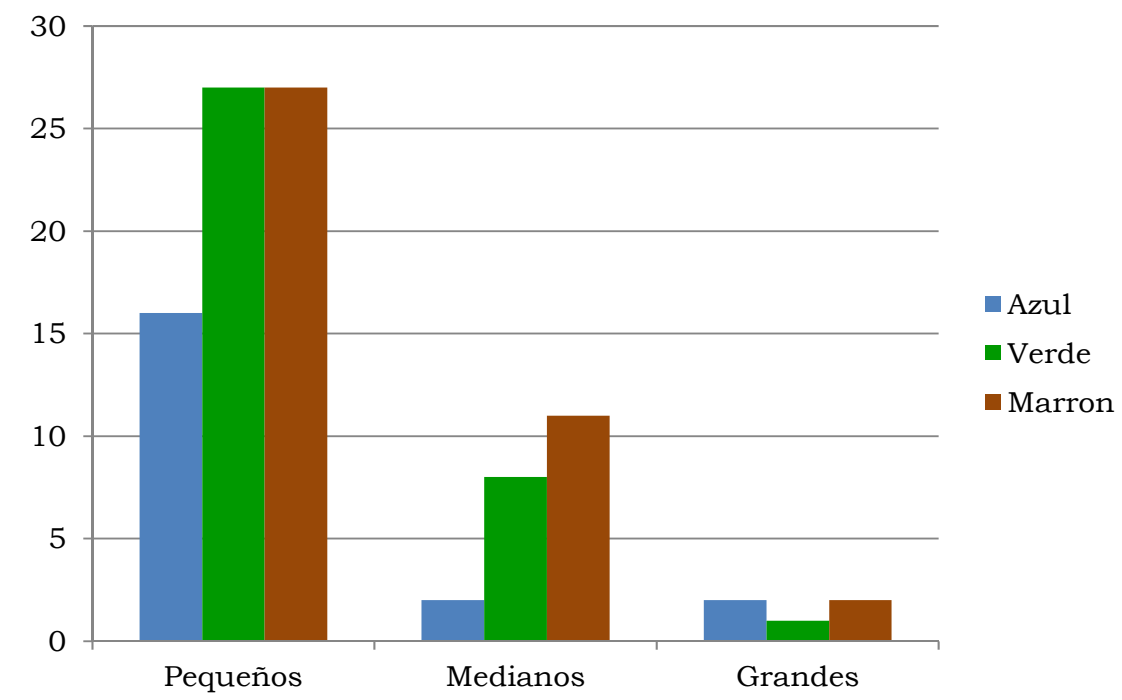

Gráfico 3: Color del iris de los ojos en función del tamaño del tumor. 


\begin{tabular}{|c|c|c|c|c|}
\hline \multicolumn{5}{|c|}{ Tabla 12 Color del iris } \\
\hline & Azul-gris & $\begin{array}{c}\text { Verde } \\
\text { avellana }\end{array}$ & Marrón & Total \\
\hline Pequeños & $16(22,85 \%)$ & $27(38,57 \%)$ & $27(38,57 \%)$ & 70 \\
\hline Medianos & $2(9,52 \%)$ & $8(38,09 \%)$ & $11(52,38 \%)$ & 21 \\
\hline Grandes & $2(40,00 \%)$ & $1(20,00 \%)$ & $2(40,00 \%)$ & 5 \\
\hline Total & $20(20,83 \%)$ & $36(37,50 \%)$ & $40(41,66 \%)$ & 96 \\
\hline
\end{tabular}

\subsection{5.- Motivo del diagnóstico}

El motivo del diagnóstico más frecuente tanto en el grupo de pequeños como medianos fue la revisión rutinaria, mientras que la totalidad de los grandes fueron sintomáticos (tabla 13), siendo las diferencias observadas estadísticamente significativas.

\begin{tabular}{|c|c|c|c|}
\hline \multicolumn{4}{|c|}{ Tabla 13 Lateralidad } \\
\hline & Revisión rutinaria & $\begin{array}{c}\text { Sintomatología } \\
\text { visual }\end{array}$ & Total \\
\hline Pequeños & $71(78,02 \%)$ & $20(22,97 \%)$ & 91 \\
\hline Medianos & $14(63,63 \%)$ & $8(36,36 \%)$ & 22 \\
\hline Grandes & 0 & $5(100 \%)$ & 5 \\
\hline Total & $85(72,03 \%)$ & $33(28,06 \%)$ & 118 \\
\hline \multicolumn{2}{|c|}{$\mathrm{p}=0,0001$} \\
\hline
\end{tabular}

\subsection{6.- Forma del tumor}

La forma tumoral predominante en los tres grupos fue la nodular; todos los tumores pequeños fueron nodulares, el $81,8 \%$ de los medianos y el $60 \%$ de los grandes (tabla 14). Las diferencias observadas fueron estadísticamente significativas $(\mathrm{p}<0,0001)$. 


\begin{tabular}{|c|c|c|c|c|}
\hline \multicolumn{5}{|c|}{ Tabla 14 Forma de los tumores } \\
\hline & Nodular & Champiñón & $\begin{array}{c}\text { Infiltrativo } \\
\text { difuso }\end{array}$ & Total \\
\hline Pequeños & $91(100 \%)$ & 0 & 0 & 91 \\
\hline Medianos & $18(81,81 \%)$ & $3(13,63 \%)$ & $1(4,54 \%)$ & 22 \\
\hline Grandes & $3(60,00 \%)$ & $2(40,00 \%)$ & 0 & 5 \\
\hline Total & $112(94,91 \%)$ & $5(4,23 \%)$ & $1(0,84 \%)$ & 118 \\
\hline
\end{tabular}

\subsection{7.- Signos de actividad}

Se registraron los signos de actividad que presentaba cada tumor, siendo la sintomatología visual y la altura mayor a $2 \mathrm{~mm}$ los más frecuentes entre los pequeños y la altura mayor a $2 \mathrm{~mm}$ el más frecuente entre los medianos (tabla 15).

\begin{tabular}{|c|c|c|c|}
\hline \multicolumn{3}{|c|}{ Tabla 15 Signos de actividad según tamaño } \\
\hline $\begin{array}{c}\text { Signo de } \\
\text { actividad }\end{array}$ & Pequeños & Medianos & Grandes \\
\hline $\begin{array}{c}\text { Sintomatología } \\
\text { visual }\end{array}$ & $20(16,94 \%)$ & $8(6,67 \%)$ & $5(4,23 \%)$ \\
\hline Altura $>2$ mm & $54(45,76 \%)$ & $21(17,79 \%)$ & $5(4,23 \%)$ \\
\hline $\begin{array}{c}\text { Pigmento } \\
\text { naranja }\end{array}$ & $17(14,40 \%)$ & $2(1,69 \%)$ & $1(0,84 \%)$ \\
\hline $\begin{array}{c}\text { Fluido } \\
\text { subretiniano }\end{array}$ & $2(1,69 \%)$ & $2(1,69 \%)$ & $4(3,38 \%)$ \\
\hline $\begin{array}{c}\text { Distancia a NO } \\
\leq 3 \text { mm }\end{array}$ & $7(5,93 \%)$ & $4(3,38 \%)$ & $3(2,54 \%)$ \\
\hline
\end{tabular}

En la tabla 16 se clasifican los tumores en función del número de signos de actividad que presentan al diagnóstico según su tamaño. Los signos de actividad son los 5 presentados en la tabla 15. En el grupo de los pequeños 17 pacientes no presentaron ningún signo de riesgo, 54 uno, 14 dos y 6 tres. Ninguno presentó cuatro o cinco factores. En el grupo de los medianos, uno no tenía ningún signo, 10 uno, 6 dos, 5 tres y ninguno cuatro o cinco. En el grupo de los grandes dos pacientes presentaban tres signos y 3 pacientes cuatro. 


\begin{tabular}{|c|c|c|c|c|c|c|c|}
\hline & 0 & 1 & 2 & 3 & 4 & 5 & Total \\
\hline Pequeños & $\begin{array}{c}17 \\
(18,68 \%)\end{array}$ & $\begin{array}{c}54 \\
(59,34 \%)\end{array}$ & $\begin{array}{c}14 \\
(15,38 \%)\end{array}$ & $\begin{array}{c}6 \\
(6,59 \%) \\
\end{array}$ & 0 & 0 & 91 \\
\hline Medianos & $\begin{array}{c}1 \\
(4,54 \%)\end{array}$ & $\begin{array}{c}10 \\
(45,45 \%)\end{array}$ & $\begin{array}{c}6 \\
(27,27 \%)\end{array}$ & $\begin{array}{c}5 \\
(22,72)\end{array}$ & 0 & 0 & 22 \\
\hline Grandes & 0 & 0 & 0 & $\begin{array}{c}2 \\
(40 \%) \\
\end{array}$ & $\begin{array}{c}3 \\
(60 \%) \\
\end{array}$ & 0 & 5 \\
\hline Total & $\begin{array}{c}18 \\
(15,25 \%)\end{array}$ & $\begin{array}{c}64 \\
(54,23 \%)\end{array}$ & $\begin{array}{c}20 \\
(16,94)\end{array}$ & $\begin{array}{c}13 \\
(11,01 \%)\end{array}$ & $\begin{array}{c}3 \\
(2,54 \%)\end{array}$ & 0 & 118 \\
\hline
\end{tabular}

\subsection{8.- Agudeza visual en el momento del diagnóstico}

La agudeza visual recogida al diagnóstico se distribuyó en cuatro grupos; menor de 0,1, entre 0,1 y 0,49, entre 0,5 y 0,79 y mayor o igual a 0,8. (Tabla 17). En el grupo de los pequeños el $82 \%$ de los pacientes presentaban agudezas visuales mayores de 0,5 en el momento del diagnóstico. En el grupo de los medianos el 54\% presentaban agudezas visuales mayores de 0,5. En el grupo de los grandes todos presentaron al diagnóstico agudezas visuales menores de 0,5 .

\begin{tabular}{|c|c|c|c|c|c|}
\hline \multicolumn{7}{|c|}{ Tabla 17 Agudeza visual al diagnóstico } \\
\hline & $<0,1$ & $0,1-0,49$ & $0,5-0,79$ & $\geq 0,8$ & Total \\
\hline Pequeños & $2(2,21 \%)$ & $14(15,38 \%)$ & $20(21,97 \%)$ & $55(60,43 \%)$ & 91 \\
\hline Medianos & $4(18,18 \%)$ & $6(27,27 \%)$ & $3(13,63 \%)$ & $9(40,90 \%)$ & 22 \\
\hline Grandes & $4(80,00 \%)$ & $1(20,00 \%)$ & 0 & 0 & 5 \\
\hline Total & $10(8,47 \%)$ & $21(17,79 \%)$ & $23(19,49 \%)$ & $64(54,23 \%)$ & 118 \\
\hline \multicolumn{7}{|c|}{$p<0,0001$} & \\
\hline
\end{tabular}

Las diferencias observadas entre los grupos fueron estadísticamente significativas $(\mathrm{p}<0,0001)$.

\subsection{9.- Motivo de la observación}

En la tabla 18 se presenta el motivo de la observación en función de los tamaños. Para los pequeños fue en todos los casos la inactividad del tumor. En el caso de los medianos la principal causa de observación fue el rechazo del tratamiento, al igual que en el caso de los grandes (Tabla 18). 


\begin{tabular}{|c|c|c|c|c|c|}
\hline \multicolumn{7}{|c|}{ Tabla 18 Motivo de la observación } \\
\hline & $\begin{array}{c}\text { Pequeño } \\
\text { inactivo }\end{array}$ & $\begin{array}{c}\text { Rechazo del } \\
\text { tratamiento }\end{array}$ & Ojo único & $\begin{array}{c}\text { Mal estado } \\
\text { general }\end{array}$ & Total \\
\hline Pequeños & $89(97,80 \%)$ & $2(2,21 \%)$ & 0 & 0 & 91 \\
\hline Medianos & 0 & $20(90,90 \%)$ & $1(4,54 \%)$ & $1(4,54 \%)$ & 0 \\
\hline Grandes & 0 & $5(100 \%)$ & 0 & $1(0,80 \%)$ & 118 \\
\hline Total & $89(75,40 \%)$ & $27(22,80 \%)$ & $1(0,80 \%)$ & \\
\hline
\end{tabular}

Las diferencias observadas entre los grupos fueron estadisticamente significativas $(\mathrm{p}<0,0001)$

\section{5.- CONTROL TUMORAL}

\subsection{1.- Crecimiento tumoral}

En la tabla 19 se representan por tamaños los casos de crecimiento tumoral.

En el caso de los tumores pequeños sólo 5 (5,49\%) crecieron en el transcurso del seguimiento. Los 5 casos fueron tratados mediante braquiterapia epiescleral consiguiéndose el control de la enfermedad.

De los tumores medianos, 9 (40,90\%) crecieron. Siete fueron sometidos a braquiterapia y dos fueron enucleados como primer tratamiento. De los tratados mediante braquiterapia uno tuvo que ser enucleado de forma secundaria debido a los efectos secundarios de la radiación.

En el caso de los grandes todos los tumores crecieron y tres de ellos fueron enucleados. Los otro dos fallecieron por causas distintas al melanoma y rechazaron cualquier tratamiento. 


\begin{tabular}{|c|c|c|c|}
\hline \multicolumn{4}{|c|}{ Tabla 19 Crecimiento tumoral } \\
\hline & No & $\mathrm{Si}$ & Total \\
\hline Pequeños & $86(94,50 \%)$ & $5(5,50 \%)$ & 91 \\
\hline Medianos & $13(59,09 \%)$ & $9(40,90 \%)$ & 22 \\
\hline Grandes & 0 & $5(100 \%)$ & 5 \\
\hline Total & $99(83,89 \%)$ & $19(16,10 \%)$ & 118 \\
\hline \multicolumn{4}{|c|}{$\mathrm{P}<0,0001$} \\
\hline
\end{tabular}

Las diferencias observadas entre los grupos fueron estadisticamente significativas $(p<0,0001)$.

En el gráfico 5 se presentan los pacientes sometidos a observación por grupos de tamaño en color verde, los que crecieron en color rojo, de los que crecieron los que fueron sometidos a braquiterapia en color azul, y en amarillo los que debieron ser enucleados.

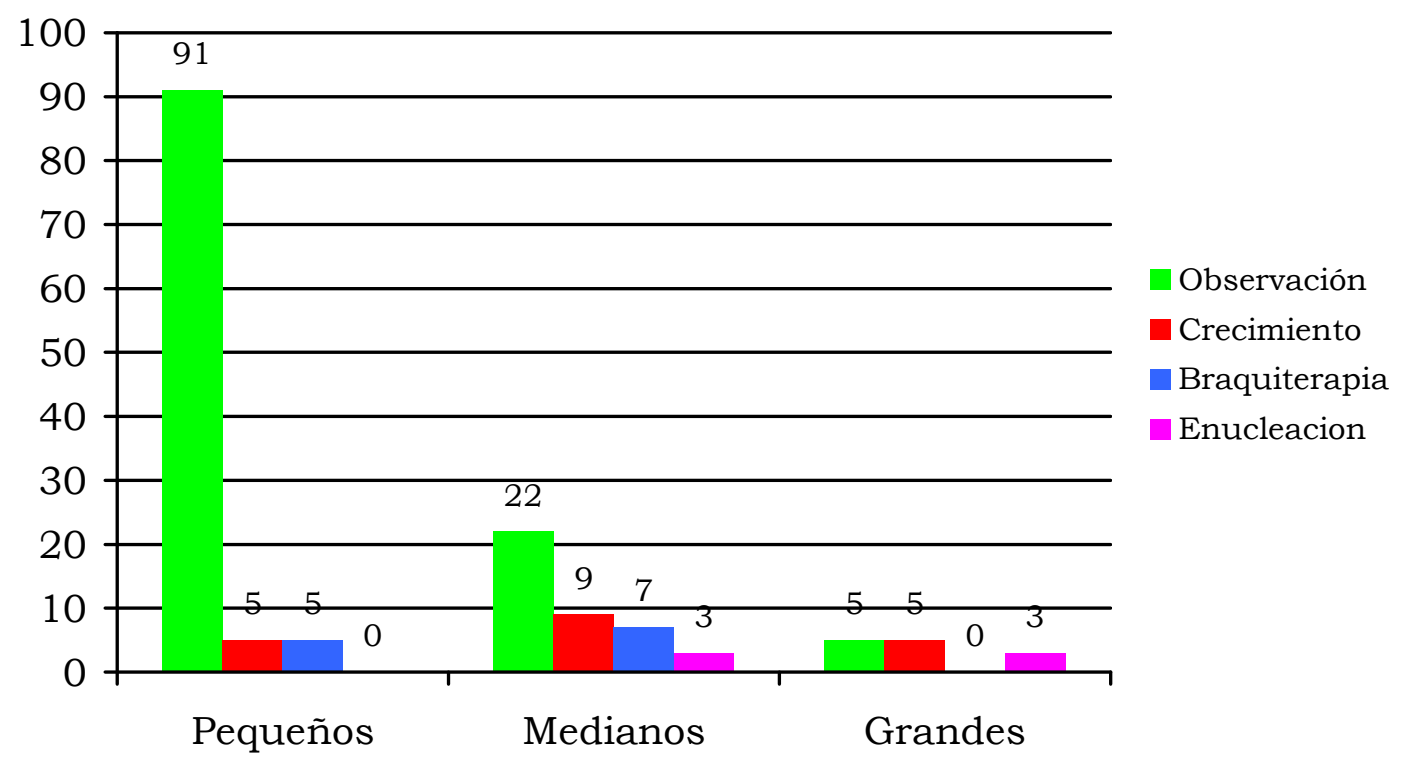

Gráfico 4: Control tumoral

\subsection{2.- Estimación del riesgo de crecimiento tumoral}

Para el análisis del riesgo de crecimiento tumoral en función del tiempo de seguimiento, se utilizó un análisis de supervivencia mediante el método de 
Kaplan Meier, utilizando la presencia de crecimiento del tumor y su fecha como evento de interés.

Los resultados de análisis para el total de tumores y la estratificación por tamaño del tumor se presentan en la tabla 20. La probabilidad de crecimiento aumenta a medida que pasa el tiempo desde el diagnóstico. Esta probabilidad de crecimiento es mayor también cuanto mayor es el tamaño del tumor.

\begin{tabular}{|c|c|c|c|}
\hline \multicolumn{4}{|c|}{ Tabla 20 Estimación del riesgo de crecimiento tumoral } \\
\hline \multirow{2}{*}{ Tamaño } & \multirow{2}{*}{ Tiempo } & \multicolumn{2}{|c|}{ Probabilidad de crecimiento } \\
\hline & & Estimación & IC $95 \%$ \\
\hline \multirow{3}{*}{ Pequeños } & 12 meses & 0,041 & 0 a 0,086 \\
\hline & 24 meses & 0,060 & 0,004 a 0,116 \\
\hline & 36 meses & 0,080 & 0,002 a 0,988 \\
\hline \multirow{3}{*}{ Medianos } & 12 meses & 0,320 & 0,106 a 0,534 \\
\hline & 24 meses & 0,524 & 0,279 a 0,769 \\
\hline & 36 meses & 0,524 & 0,279 a 0,769 \\
\hline \multirow{3}{*}{ Grandes } & 12 meses & 0,600 & 0,171 a 1 \\
\hline & 24 meses & 0,600 & 0,171 a 1 \\
\hline & 36 meses & 0,600 & 0,171 a 1 \\
\hline \multirow{3}{*}{ TOTAL } & 12 meses & 0,127 & 0,061 a 0,194 \\
\hline & 24 meses & 0,195 & 0,111 a 0,194 \\
\hline & 36 meses & 0,195 & 0,111 a 0,280 \\
\hline
\end{tabular}

En la tabla 21 se presentan los tiempos medios, en meses, que los tumores permanecen sin crecer, en función del tamaño del mismo en el momento del diagnóstico. En el grupo de los tumores pequeños el tiempo es mayor que para los medianos y el de estos a su vez es mayor que para los grandes. 
Tabla 21 Tiempo (meses) hasta crecimiento tumoral

\begin{tabular}{|c|c|c|}
\hline & Media & IC $95 \%$ \\
\hline Pequeños & 165,75 & 154,48 a 177,03 \\
\hline Medianos & 86,89 & 47,88 a 125,90 \\
\hline Grandes & 62,80 & 3,23 a 122,36 \\
\hline Total & 146,19 & 132,01 a 160,37 \\
\hline
\end{tabular}

Se ha encontrado diferencias significativas entre las funciones de supervivencia de los tumores pequeño con los medianos y grandes, pero no entre estos dos últimos entre sí (tabla 22):

\begin{tabular}{|c|c|c|}
\hline \multicolumn{3}{|c|}{ Tabla 22 Comparación por pares } \\
\hline & Medianos & Grandes \\
\hline Pequeños & 0,000 & 0,000 \\
\hline Medianos & - & 0.610 \\
\hline
\end{tabular}

Las figuras correspondientes a los análisis de supervivencia anteriormente citados, se presentan para el total de tumores (gráfico 5) y la comparación por tamaños (gráfico 6).

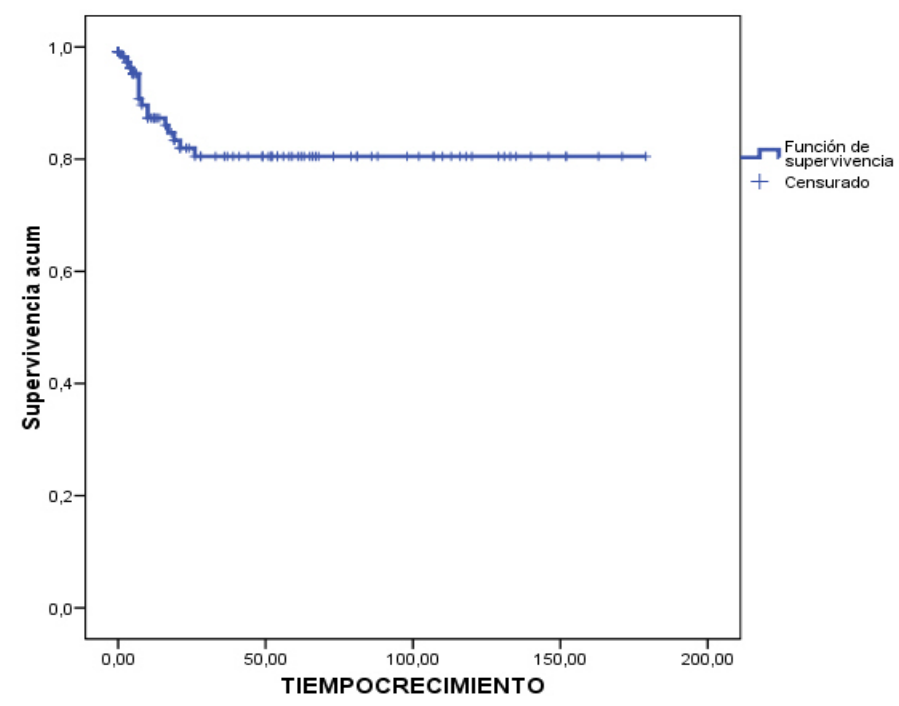

Gráfico 5: Curva de crecimiento tumoral global. 


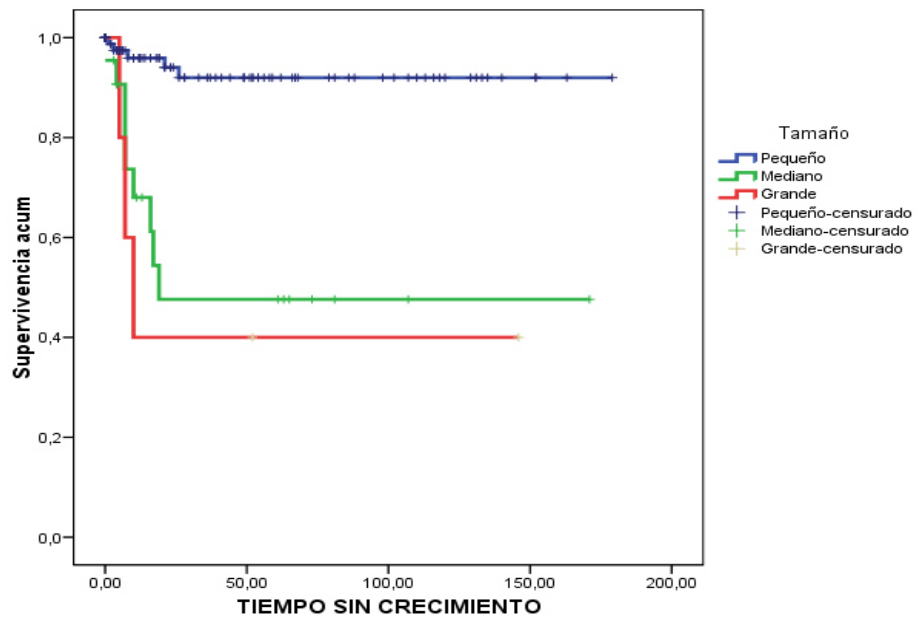

TIEMPO CRECIMIENTO

Gráfico 6: Curvas de crecimiento tumoral por tamaños.

Para la identificación de los factores pronósticos de crecimiento tumoral, se ajustó un modelo de riesgos proporcionales de Cox cuyos resultados se presentan en la tabla 23. De las variables introducidas en el modelo, sólo la sintomatología visual, la presencia de pigmento naranja y el tamaño del tumor contribuyeron de forma significativa a la explicación del crecimiento tumoral.

\begin{tabular}{|c|c|c|c|c|}
\hline \multicolumn{3}{|c|}{ Tabla 23 Modelo de riesgos proporcionales de Cox de los factores } \\
pronósticos de crecimiento tumoral
\end{tabular}

* En relación a los tumores pequeños.

Los valores que aparecen en la columna "Exp (B)" reflejan el incremento en el riesgo de crecimiento tumoral que supone tener los factores que se recogen en la tabla. 


\section{6.- EVOLUCIÓN DE LA FUNCIÓN VISUAL}

El análisis de la evolución visual, se realizó comparando la media de la agudeza visual en el momento del diagnóstico con dicho valor en la última revisión, en función de que el tumor hubiera recibido tratamiento o no. Los resultados se presentan en la tabla 24.

\begin{tabular}{|c|c|c|c|c|c|c|c|}
\hline \multicolumn{8}{|c|}{ Tabla 24 evolución de la agudeza visual } \\
\hline \multirow{2}{*}{ Tamaño } & \multirow{2}{*}{ Tto } & \multirow{2}{*}{$\mathbf{N}$} & \multicolumn{2}{|c|}{ Diagnóstico } & \multicolumn{2}{|c|}{ Última revisión } & \multirow{2}{*}{$\mathbf{p}$} \\
\hline & & & Media & D.T. & Media & D.T. & \\
\hline \multirow{2}{*}{ Pequeño } & No & 73 & 0,78 & 0,31 & 0,74 & 0,28 & 0,25 \\
\hline & $\mathrm{Si}$ & 5 & 0,42 & 0,37 & 0,34 & 0,41 & 0,50 \\
\hline \multirow{2}{*}{ Mediano } & No & 13 & 0,63 & 0,60 & 0,50 & 0,34 & 0,42 \\
\hline & $\mathrm{Si}$ & 7 & 0,69 & 0,32 & 0,22 & 0,26 & 0,01 \\
\hline \multirow{2}{*}{ Grande } & No & 2 & 0,10 & 0,14 & 0,15 & 0,21 & 0,31 \\
\hline & $\mathrm{Si}$ & & & & & & \\
\hline
\end{tabular}

En todos los casos se observa una disminución de la agudeza visual tanto en aquello tumores que recibieron tratamiento como en los que no. No obstante, esta disminución solo es significativa en el caso de los tumores medianos que recibieron tratamiento. No se dispone de información suficiente debido al escaso número de pacientes de pacientes del grupo de los tumores grandes, y además los tres casos que faltan murieron y/o fueron enucleados.

\section{7.- SUPERVIVENCIA DE LOS PACIENTES}

De los 118 pacientes estudiados, 16 (13,55\%) habian fallecido en el momento de cerrar el estudio y tan solo $2(1.69 \%)$ fallecieron a causa de metástasis de melanoma de coroides.

En la tabla 25 se presentan las causas de muerte de los pacientes según el tamaño del tumor en el momento del diagnóstico. En el grupo de los pacientes con tumores pequeños se produjeron 8 muertes y todas ellas por causas distintas al melanoma. En el grupo de los medianos hubo 3 muertes, una relacionada con la enfermedad ocular y otras dos por causas distintas. 
Por último en el grupo de los grandes todos los pacientes murieron, pero solo uno debido a la enfermedad tumoral.

\begin{tabular}{|c|c|c|c|}
\hline \multicolumn{4}{|c|}{ Tabla 25 causas de muerte } \\
\hline & Metástasis & Otras causas & Total \\
\hline Pequeños & 0 & $8(100 \%)$ & 8 \\
\hline Medianos & $1(33,33 \%)$ & $2(66,66 \%)$ & 3 \\
\hline Grandes & $1(20 \%)$ & $4(80 \%)$ & 5 \\
\hline Total & $2(12,50 \%)$ & $14(87,50 \%)$ & 16 \\
\hline
\end{tabular}

En el gráfico 7 se representa la mortalidad total en cada uno de los grupos de tamaño tumoral en verde y el motivo de ésta; diseminación metastásica del melanoma coroideo en azul y por causa ajena a éste en fucsia.

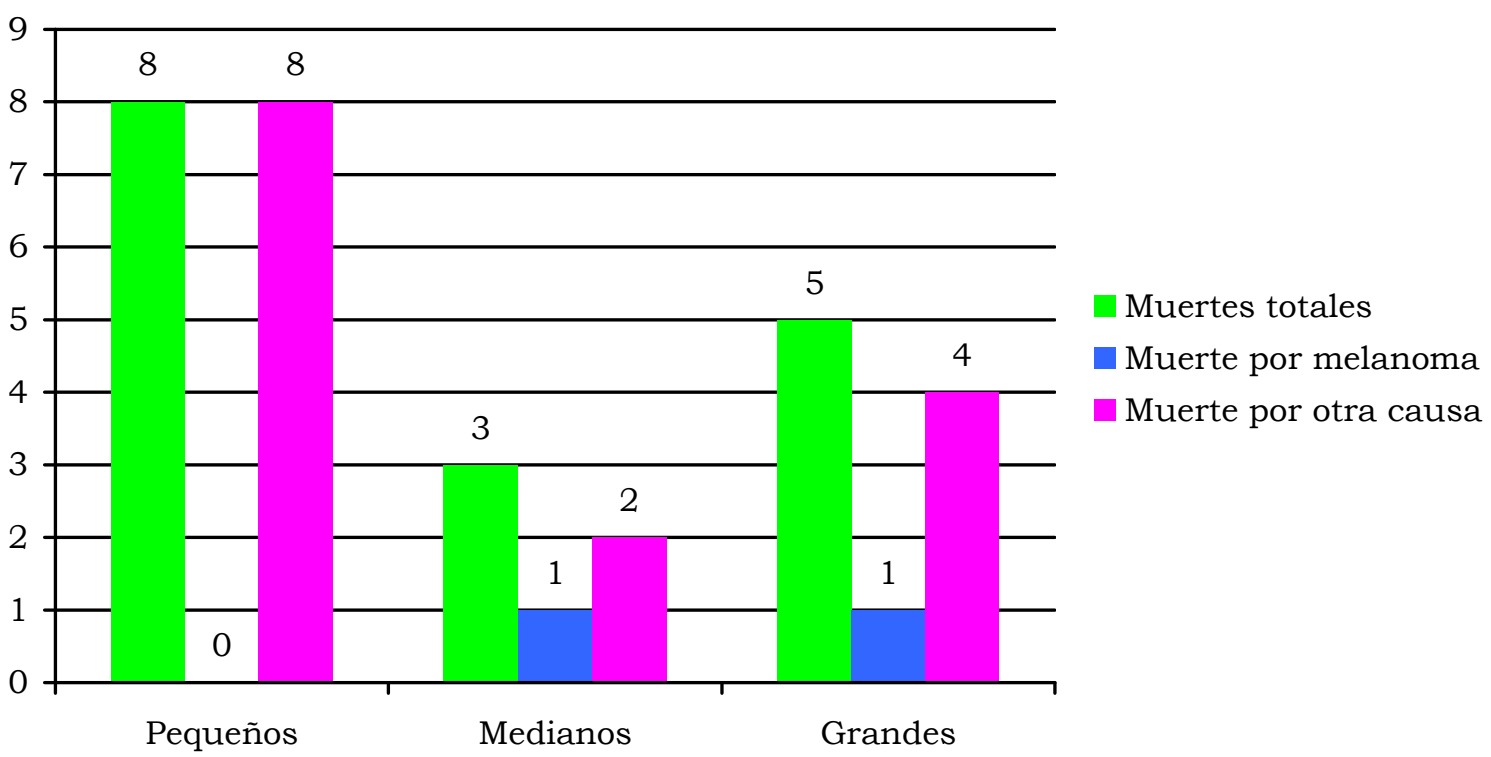

Gráfico 7: Causas de muerte

\subsection{1.- Supervivencia global}

En la tabla 26 se presentan las probabilidades acumuladas de supervivencia a los 12, 36 y 60 meses para el total de la muestra y según el tamaño del tumor, con sus correspondientes intervalos de confianza. 


\begin{tabular}{|c|c|c|c|}
\hline \multicolumn{3}{|c|}{ Tabla 26 Probabilidad acumulada de supervivencia } \\
\hline \multirow{3}{*}{ Tamaño } & \multirow{2}{*}{ Tiempo } & \multicolumn{2}{|c|}{ Supervivencia acumulada } \\
\cline { 3 - 4 } & & Estimación & IC $95 \%$ \\
\hline \multirow{3}{*}{ Pequeños } & 12 meses & 0,978 & 0,948 a 1,000 \\
\cline { 2 - 4 } & 36 meses & 0,936 & 0,881 a 0,990 \\
\cline { 2 - 4 } & 60 meses & 0,845 & 0,756 a 0,935 \\
\hline \multirow{3}{*}{ Gedianos } & 12 meses & 1,000 & \\
\cline { 2 - 4 } & 36 meses & 0,980 & 0,941 a 1,000 \\
\cline { 2 - 4 } & 60 meses & 0,890 & 0,792 a 0,988 \\
\hline & 12 meses & 0,950 & 0,854 a 1,000 \\
\cline { 2 - 4 } & 36 meses & 0,894 & 0,755 a 1,000 \\
\hline \multirow{3}{*}{ TOTAL } & 60 meses & 0,813 & 0,615 a 1,000 \\
\cline { 2 - 4 } & 12 meses & 0,800 & 0,450 a 1,000 \\
\cline { 2 - 4 } & 36 meses & 0,400 & 0,000 a 0,830 \\
\hline
\end{tabular}

La representación gráfica de las funciones de supervivencia completas se presenta en los gráficos 8 y 9

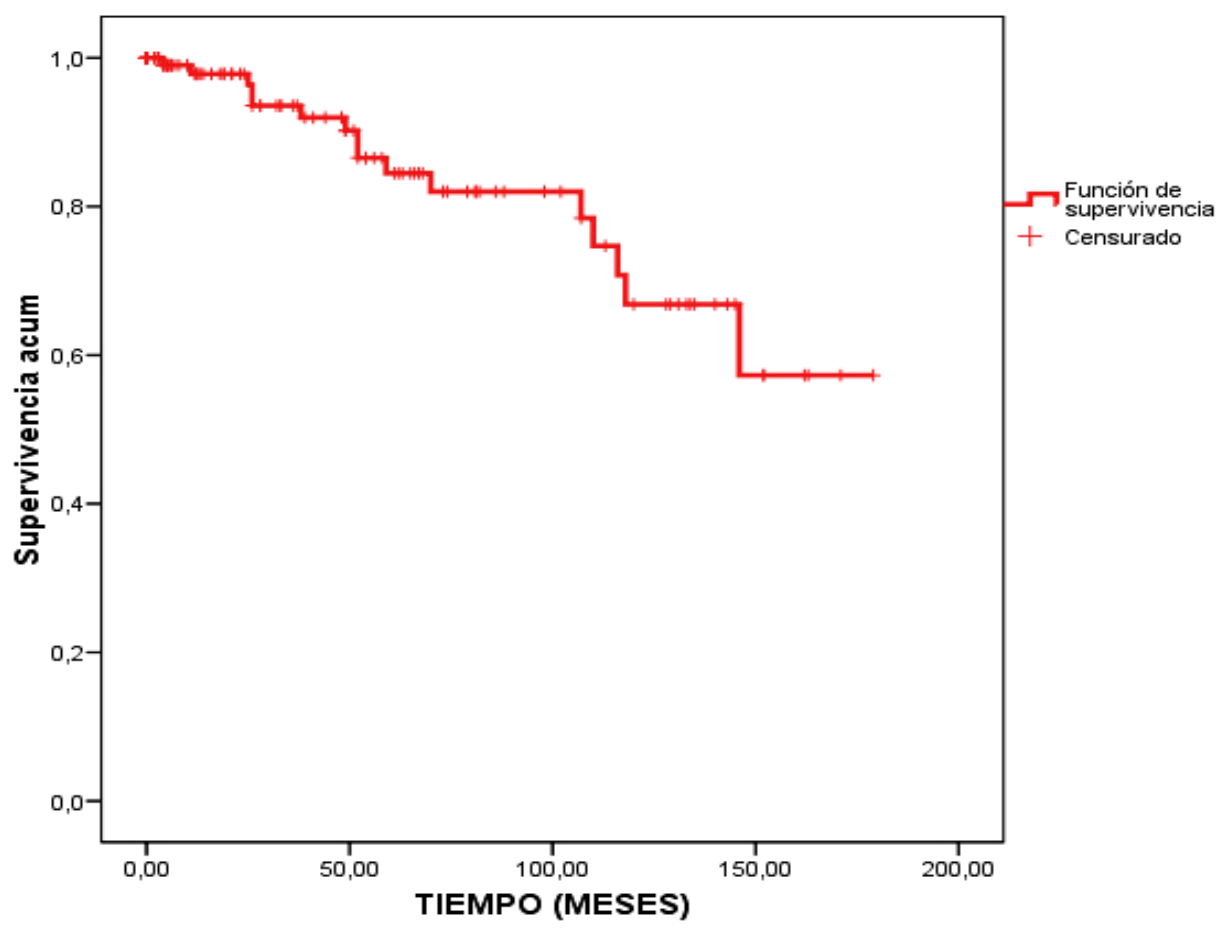

Gráfico 8: curva global de supervivencia por todas las causas. 


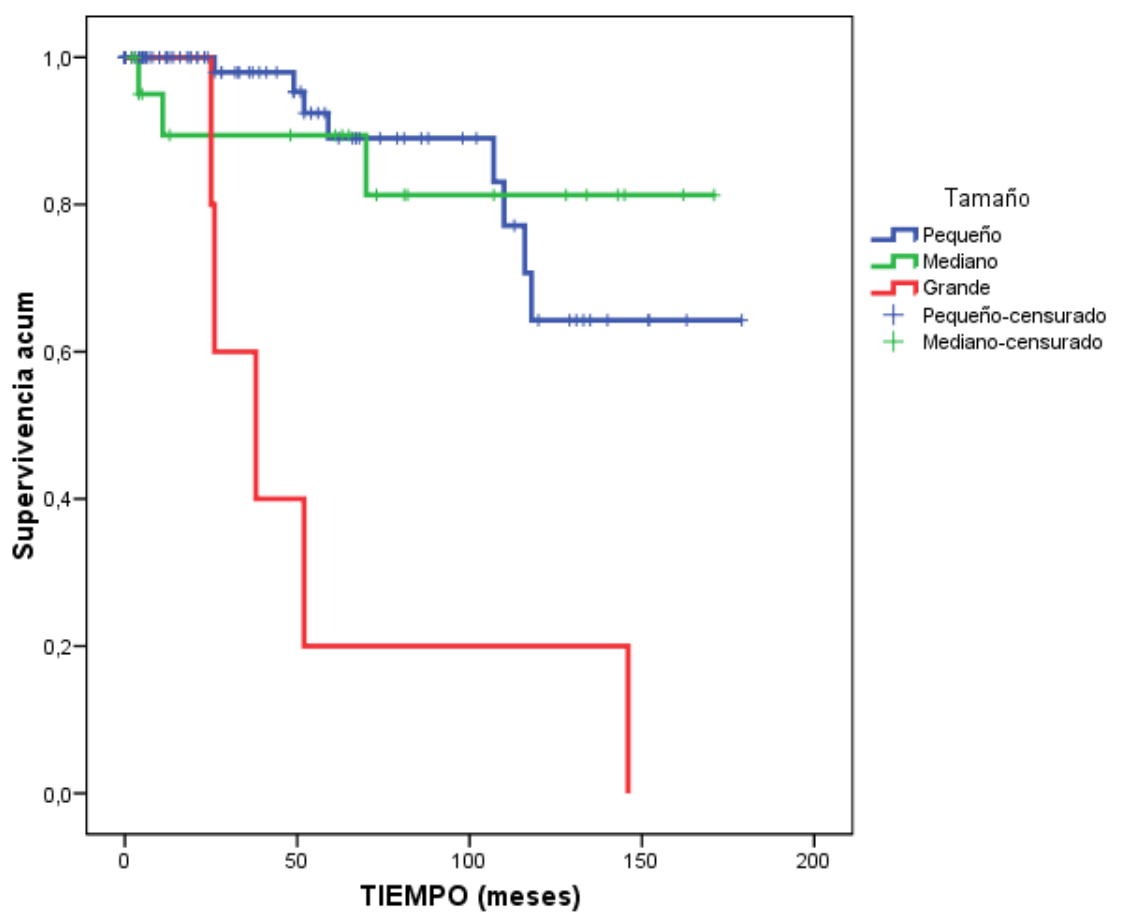

Gráfico 9: curva de supervivencia por todas las causas según tamaños.

A los 5 años de seguimiento, la probabilidad acumulada de supervivencia fue de $84,5 \%$. En el caso de los tumores pequeños, dicha probabilidad asciende hasta $89,0 \%$ y en el de los medianos desciende hasta $81,3 \%$. En el caso de los tumores grandes la supervivencia a los 60 meses fue del $0 \%$, ya que los 5 pacientes fallecieron durante el seguimiento.

El tiempo medio de supervivencia, oscila entre los 57,4 meses en el caso de los tumores grandes y los 148.3 meses en el caso de los pequeños (tabla 27).

\begin{tabular}{|c|c|c|}
\hline \multicolumn{3}{|c|}{ Tabla 27 Tiempo (meses) medio de supervivencia por todas } \\
& Media & IC $95 \%$ \\
\hline Pequeños & 148,323 & 130,469 a 166,178 \\
\hline Medianos & 145,499 & 119,144 a 171,855 \\
\hline Grandes & 57,400 & 12,940 a 101,860 \\
\hline Total & 141,206 & 125,694 a 156,717 \\
\hline
\end{tabular}


Las diferencias son estadísticamente significativas entre los tumores grandes y los otros dos, pero no entre tumores pequeños y medianos (tabla 28).

\begin{tabular}{|c|c|c|}
\hline \multicolumn{3}{|c|}{ Tabla 28 Comparación por pares } \\
(significación estadistica del test log-rank) \\
\hline & Medianos & Grandes \\
\hline Pequeños & 0,889 & 0,000 \\
\hline Medianos & & 0,002 \\
\hline
\end{tabular}

El estudio de los factores pronósticos introducidos en un modelo de riesgos proporcionales de Cox (edad, sintomatología visual, fluido subretiniano, altura superior a $2 \mathrm{~mm}$, tamaño, crecimiento tumoral, tratamiento y extensión extraocular y sistémica) se presenta en la tabla 29. Solamente la edad y fundamentalmente la extensión extraocular y/o sistémica permanecieron como factores pronósticos significativos de mortalidad.

\begin{tabular}{|c|c|c|c|c|}
\hline \multicolumn{3}{|c|}{ Tabla 29 Modelo de riesgos proporcionales de Cox de los factores } \\
pronósticos de mortalidad \\
\hline \multirow{2}{*}{ F. pronóstico } & Sig. & Exp (B) & \multicolumn{2}{|c|}{$\mathbf{9 5 , 0}$ IC para Exp (B) } \\
\cline { 4 - 5 } & 0,000 & 1,104 & 1,050 & 1,161 \\
\hline Edad & 0,001 & 28,467 & 4,072 & 199,023 \\
\hline $\begin{array}{c}\text { Extensión } \\
\text { extraocular y/o } \\
\text { sistémica }\end{array}$ & 0 & & & \\
\hline
\end{tabular}

\subsection{2.- Supervivencia especifica}

Los resultados que se refieren a la mortalidad por melanoma y el análisis de supervivencia resultante se presentan en los gráficos 10 y 11 . 


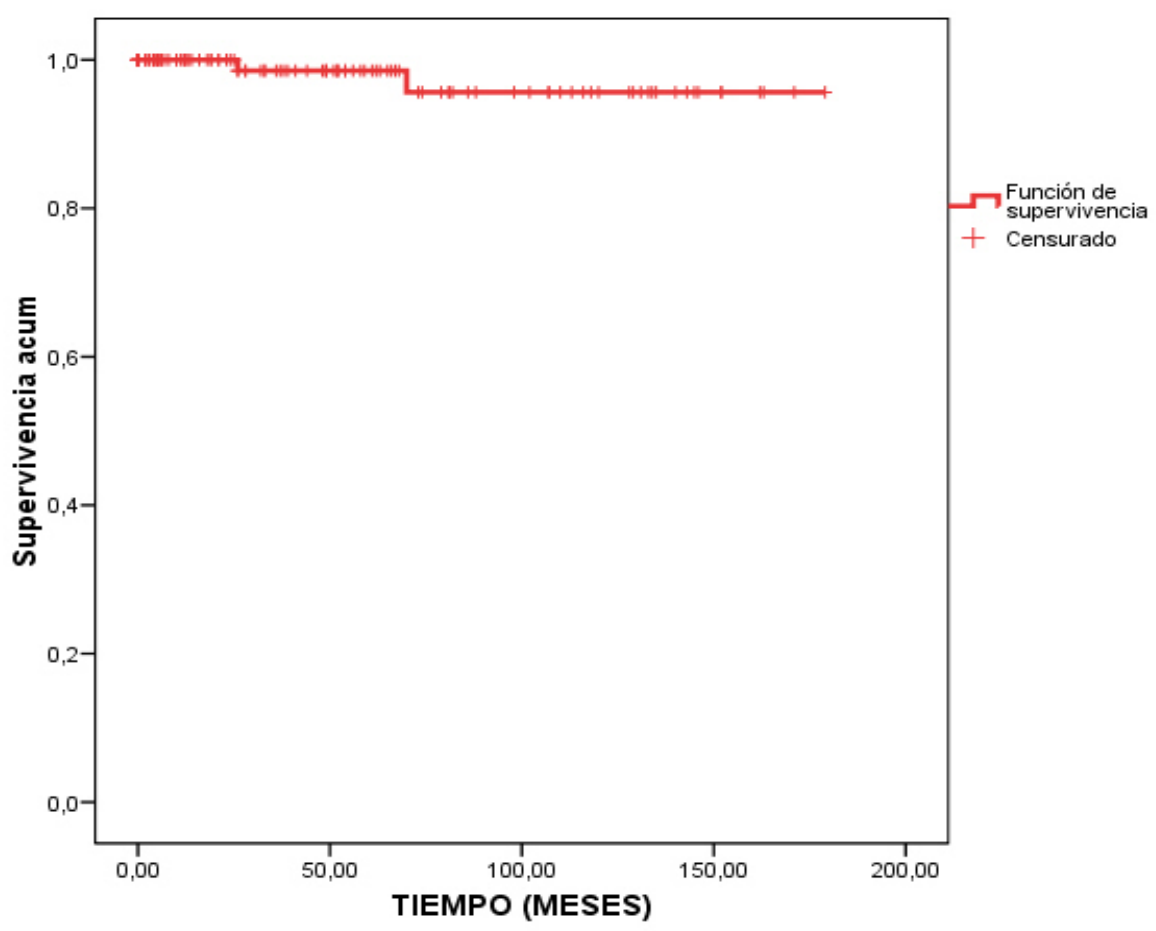

Gráfico 10: curva de mortalidad especifica por melanoma.
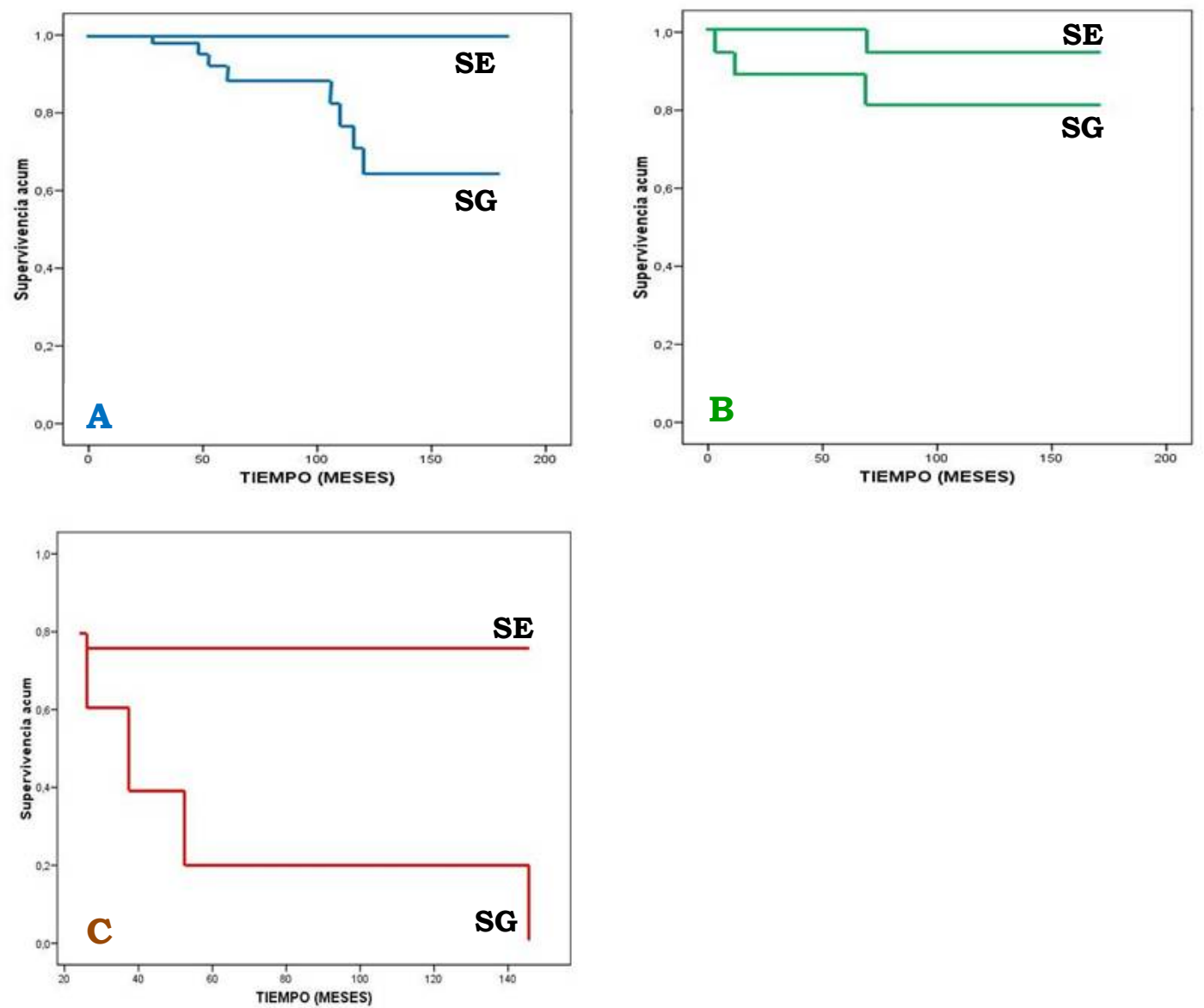

Gráfico 11: Supervivencia especifica (SE) por tamaños, comparada con la global $(\mathrm{SG})$. En azul (A) para los pequeños, en verde (B) para los medianos y en rojo (C) para los grandes. 
Solo dos pacientes de los 118 analizados, fallecieron por causas relacionadas con el tumor: uno de ellos grande a los 26 meses de seguimiento y otro mediano, a los 70 meses. El tiempo medio de supervivencia fue de 173,6 meses (IC 95\%: 166,1 a 181,0). La comparación de los tiempos de supervivencia de los tumores medianos y grandes se presenta en la tabla 30; la menor supervivencia en relación a las causas específicas de muerte de los tumores grandes no fue estadisticamente significativa. No fue posible ajustar un modelo de riesgos proporcionales de Cox.

\begin{tabular}{|c|c|c|}
\hline \multicolumn{2}{|c|}{ Tabla 30 Tiempo medio de supervivencia según tamaño } \\
tumoral \\
\hline & Media & IC $95 \%$ \\
\hline Medianos & 161,8 & 144,6 a 178,9 \\
\hline Grandes & 116,0 & 65,1 a 166,9 \\
\hline Total & 173,6 & 166,1 a 181,0 \\
\hline
\end{tabular}




\section{DISCUSIÓN}

En los ultimos años el manejo de las lesiones melanociticas coroideas de tamaño pequeño ha suscitado una enorme controversia entre los especialistas en Oftalmología, de forma que mientras unos sectores abogan por un tratamiento radical y precoz de estas lesiones para prevenir su transformación y diseminación metastásica, otros por el contrario, defienden la observación de lesiones que no progresan y cuyo tratamiento supone importantes efectos secundarios para el paciente. Las series publicadas a este respecto son escasas y los resultados dispares.

En este contexto polémico, los resultados del presente estudio muestran que, en una población de nuestro medio (probablemente diferente a las previamente publicadas por motivos raciales, de pigmentación y de latitud geográfica) la observación periódica de pacientes afectos de melanoma de coroides, cumple los objetivos terapéuticos con respecto al control tumoral, conservación de la agudeza visual y sin menoscabo en la supervivencia.

En cuanto al control tumoral, objetivo prioritario de un tratamiento conservador, en el grupo de los melanomas pequeños solo se produjo un $5.5 \%$ de crecimiento de las lesiones, mientras que en el grupo de los medianos y de los grandes el porcentaje es mucho más elevado y las diferencias estadisticamente significativas.

La agudeza visual de los pacientes que no recibieron tratamiento, como es lógico, se mantuvo en niveles mayores que en aquellos que fueron tratados. 
Ninguno de los pacientes del grupo de los melanomas pequeños murio a causa de la extensión metastasica de la enfermedad en el tiempo de seguimiento, lo que apoya a la observación como alternativa terapeútica en estas lesiones.

\section{1.- LIMITACIONES Y FORTALEZAS}

La principal limitación del presente estudio es el seguimiento medio de los pacientes (51,15 meses), aunque es de más de cinco años (60 meses) en el $36,44 \%$ de los pacientes incluidos.

Existen muy pocos estudios de observacion en pacientes con lesiones melanociticas pequeñas de los cuales los mas relevantes son el estudio sobre mortalidad del COMS 9 que incluye 204 pacientes con un seguimiento medio de 92 meses y el del grupo de Shields y cols. ${ }^{12}$ que analiza 1329 con un seguimiento meido de 53 meses.

Es muy importante destacar que este estudio presenta la mayor serie de pacientes con melanomas pequeños en nuestro pais. Ademas el seguimiento de los pacientes ha sido exahustivo, con pérdidas de seguimiento mínimas (por debajo del 1\%), el diagnóstico ha sido estandarizado y ajustado a los criterios internacionales, y representa uno de los pocos estudios realizados en Europa, lo que hace que tenga un gran interés para el estudio de la historia natural de las lesiones melanociticas coroideas pequeñas,tanto a nivel general como en nuestro medio en particular.

\section{2.- DISCUSIÓN DE LA DESCRIPCIÓN GENERAL DE LA MUESTRA}

En el análisis de la edad llama la atención la distribución bimodal de la edad media de los pacientes, apareciendo un primer pico de incidencia (gráfico 1, pag 57) entre los 40 - 45 años y un segundo pico entre los 70 - 75 años. En estudios epidemiológicos realizados en Estados Unidos y en Europa, se observa una curva de incidencia ascendente que tiene su pico a partir de los 65 años (gráfico 12), pero no aparece el primer pico detectado en esta serie. ${ }^{116,117}$ Este pico inicial puede estar en relación con la naturaleza de la 
muestra; los pacientes con tumores pequeños sometidos a observación (que son la mayoria de los que la componen) están asintomáticos en el momento del diagnóstico, que se realiza en exploraciones rutinarias a edades tempranas lo que concuerda con el primer pico de incidencia detectado.

\section{Uveal Melanoma: Age-specific Rates}

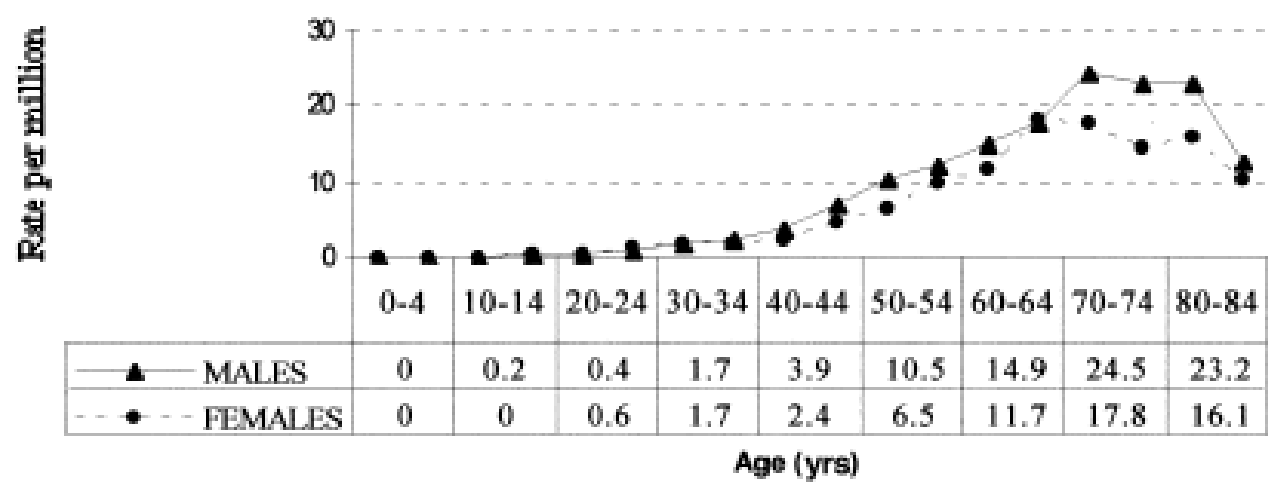

Gráfico 12: Número de pacientes por rango de edad en la población americana (tomado de Singh AD, Topham A. Incidence of uveal melanoma in the United States: 1973-1997. Ophthalmology 2003; 110: 956-961).

Por otra parte, se observa un aumento de la edad media con el tamaño de los tumores, lo que apoya que los tumores crecen con el tiempo, o lo que es lo mismo, que cuanto antes se diagnostican más pequeños son, y por lo tanto mejor es su pronóstico.

Con respecto del análisis del sexo de los pacientes, en el grupo de los tumores pequeños y de los tumores medianos el diagnóstico fue más frecuente en mujeres siendo las diferencias estadísticamente significativas. Este hecho es muy significativo puesto que en los estudio epidemiológicos previamente publicados, este tumor predomina en varones.116,117 Al igual que las diferencias detectadas en la edad, el hecho de que la serie esté constituida en su mayor parte por tumores pequeños y asintomáticos detectados en su mayor parte a raiz de exploraciones rutinarias puede estar en relación con el predominio de sexo femenino. Para el grupo de los medianos sin embargo, el predominio de mujeres, contrasta con los resultados previamente publicados.

El seguimiento medio fue de 51,15 meses, si bien más del $52 \%$ de los pacientes de la muestra tienen un seguimiento superior a tres años y más del 
$36 \%$ un seguimiento superior a cinco años. No cabe duda que cuanto mayor sea el segumiento más fiable es la interpretación de los resultados del estudio, pero el seguimiento de esta serie es suficiente para permitir extraer conclusiones interpretadas con las debidas cautelas. Respecto a las pérdidas de seguimiento, suponen un porcentaje muy bajo del total de la muestra.

\section{3.- DISCUSIÓN DE LAS CARACTERÍSTICAS GENERALES}

La mayoria de los pacientes no tuvieron exposiciones prolongadas a la luz solar, lo que concuerda con la falta de relación entre la radiación ultravioleta y el melanoma uveal previamente descrita en la literatura. ${ }^{42}$ De la misma manera, un porcentaje muy bajo de los pacientes incluidos estaban inmunodeprimidos, padecian depresión o tenían antecedentes personales de melanoma. Respecto al hábito tabáquico la mayoria $(77,88 \%)$ eran no fumadores; el melanoma uveal no se ha relacionado claramente con el consumo de esta sustancia. ${ }^{118}$

Tres pacientes padecian o habian padecido en el momento del diagnóstico tumoraciones malignas cutáneas. Del mismo modo un paciente presentaba cáncer de próstata, otra de mama y otra de útero. No parece que exista relación por lo tanto entre el melanoma y estas neoplasias secundarias. Los resultados de diferentes estudios que han intentado poner en relación el melanoma coroideo con neoplasias malignas secundarias son dispares. 40,119

La patología ocular concomitante más prevalente fue la catarata, que estaba presente tanto en el ojo afecto como en el contralateral en el 35,59\% de los pacientes incluidos en el estudio. Este hallazgo es congruente con la media de edad de los pacientes, puesto que la catarata es una alteración ocular propia de edades avanzadas. Respecto de otras patologias como la ambliopía, la DMAE, el glaucoma, o la retinopatía diabética, su prevalencia fue mucho menor, pero en el caso de afectación del ojo contralateral, condicionó la observación como primera intención terapeútica en aras de conservar la función visual. 


\section{4.- DISCUSIÓN DE LAS CARACTERÍSTICAS OCULARES Y TUMORALES}

\subsection{1.- Características generales oculares y tumorales}

Puesto que uno de los criterios de inclusión era que los tumores debían asentar en la coroides, todos los pacientes incluidos en el presente estudio tenian melanomas en esta localización. No se incluyeron ni pacientes con melanomas de iris ni de cuerpo ciliar.

La mayoria de los tumores que se incluyeron en el estudio tenían tamaño pequeño (según clasificación COMS)43 puesto que es en estos melanomas donde está indicada la observación como actitud terapeútica primaria. Los casos clasificados como medianos y grandes fueron sometidos a observación cuando rechazaron ser tratados. Esto hace que el presente trabajo incluya un grupo de gran interés de tumores de tamaño mediano en el que los pacientes rechazaron el tratamiento dado que no existen series de este tipo en la literatura.

En el grupo de los tumores pequeños se observa un predominio del color verde y del marron sobre el azul y lo mismo ocurre en el grupo de los medianos (gráfico 3 pág. 74). Esto contrasta con las series publicadas con anterioridad $^{120}$ en las que estas lesiones asientan más frecuentemente en personas con ojos claros. Esto se debe probablemente a que dichas series pertenecen a paises nórdicos y a Estados Unidos, donde la prevalencia de iris claros es mayor que en nuestro medio, donde son los oscuros los que predominan. De hecho la distribución encontrada en el presente estudio viene a corroborar lo ya observado en un trabajo anterior de este grupo de investigación. 23

En el grupo de los melanomas pequeños casi el $80 \%$ fueron asintomáticos, lo cual es lógico puesto que las lesiones pequeñas fueron en su mayor parte inactivas. Es llamativo que en el grupo de los medianos mas de la mitad fueron también asintomáticos. Esta fuerte tendencia a la ausencia de sintomas hace fundamental una buena exploración del fondo de ojo en las revisiones rutinarias, pues pueden ayudar al diagnóstico precoz de la 
enfermedad lo que implica una menor morbilidad debida a los tratamientos y una mejora del riesgo de diseminación mestastásica.

\subsection{2.- Signos de actividad}

Son muchos los trabajos que han estudiado los signos de actividad de las lesiones melanocíticas sospechosas. En nuestro medio es destacable el publicado por Fernandez Sañudo y colaboradores, del Hospital Puerta de Hierro de Madrid, ${ }^{121}$ en el que se revisaron retrospectivamente catorce pacientes que analiza como fatores de riesgo la presencia de sintomas, el espesor de la lesión, el contacto con el nervio óptico y el crecimiento documenta y en la que tan solo se observa un caso de crecimiento tumoral. E1 estudio con mayor número de pacientes ha sido realizado por Shields y cols del Wills Eye Institute en Philadelphia (EEUU), publicando una primera parte en 1995 (con 1329 ojos) en el que se describen como factores de actividad relacionados estadísticamente con el riesgo de crecimiento y diseminación metastasica de la enfermedad los siguientes: la altura superior a $2 \mathrm{~mm}$, la presencia de pigmento naranja, la presencia de fluido subretiniano, la presencia de síntomas clínicos, y la localización del borde de la lesión contactando con el nervio optico. ${ }^{11}$ En 2000 el mismo grupo publica un trabajo en el que estudia la importancia sobre el riesgo de crecimiento de los factores antes enunciados (1287 ojos) de forma que la asociaciación de tres o mas de estos factores supone un aumento del $50 \%$ del riesgo de crecimiento. ${ }^{113}$ Finalmente en el año 2009, se publica, con una muestra de 2514 ojos, el último estudio, en el que se añaden dos nuevos signos de crecimiento, la presencia de vacío ecogénico en la ecografia y la ausencia de halo atrófico. ${ }^{12}$ Para estos autores la presencia de drusas en la superficie del tumor no tiene relevancia estadísticamente significativa como factor protector, pero si ha sido descrita en estudios publicados por Singh ${ }^{114}$ y en el reporte 5 del COMS. 8

En el presente trabajo se han empleado los cinco factores clásicos descrtitos por Shields y cols para decidir cuando tratar o cuando seguir observando. 
A diferencia del estudio de Shields, en el que la sintomatologia visual fue el factor más prevalente, en la presente serie fue la altura superior a 2 $\mathrm{mm}$, presente en mas del $45 \%$ de los ojos, seguido muy de lejos por la presencia de sintomatología visual (tabla 31).

\begin{tabular}{|c|c|c|}
\hline \multicolumn{2}{|c|}{ Tabla 31 Signos de actividad en el grupo de los } \\
tumores de tamaño pequeño
\end{tabular}

En el caso de los tumores medianos la altura superior a $2 \mathrm{~mm}$ vuelve a ser el factor más prevalente, seguido, tambien muy de lejos, de la sintomatologia visual. Es importante recalcar que en el grupo de los medianos los sintomas visuales fueron muy poco frecuentes contra lo que cabria esperar, puesto que cuanto más grande es un tumor, más sitomático se espera que sea.

De estos resultados puede deducirse que la proporción de pacientes diagnósticados en controles rutinarios es mayor que en las series publicadas anteriormente, en las que existe un mayor porcentaje de pacientes sintomáticos.

Respecto de la asociación de factores de riesgo en el grupo de los tumores pequeños casi el $60 \%$ presentaban un unico factor y casi el $19 \%$ ninguno. Esto contrata tambien con la serie de Shields en la que un tercio de 
los tumores presentaban 3 factores de riesgo y casi otro tercio al menos dos (Tabla 32).

Tabla 32 Número de signos de actividad en el grupo de los tumores de tamaño pequeño

\begin{tabular}{|c|c|c|c|c|c|c|c|}
\hline & 0 & 1 & 2 & 3 & 4 & 5 & Total \\
\hline $\begin{array}{c}\text { Presente } \\
\text { estudio }\end{array}$ & $\begin{array}{c}17 \\
(18,68 \%)\end{array}$ & $\begin{array}{c}54 \\
(59,34 \%)\end{array}$ & $\begin{array}{c}14 \\
(15,38 \%)\end{array}$ & $\begin{array}{c}6 \\
(6,59 \%)\end{array}$ & 0 & 0 & 91 \\
\hline $\begin{array}{c}\text { Shields y } \\
\text { cols. } 113\end{array}$ & $\begin{array}{c}4 \\
(0,02 \%)\end{array}$ & $\begin{array}{c}178 \\
(12,34 \%)\end{array}$ & $\begin{array}{c}453 \\
(31,41 \%)\end{array}$ & $\begin{array}{c}497 \\
(34,46 \%)\end{array}$ & $\begin{array}{c}254 \\
(17,61 \%)\end{array}$ & $\begin{array}{c}56 \\
(3,88 \%)\end{array}$ & 1442 \\
\hline
\end{tabular}

En el caso de los tumores medianos el $45 \%$ de los tumores tenian un factor de riesgo seguido de un $27 \%$ de tumores con dos factores de riesgo. Llama la atención que exista mayor porcentaje de tumores con más signos de actividad que en el caso de los pequeños, y que sin embargo el grupo de los medianos tenga menor porcentaje de casos sintomáticos.

Todos los tumores del grupo de los grandes tenian tres o más factores de riesgo, lo cual es esperable tratandose de tumores activos.

En nuestra muestra tan solo el pigmento naranja y la sintomatología visual demostraron presentar asociación estadistica con el riesgo de crecimiento tumoral.

\subsection{3.- Agudeza visual en el momento del diagnóstico}

La agudeza visual en el grupo de los pequeños fue mayor de 0.5 en mas del $82 \%$ de los ojos estudiados y en más del 54\% de los ojos con tumores medianos. Esto es un hecho muy importante a tener en cuenta a la hora de tomar una decisión terapeútica, puesto que los tratamientos que se emplean para la inactivación de los tumores suponen una merma considerable e irreversible de la función visual. ${ }^{122}$

\subsection{4.- Motivo del observación}

En el caso de los tumores medianos y grandes solo se observó a pacientes que rechazaron el tratamiento, informándoseles convenientemente de los riesgos que asumian. 


\section{5.- DISCUSIÓN DEL CONTROL TUMORAL}

\subsection{1.- Crecimiento tumoral.}

El pontencial metastásico de estas lesiones es el principal argumento para indicar su tratamiento. En este sentido se considera el crecimiento como un factor claro de activación y riesgo de diseminación. ${ }^{11}$

En el grupo de los tumores pequeños el número de lesiones que progresaron es muy bajo, lo que demuestra que la observación estas lesiones no compromete el control tumoral.

\begin{tabular}{|c|c|c|c|c|}
\hline \multicolumn{5}{|c|}{ Tabla 33 Crecimiento de melanomas pequeños bajo observación } \\
\hline & $\begin{array}{c}\text { Presente } \\
\text { estudio }\end{array}$ & $\begin{array}{c}\text { Shields y } \\
\text { cols }{ }^{11}\end{array}$ & Singh cols ${ }^{114}$ & COMS n58 $^{\circ}$ \\
\hline $\mathbf{N}$ & 91 & 1287 & 240 & 188 \\
\hline $\begin{array}{c}\text { Tumores que } \\
\text { crecieron }\end{array}$ & $5(5,49 \%)$ & $235(18,25 \%)$ & $11(4,58 \%)$ & $46(24,46 \%)$ \\
\hline $\begin{array}{c}\text { Seguimiento } \\
\text { medio }\end{array}$ & 51.15 meses & 60 meses & 50 meses & 60 meses \\
\hline
\end{tabular}

En la tabla 33 se exponen los datos de crecimento del presente estudio en melanomas pequeños comparados con otras series previamente descritas en la literatura. Llama la atención la enorme diferencia que existe con las grandes series de Shields y del COMS, donde la incidencia de crecimiento en el seguimiento prácticamenet cuadruplica la del presente estudio con menos de un año mas de seguimiento medio. Esta enorme diferencia puede deberse a las diferencias raciales que existen entre los individuos que forman estas series (norteamericanos) y la del presente estudio; sin embargo los datos son prácticamente superponibles a la serie de Singh, formada tambien por pacientes de esta nacionalidad.

Respecto al comportamiento en los tumores medianos los datos obtenidos son muy interesantes debido a la falta de series en la literatura que aborden este supuesto. Prácticamente la mitad de los tumores crecieron lo que 
nos da una valiosa información clinica que puede emplearse para informar al os pacientes con diagnóstico reciente de melanoma uveal que dudan de la necesidad de recibir tratamiento.

Es importante tambien remarcar la diferencia en la probabilidad de creciemiento entre los tumores pequeños por un lado y los medianos y grandes por otro, hecho queapoya la principal hipotesis de este trabajo; la observación periódica de estas lesiones supone un riesgo de crecimiento muy bajo.

\subsection{2.- Estimación del riesgo de crecimiento tumoral}

El estudio del riesgo de crecimiento tumoral estimado para los tres grupos de tumores (pequeños, medianos y grandes) arroja los siguientes hallazgos:

- la probabilidad de crecimiento de los tumores pequeños respecto de los medianos y los grandes a uno, dos y tres años, es mucho mas baja (Tabla 20, pag 80).

- El tiempo medio de seguimiento hasta que se produce el crecimiento del tumor es mucho más largo (más del doble) para los tumores pequeños que para los grandes (tabla 21, pág 81).

- Las funciones de superviviencia (Kaplan-Meier) presentan diferencias estadisticamente significativas entre los tumores pequeños y los grandes y medianos, pero no entre estos dos últimos (Tabla 22, página 81 y gráfico 6, pág 82).

Estos hallazgos refuerzan la afirmación con la que termina el epígrafe anterior, los tumores pequeños crecen menos, y mucho mas tarde que los medianos o los grandes.

\section{6.- DISCUSIÓN DE LA EVOLUCIÓN DE LA FUNCIÓN VISUAL}

La disminución de la agudeza visual en el grupo de los pequeños que no fueron tratados es mínima entre la exploración inicial y el último seguimiento (apenas cuatro centésimas) y es lógicamente atribuible al paso del tiempo y el desarrollo de cataratas por los pacientes. En el caso de los tumores pequeños 
que precisaron de tratamiento, se parte de una agudeza visual media más baja en el momento del diagnóstico (en relación con las alteraciones visuales que produce el propio tumor) y la agudeza visual media en la última revisión es tambien más baja; siendo este fenómeno atribuible por un lado al nivel visual de inicio y a los efectos secundarios derivados del tratamiento, si bien las diferencias observadas no fueron estadisticamente significativas.

En cuanto al grupo de los medianos los resultados en cuanto a la diferencia de agudeza visual entre el diagnóstico y la ultima revisión entre los pacientes no tratados de nuevo es muy pequeña (apenas una línea) y no tiene significación estadística, mientras que en el grupo de los tratados la caida de la agudeza visual como consecuencia de los efectos secundarios del tratamiento es enorme y las diferencias observadas estadísticamente significativas (Tabla 23, página 82). Esto es congruente con lo previamente observado por el grupo de investigación (gráfico 13) y otros estudios más amplios. ${ }^{122}$

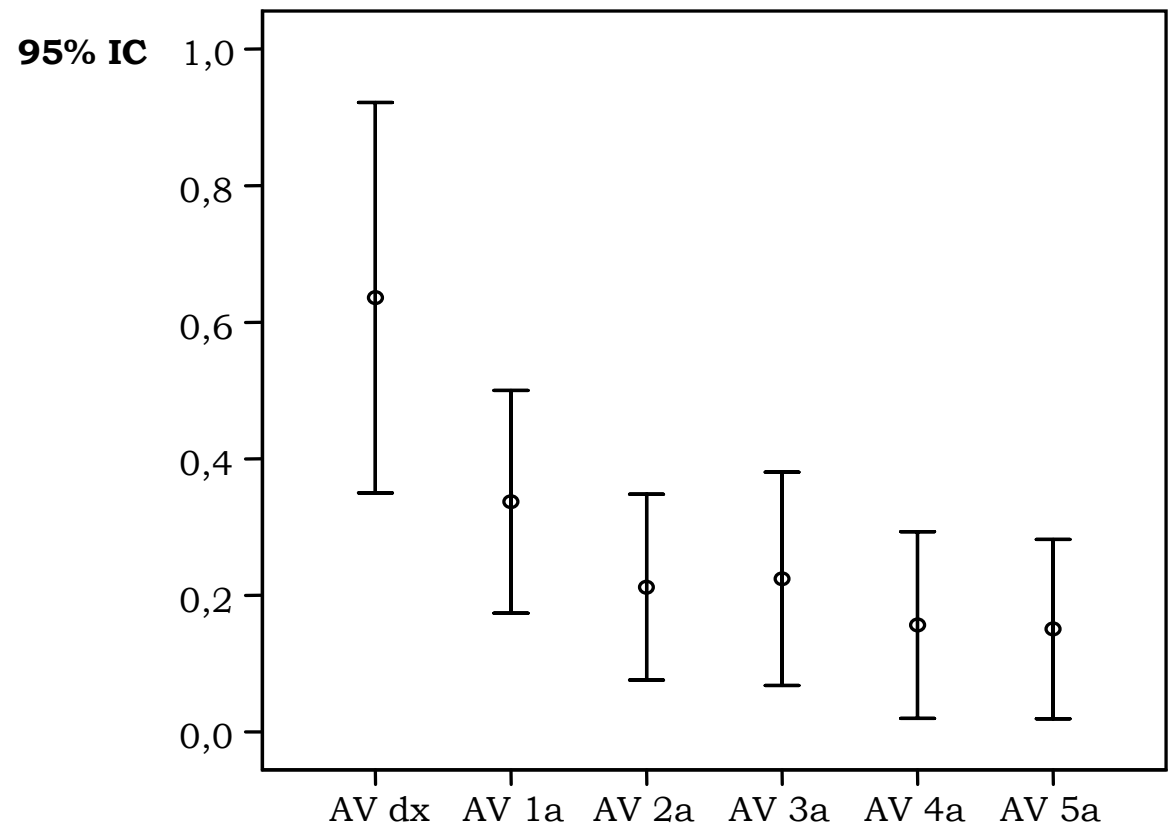

Gráfico 13: Evolución de la agudeza visual en pacientes diagnosticados de melanoma uveal y tratados con braquiterapia epiescleral (Garcia-Alvarez et al. Iodine-125 episcleral brachytherapy for uveal melanoma: 102 cases. International Society of Ocular Oncology. Siena (Italia). 2007)

Es muy significativa la desigual disminución de la agudeza visual si comparamos el grupo de tumores pequeños tratados y el grupo de medianos tratados; mientras que en el primer grupo la agudeza visual media respecto 
del momento del diagnóstico a la última revisión cae apenas menos de una linea, en el caso de los medianos la caida es de más de cuatro líneas; esto responde a la tasa de dosis aplicada en ambos grupos; a mayores volumenes tumorales, mayor dosis terapéutica y por lo tanto mas efectos secundarios. ${ }^{122}$

De los resultados del estudio se desprende por lo tanto que en el grupo de los tumores pequeños la observación cumple uno de los objetivos del presente trabajo, puesto que la función visual de los pacientes que no fueron tratados prácticamente se mantiene a lo largo del estudio, y la de los que a lo largo del seguimiento precisaron ser tratados disminuye muy poco en comparación con los pacientes del grupo de los tumores medianos.

\section{7.- DISCUSIÓN DE LA SUPERVIVENCIA DE LOS PACIENTES}

Es evidente que el objetivo mas importante de este estudio es aportar datos acerca de la supervivencia de los pacientes con lesiones melanocíticas indeterminadas o melanomas pequeños inactivos y comprobar la seguridad de la observación en los melanomas coroideos pequeños.

La cuestión acerca de si la observación hasta que haya signos de crecimiento en este tipo de lesiones puede aumentar el riesgo de aparición de metástasis todavía no tiene respuesta, y son pocos los trabajos publicados acerca de este tema, y son dificilmente comparables debido a que parten de muestras de poblaciones, clasificaciones y seguimientos muy diferentes.

Si bien en carcinomas como el de mama o el de pulmón el desarrollo de los métodos diagnósticos y terapéuticos han permitido una mejoría del pronóstico de los pacientes afectados con el paso de los años, en el caso del melanoma de coroides estos avances no han supuesto un aumento de la supervivencia como se puede observar en la gráfica 14; la supervivencia a 5 años de los pacientes en la década de los 90 era idéntica a la de los 70. Este hecho se achaca a una falta de compresnión de la historia natural de esta enfermedad; está claro que los mecanismos de diseminación tumoral aun no se comprenden y no se ven condicionados por el tratamiento. 


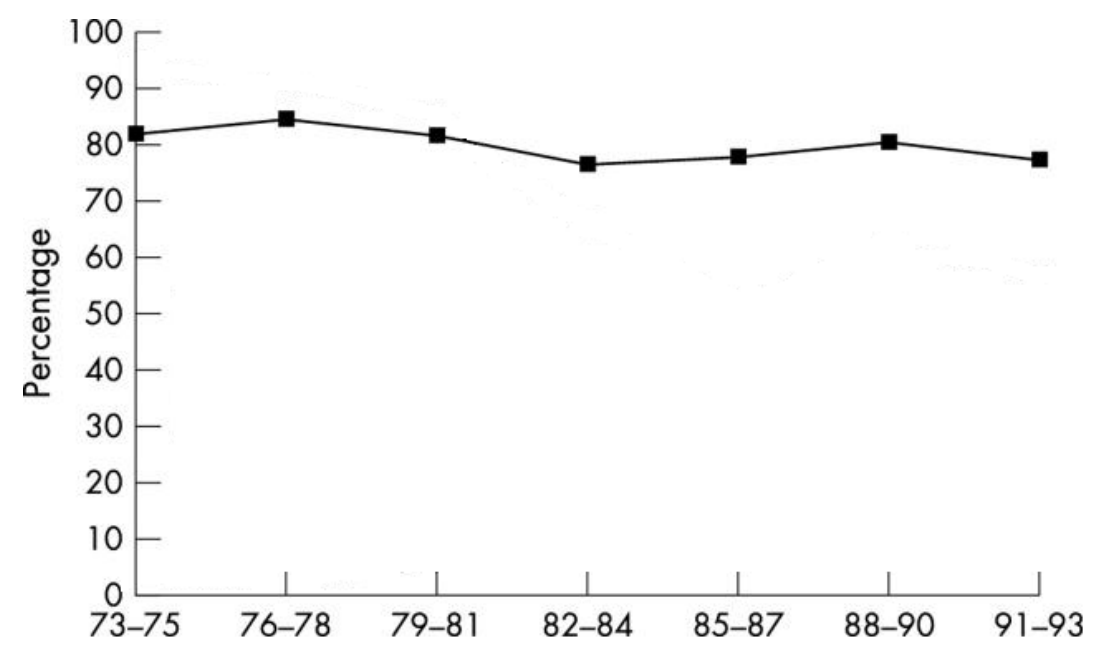

Gráfico 14: supervivencia a los cinco años del diagnóstico de los pacientes afectos de melanoma uveal por fechas de diagnóstico (modificado de Singh AD, Topham A. Survival rates with uveal melanoma in the United States: 1973-1997. Ophthalmology. 2003 May;110(5):962-5).

En el presente estudio, en una muestra de 118 pacientes, homogénea en cuanto a raza y origen, con un seguimiento medio de 51 meses (0-179 meses), y con tan solo 6 pérdidas de seguimiento, se ha observado una mortalidad global de16 pacientes $(13,55 \%)$ de los cuales tan solo $2(1,7 \%)$ fallecieron a causa del melanoma, y ninguno ellos pertenecía al grupo de tumores pequeños.

En el grupo de los pacientes con tumores medianos y en el de los grandes solo aparece un caso respectivamente de diseminación metástasica; si bien estos datos deben ser tomados con mas cautela por la menor proporción de sujetos incluidos, suponen una proporción muy baja que además está dentro de los limites que se han observado para lesiones que si reciben tratamiento (En los resultados del COMS 4 se presenta un 25\% de metástasis a los 5 años en pacientes tratados).

Esta ausencia de diseminación metastásica en los pacientes del grupo de los tumores pequeños es sin duda el hallazgo mas importante. El hecho de que a lo largo del seguimiento en estos pacientes no se observa enfermedad metastásica apoya contundentemente la seguridad de la observación como alternativa al tratamiento precoz de estas lesiones. 
Lane y cols. ${ }^{123}$ estudiaron una serie grande de tumores melanocíticos pequeños $(n=1063)$ entre los que incluye un grupo de 334 pacientes registrados entre los años 1976 a 1996, y que presentan características similares al grupo de tumores pequeños del presente trabajo $(0,5-2 \mathrm{~mm}$ altura y $<10 \mathrm{~mm}$ de base), encontrando sólo 2 fallecimientos a causa de melanoma $(0,6 \%)$ con un riesgo para metástasis a los 5,10 y 15 años de $0 \%, 1 \%$ y 3\% respectivamente. Estos datos coinciden con los de nuestro estudio, ya que con un seguimiento medio de casi 5 años no hemos encontrado ningun fallecimiento por metástasis de melanoma.

Por otra parte, el informe número 4 del $\mathrm{COMS}^{9}$, analizando la evolución de 204 pacientes con melanomas pequeños, con los mismos criterios de clasificación por tamaño que se han seguido en el presente estudio, encuentra una mortalidad global a los 5 y 8 años del $6 \%$ y 14,9\% respectivamente, pero tan solo $6(2.9 \%)$ pacientes fallecieron a causa de metástasis del melanoma, concluyendo que pacientes sanos de 60 años, con melanomas pequeños, tienen un bajo riesgo de fallecer a causa de la enfermedad. Las diferencias con respecto a la mortalidad global que en nuestro estudio ascienden hasta el $11 \%$ en tumores pequeños, se deben a que en nuestro caso, no ha habido una selección previa de pacientes que tuvieran como requisito el no padecer enfermedades crónicas ni haber sido tratados previemente por otros cánceres como en el COMS, pudiendo asimilar esta mortalidad a la de la población general de la muestra estudiada.

Shields y cols. ${ }^{11}$ estudiando una muestra de 1329 pacientes de origen norteamericano con lesiones melanociticas pequeñas con criterios de clasificación muy similares a los del COMS y por lo tanto a los de este estudio, con un seguimiento medio de 51 meses, encuentran metástasis en el 3\% de los sujetos, una cifra prácticamente igual a la del estudio del COMS, y de nuevo muy superior a los resultados del presente estudio.

De nuevo llaman la atención las diferencias observadas con otras series previamente publicadas, que estudian poblaciones de los Estados Unidos, donde la mortalidad específica en pacientes afectos de esta enfermedad es del tres por ciento a los cinco años en los estudios publicados por Shields y por el COMS (tabla 34). 
Tabla 34 Mortalidad por melanoma de coroides en pacientes con tumores clasificados como pequeños bajo observación

\begin{tabular}{|c|c|c|c|c|}
\hline & $\begin{array}{c}\text { Presente } \\
\text { estudio }\end{array}$ & $\begin{array}{c}\text { Shields y } \\
\text { cols. } 11\end{array}$ & CoMs n $\mathbf{4}^{\mathbf{4}}$ & $\begin{array}{c}\text { Lane } \mathbf{y} \\
\text { cols. 123 }\end{array}$ \\
\hline $\mathbf{N}$ & 91 & 1329 & 204 & 334 \\
\hline Muertes & 0 & $35(3 \%)$ & $6(3.1 \%)$ & 0 \\
\hline $\begin{array}{c}\text { Seguimiento } \\
\text { medio }\end{array}$ & 51.15 meses & 53 meses & 60 meses & 60 meses \\
\hline
\end{tabular}

En resumen en la muestra estudiada no se han encontrado fallecimientos a causa de melanoma en la muestra de tumores pequeños y tan solo una en la de medianos, apoyando estos resultados en este periodo de seguimiento la malignidad de estos tumores es muy baja y la observación es una alternativa terapeútica que no pone en riesgo la vida del paciente, pudiendo aplicar el tratamiento en los casos en que muestren signos de actividad o crecimiento.

Esta mortalidad parece menor que la publicada en estudios previos, puede ser porque la población es diferente en cuanto a características demográficas, pero hay que tener en consideración varios factores en la interpretación de estos datos. El primero, es que con mayor tiempo de seguimiento pueden aparecer fallecimientos atribuibles al melanoma, ya que la transformación maligna puede llevar décadas y la confirmación de estos resultados se vería reforzada con mayor tiempo de seguimiento. En segundo lugar, para poder afirmar que la observación no aumenta el riesgo de aparición de metástasis se debería realizar un ensayo clínico prospectivo randomizando a los pacientes a observación versus tratamiento. 


\section{8.- ALGORITMO DE MANEJO DE LAS LESIONES MELANOCITICAS PEQUEÑAS}

De los resultados obtenidos en este estudio en cuanto a seguridad en la observación de los tumores melanociticos coroideos pequeños se deduce que dichas lesiones pueden observarse si no hay evidencia de crecimiento (en cuyo caso deben ser tratadas inmediatamente) atendiendo a la presencia de los factores de riesgo estudiados:

- Presencia de pigmento naranja

- Presencia de fluido subretiniano

- Presencia de síntomas

- Cercania al nervio óptico $(\leq 3 \mathrm{~mm})$

- Espesor tumoral $\geq 2 \mathrm{~mm}$

La presencia de tres o más de estos signos supone un aumento del riesgo de crecimiento de la lesión que justifica la necesidad de tratamiento. En la figura 23 se presenta el algoritmo de decisión terapeútica que resume lo antes expuesto.

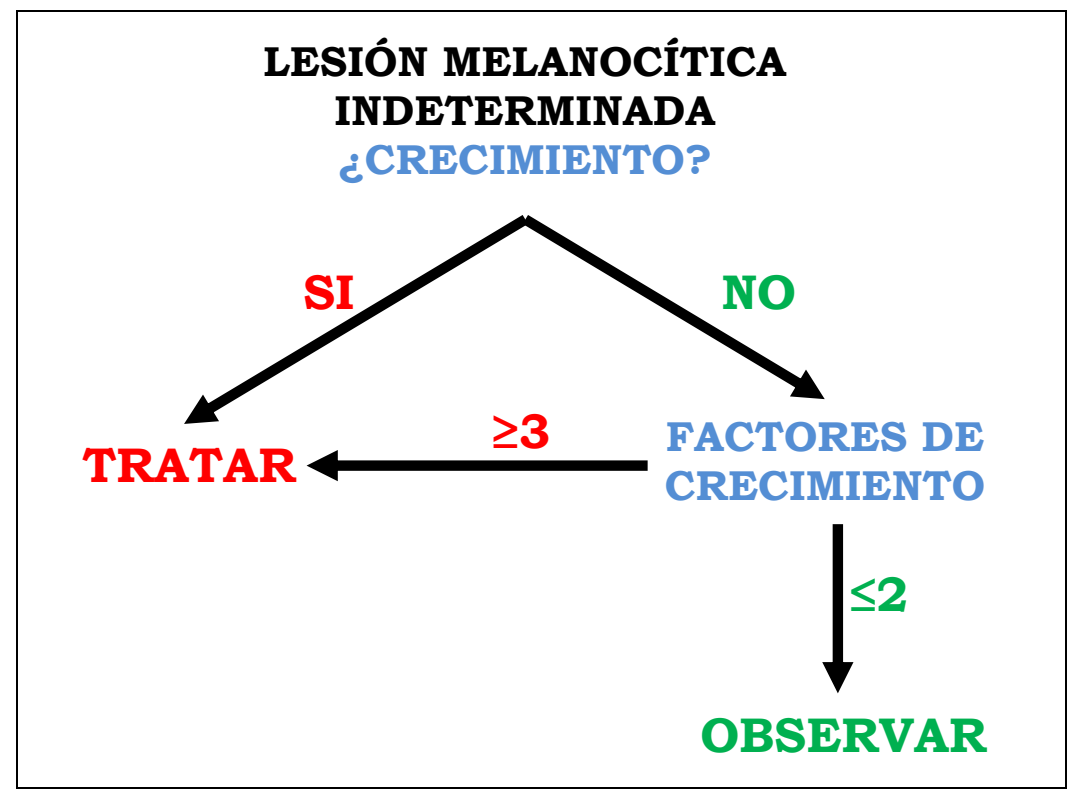

Figura 23: Algoritmo de decisión terapeútica en las lesiones melanociticas sospechosas. 


\section{CONCLUSIONES}

El análisis de los resultados obtenidos en el presente trabajo permite concluir:

1.- La observación sin tratamiento de los melanomas coroideos pequeños en la muestra estudiada cumple los siguientes objetivos terapéuticos:

a.- Control tumoral: la progresión o crecimiento de las lesiones vigiladas sin tratamiento es muy baja, similar a la que se consigue realizando tratamientos conservadores (braquiterapia, radioterapia externa con protones). Además los tumores pequeños crecen menos, y mucho más tarde que los medianos o los grandes

b.- Mantenimiento de la agudeza visual: los pacientes vigilados sin tratamiento conservan a lo largo del seguimiento una función visual mejor que los sometidos a tratamiento.

c.- Los lesiones coroideas melanocíticas indeterminadas y/o melanomas de tamaño pequeño, han mostrado un nivel de malignidad muy bajo, justificando la actitud de monitorización de estos tumores hasta que aparezcan signos de actividad/crecimiento interpretados como de transformación maligna.

2.- Los resultados del presente trabajo respecto de la progresión local de la enfermedad y de la diseminación sistémica difieren llamativamente de los anteriormente publicados en series de Norteamérica y el norte de Europa. En 
la presente serie el crecimiento de las lesiones pequeñas es menos frecuente y no aparece diseminación metastásica.

3.- Las variables identificadas como predictivas de crecimiento tumoral en esta muestra han sido la sintomatología visual y el pigmento naranja.

4.- En el presente estudio se ha detectado una mayor proporción de casos asintomáticos tanto en el grupo de los melanomas pequeños como en el de los medianos.

5.- Solamente la edad y la presencia de extensión extraocular y/o sistémica influyeron en la supervivencia del paciente. 


\section{TRABAJO FUTURO}

Los resultados del presente estudio pueden ser el punto de partida para estudiar en profundidad factores hasta ahora no estudiados, y probablemente asociados a condicionantes raciales, que hacen que los datos obtenidos difieran de los previamente publicados en series de pacientes provenientes del norte de Europa y de Estados Unidos.

Un seguimiento prolongado en el tiempo de los pacientes de la muestra permitirá asentar las conclusiones obtenidas en el presente estudio. 


\section{BIBLIOGRAFÍA}

1. Bell DJ, Wilson MW. Choroidal melanoma: natural history and management options. Cancer control journal of the Moffitt Cancer Center. 11(5):296-303.

2. McLean IW, Saraiva VS, Burnier MN. Pathological and prognostic features of uveal melanomas. Canadian journal of ophthalmology. Journal canadien d'ophtalmologie. 2004;39(4):343-50.

3. Kroll S, Char DH, Quivey J, Castro J. A comparison of cause-specific melanoma mortality and all-cause mortality in survival analyses after radiation treatment for uveal melanoma. Ophthalmology. 1998;105(11):20352045.

4. Anon. - Collaborative Ocular Melanoma Study Group. Development of metastatic disease after enrollment in the COMS trials for treatment of choroidal melanoma. Collaborative Ocular Melanoma Study Group Report No. 26.

5. Singh AD, Rennie IG, Kivela T, Seregard S, Grossniklaus H. The Zimmerman-McLean-Foster hypothesis: 25 years later. The British journal of ophthalmology. 2004;88(7):962-7.

6. Straatsma BR, Diener-West M, Caldwell R, Engstrom RE. Mortality after deferral of treatment or no treatment for choroidal melanoma. American journal of ophthalmology. 2003;136(1):47-54.

7. Shields CL, Shields JA. Clinical features of small choroidal melanoma. Current opinion in ophthalmology. 2002;13(3):135-41.

8. Anon. Factors predictive of growth and treatment of small choroidal melanoma: COMS Report No. 5. The Collaborative Ocular Melanoma Study Group. Archives of ophthalmology. 1997;115(12):1537-44.

9. Anon. Mortality in patients with small choroidal melanoma. COMS report no. 4. The Collaborative Ocular Melanoma Study Group. Archives of ophthalmology. 1997;115(7):886-93.

10. Gass JD. Observation of suspected choroidal and ciliary body melanomas for evidence of growth prior to enucleation. Ophthalmology. 1980;87(6):523-8.

11. Shields CL, Shields JA, Kiratli H, De Potter P, Cater JR. Risk factors for growth and metastasis of small choroidal melanocytic lesions. Ophthalmology. 1995; 102(9):1351-61. 
12. Shields CL, Furuta M, Berman EL, et al. Choroidal nevus transformation into melanoma: analysis of 2514 consecutive cases. Archives of ophthalmology. 2009;127(8):981-7.

13. Augsburger JJ. Is observation really appropriate for small choroidal melanomas. Transactions of the American Ophthalmological Society. 1993;91:147-68; discussion 169-75.

14. Chang AE, Karnell LH, Menck HR. The National Cancer Data Base report on cutaneous and noncutaneous melanoma: a summary of 84,836 cases from the past decade. The American College of Surgeons Commission on Cancer and the American Cancer Society. Cancer. 1998;83(8):1664-78.

15. Singh A. Incidence of uveal melanoma in the United States: 1973-1997. Ophthalmology. 2003;110(5):956-961.

16. Barzilai DA, Koroukian SM, Neuhauser D, et al. The sensitivity of Medicare data for identifying incident cases of invasive melanoma (United States). Cancer causes \& control : CCC. 2004;15(2):179-84.

17. Singh AD, Bergman L, Seregard S. Uveal melanoma: epidemiologic aspects. Ophthalmology clinics of North America. 2005;18(1):75-84, viii.

18. Bergman L, Seregard S, Nilsson B, et al. Incidence of uveal melanoma in Sweden from 1960 to 1998 . Investigative ophthalmology \& visual science. 2002;43(8):2579-83.

19. Strickland D, Lee JA. Melanomas of eye: stability of rates. American journal of epidemiology. 1981;113(6):700-2.

20. Egan KM, Seddon JM, Glynn RJ, Gragoudas ES, Albert DM. Epidemiologic aspects of uveal melanoma. Survey of ophthalmology. 32(4):239-51.

21. Hu D-N, Yu G-P, McCormick SA, Schneider S, Finger PT. Population-based incidence of uveal melanoma in various races and ethnic groups. American journal of ophthalmology. 2005;140(4):612-7.

22. Kaneko A. [Malignant ophthalmic tumors]. Nippon rinsho. Japanese journal of clinical medicine. 1993;51 Suppl:1013-20.

23. Muiños Díaz Y, Saornil MA, Almaraz A, et al. Iris color: validation of a new classification and distribution in a Spanish population-based sample. European journal of ophthalmology. 19(4):686-9.

24. Yanoff M, Zimmerman LE. Histogenesis of malignant melanomas of the uvea. II. Relationship of uveal nevi to malignant melanomas. Cancer. 1967;20(4):493-507.

25. Sahel JA, Pesavento R, Frederick AR, Albert DM. Melanoma arising de novo over a 16-month period. Archives of ophthalmology. 1988;106(3):381-5.

26. Singh AD, Kalyani $\mathrm{P}$, Topham A. Estimating the risk of malignant transformation of a choroidal nevus. Ophthalmology. 2005;112(10):1784-9. 
27. Singh AD, Donoso LA, Jackson L, et al. Familial uveal melanoma: absence of constitutional cytogenic abnormalities in 14 cases. Archives of ophthalmology. 1996;114(4):502-3.

28. Singh AD, Shields CL, Shields JA, Sato T. Uveal melanoma in young patients. Archives of ophthalmology. 2000;118(7):918-23.

29. Verdaguer J. Prepuberal and puberal melanomas in ophthalmology. American journal of ophthalmology. 1965;60(6):1002-11.

30. Shammas HF, Watzke RC. Bilateral choroidal melanomas. Case report and incidence. Archives of ophthalmology. 1977;95(4):617-23.

31. Singh AD, Shields CL, Shields JA, De Potter P. Bilateral primary uveal melanoma. Bad luck or bad genes? Ophthalmology. 1996;103(2):256-62.

32. López-Caballero C, Saornil-Alvarez MA, Blanco-Mateos G, et al. [Choroidal melanoma in ocular melanosis]. Archivos de la Sociedad Española de Oftalmología. 2003;78(2):99-102.

33. Carreño E, Saornil MA, Garcia-Alvarez C, et al. Prevalence of ocular and oculodermal melanocytosis in Spanish population with uveal melanoma. Eye (London, England). 2011.

34. Bataille V, Sasieni P, Cuzick J, et al. Risk of ocular melanoma in relation to cutaneous and iris naevi. International journal of cancer. Journal international du cancer. 1995;60(5):622-6.

35. Folberg R. The familial occurrence of cutaneous melanoma, intraocular melanoma, and the dysplastic nevus syndrome. American journal of ophthalmology. 1983;96(6):815-6.

36. Ohta M, Nagai $H$, Shimizu $M$, et al. Rarity of somatic and germline mutations of the cyclin-dependent kinase 4 inhibitor gene, CDK4I, in melanoma. Cancer research. 1994;54(20):5269-72.

37. Honavar SG, Singh AD, Shields CL, Shields JA, Eagle RC. Iris melanoma in a patient with neurofibromatosis. Survey of ophthalmology. 45(3):231-6.

38. Singh AD, Damato B, Howard P, Harbour JW. Uveal melanoma: genetic aspects. Ophthalmology clinics of North America. 2005;18(1):85-97, viii.

39. Turner BJ, Siatkowski RM, Augsburger JJ, et al. Other cancers in uveal melanoma patients and their families. American journal of ophthalmology. 1989;107(6):601-8.

40. Caminal JM, Martínez J, Arias LL, et al. [Multiple neoplasms in patients with uveal melanoma]. Archivos de la Sociedad Española de Oftalmología. 2007;82(9):535-40.

41. Holly EA, Aston DA, Ahn DK, Kristiansen JJ, Char DH. No excess prior cancer in patients with uveal melanoma. Ophthalmology. 1991;98(5):608-11. 
42. Singh AD, Rennie IG, Seregard S, Giblin M, McKenzie J. Sunlight exposure and pathogenesis of uveal melanoma. Survey of ophthalmology. 49(4):419-28.

43. Shah CP, Weis E, Lajous M, Shields JA, Shields CL. Intermittent and chronic ultraviolet light exposure and uveal melanoma: a meta-analysis. Ophthalmology. 2005;112(9):1599-607.

44. Ajani UA, Seddon JM, Hsieh CC, et al. Occupation and risk of uveal melanoma. An exploratory study. Cancer. 1992;70(12):2891-900.

45. Group COMS. COMS Manual of Procedures National Technical Information Service. Springfield, VA; 1995.

46. Kujala E, Kivelä T. Tumor, node, metastasis classification of malignant ciliary body and choroidal melanoma evaluation of the 6th edition and future directions. Ophthalmology. 2005;112(6):1135-44.

47. Pach JM, Robertson DM, Taney BS, et al. Prognostic factors in choroidal and ciliary body melanomas with extrascleral extension. American journal of ophthalmology. 1986;101(3):325-31.

48. Char DH, Stone RD, Crawford JB, et al. Diffuse melanoma of the choroid. The British journal of ophthalmology. 1980;64(3):178-80.

49. Mooy CM, De Jong PT. Prognostic parameters in uveal melanoma: a review. Survey of ophthalmology. 41(3):215-28.

50. McLean IW, Foster WD, Zimmerman LE, Martin DG. Inferred natural history of uveal melanoma. Investigative ophthalmology \& visual science. 1980;19(7):760-70.

51. Zakka KA, Foos RY, Omphroy CA, Straatsma BR. Malignant melanoma. Analysis of an autopsy population. Ophthalmology. 1980;87(6):549-56.

52. Kujala E, Mäkitie T, Kivelä T. Very long-term prognosis of patients with malignant uveal melanoma. Investigative ophthalmology \& visual science. 2003;44(11):4651-9.

53. Kath R, Hayungs J, Bornfeld N, et al. Prognosis and treatment of disseminated uveal melanoma. Cancer. 1993;72(7):2219-23.

54. Lane AM, Egan KM, Harmon D, et al. Adjuvant interferon therapy for patients with uveal melanoma at high risk of metastasis. Ophthalmology. 2009; $116(11): 2206-12$.

55. Shammas HF, Blodi FC. Prognostic factors in choroidal and ciliary body melanomas. Archives of ophthalmology. 1977;95(1):63-9.

56. Augsburger JJ, Gamel JW. Clinical prognostic factors in patients with posterior uveal malignant melanoma. Cancer. 1990;66(7):1596-600. 
57. Char DH, Kroll S, Phillips TL. Uveal melanoma. Growth rate and prognosis. Archives of ophthalmology. 1997;115(8):1014-8.

58. Kaiserman I, Anteby I, Chowers I, et al. Post-brachytherapy initial tumour regression rate correlates with metastatic spread in posterior uveal melanoma. The British journal of ophthalmology. 2004;88(7):892-5.

59. Folberg R, Salomao D, Grossniklaus HE, et al. Recommendations for the reporting of tissues removed as part of the surgical treatment of common malignancies of the eye and its adnexa. The Association of Directors of Anatomic and Surgical Pathology. Human pathology. 2003;34(2):114-8.

60. GR C. Malignant melanotic tumors of the eye: a study of histologic types in 111 cases. Trans Am Acad Ophthalmol Otolaryngol. 1931;36:131-142.

61. McLean IW, Zimmerman LE, Evans RM. Reappraisal of Callender's spindle a type of malignant melanoma of choroid and ciliary body. American journal of ophthalmology. 1978;86(4):557-64.

62. Pe'er J, Gnessin H, Shargal Y, Livni N. PC-10 immunostaining of proliferating cell nuclear antigen in posterior uveal melanoma. Enucleation versus enucleation postirradiation groups. Ophthalmology. 1994;101(1):56-62.

63. Cruz PO de la, Specht CS, McLean IW. Lymphocytic infiltration in uveal malignant melanoma. Cancer. 1990;65(1):112-5.

64. Folberg R, Rummelt V, Parys-Van Ginderdeuren R, et al. The prognostic value of tumor blood vessel morphology in primary uveal melanoma. Ophthalmology. 1993;100(9):1389-98.

65. Damato B, Duke C, Coupland SE, et al. Cytogenetics of uveal melanoma: a 7-year clinical experience. Ophthalmology. 2007;114(10):1925-31.

66. Damato B, Coupland SE. Translating uveal melanoma cytogenetics into clinical care. Archives of ophthalmology. 2009;127(4):423-9.

67. Anon. Accuracy of diagnosis of choroidal melanomas in the Collaborative Ocular Melanoma Study. COMS report no. 1. Archives of ophthalmology. 1990;108(9): 1268-73.

68. Scott IU, Murray TG, Hughes JR. Evaluation of imaging techniques for detection of extraocular extension of choroidal melanoma. Archives of ophthalmology. 1998;116(7):897-9.

69. Verbeek AM, Thijssen JM, Cuypers MH, Brink H, Deutman AF. Echographic classification of intraocular tumours. A 15-year retrospective analysis. Acta ophthalmologica. 1994;72(4):416-22.

70. Coleman DJ. Ocular tumor patterns. Bibliotheca ophthalmologica : supplementa ad ophthalmologica. 1975;(83):136-40.

71. Lieb WE, Shields JA, Cohen SM, et al. Color Doppler imaging in the management of intraocular tumors. Ophthalmology. 1990;97(12):1660-4. 
72. Conway RM, Chew T, Golchet $\mathrm{P}$, et al. Ultrasound biomicroscopy: role in diagnosis and management in 130 consecutive patients evaluated for anterior segment tumours. The British journal of ophthalmology. 2005;89(8):950-5.

73. Char DH, Stone RD, Irvine AR, et al. Diagnostic modalities in choroidal melanoma. American journal of ophthalmology. 1980;89(2):223-30.

74. Sallet G, Amoaku WM, Lafaut BA, Brabant P, De Laey JJ. Indocyanine green angiography of choroidal tumors. Graefe's archive for clinical and experimental ophthalmology $=$ Albrecht von Graefes Archiv für klinische und experimentelle Ophthalmologie. 1995;233(11):677-89.

75. Shields CL, Shields JA, De Potter P. Patterns of indocyanine green videoangiography of choroidal tumours. The British journal of ophthalmology. 1995;79(3):237-45.

76. Muscat S, Parks S, Kemp E, Keating D. Secondary retinal changes associated with choroidal naevi and melanomas documented by optical coherence tomography. The British journal of ophthalmology. 2004;88(1):1204.

77. Materin MA, Raducu R, Bianciotto C, Shields CL. Fundus autofluorescence and optical coherence tomography findings in choroidal melanocytic lesions. Middle East African journal of ophthalmology. 2010;17(3):201-6.

78. Mafee MF, Peyman GA, McKusick MA. Malignant uveal melanoma and similar lesions studied by computed tomography. Radiology. 1985;156(2):4038.

79. Bond JB, Haik BG, Mihara F, Gupta KL. Magnetic resonance imaging of choroidal melanoma with and without gadolinium contrast enhancement. Ophthalmology. 1991;98(4):459-66.

80. Singh AD, Bhatnagar P, Bybel B. Visualization of primary uveal melanoma with PET/CT scan. Eye (London, England). 2006;20(8):938-40.

81. Lorigan JG, Wallace S, Mavligit GM. The prevalence and location of metastases from ocular melanoma: imaging study in 110 patients. AJR. American journal of roentgenology. 1991;157(6):1279-81.

82. Shields JA. Lesions simulating malignant melanoma of the posterior uvea. Archives of ophthalmology. 1973;89(6):466-71.

83. Ferry AP. Lesions mistaken for malignant melanoma of the posterior uvea. A clinicopathologic analysis of 100 cases with ophthalmoscopically visible lesions. Archives of ophthalmology. 1964;72:463-9.

84. Augsburger JJ, Corrêa ZM, Schneider S, et al. Diagnostic transvitreal fineneedle aspiration biopsy of small melanocytic choroidal tumors in nevus versus melanoma category. Transactions of the American Ophthalmological Society. 2002;100:225-32 
85. Augsburger JJ, Coats TD, Lauritzen K. Localized suprachoroidal hematomas. Ophthalmoscopic features, fluorescein angiography, and clinical course. Archives of ophthalmology. 1990;108(7):968-72.

86. Bardenstein DS, Char DH, Irvine AR, Stone RD. Extramacular disciform lesions simulating uveal tumors. Ophthalmology. 1992;99(6):944-51.

87. Shields CL, Shields JA, Gross NE, Schwartz GP, Lally SE. Survey of 520 eyes with uveal metastases. Ophthalmology. 1997;104(8):1265-76.

88. Sobottka B, Schlote T, Krumpaszky HG, Kreissig I. Choroidal metastases and choroidal melanomas: comparison of ultrasonographic findings. The British journal of ophthalmology. 1998;82(2):159-61.

89. Shields JA, Font RL. Melanocytoma of the choroid clinically simulating a malignant melanoma. Archives of ophthalmology. 1972;87(4):396-400.

90. Hungerford JL. Management of ocular melanoma. British medical bulletin. 1995;51(3):694-716.

91. Hykin PG, McCartney AC, Plowman PN, Hungerford JL. Postenucleation orbital radiotherapy for the treatment of malignant melanoma of the choroid with extrascleral extension. The British journal of ophthalmology. 1990;74(1):36-9.

92. Zimmerman LE, McLean IW, Foster WD. Does enucleation of the eye containing a malignant melanoma prevent or accelerate the dissemination of tumour cells. The British journal of ophthalmology. 1978;62(6):420-5.

93. Moore RF. Choroidal sarcoma treated by the intraocular insertion of radon seeds. The British journal of ophthalmology. 1930;14(4):145-52.

94. Astrahan MA, Szechter A, Finger PT. Design and dosimetric considerations of a modified COMS plaque: the reusable "seed-guide" insert. Medical physics. 2005;32(8):2706-16.

95. Nath R, Anderson LL, Luxton G, et al. Dosimetry of interstitial brachytherapy sources: recommendations of the AAPM Radiation Therapy Committee Task Group No. 43. American Association of Physicists in Medicine. Medical physics. 1995;22(2):209-34.

96. Anon. The Collaborative Ocular Melanoma Study (COMS) randomized trial of pre-enucleation radiation of large choroidal melanoma I: characteristics of patients enrolled and not enrolled. COMS report no. 9. American journal of ophthalmology. 1998;125(6):767-78.

97. Puusaari I, Heikkonen J, Summanen P, Tarkkanen A, Kivelä T. Iodine brachytherapy as an alternative to enucleation for large uveal melanomas. Ophthalmology. 2003;110(11):2223-34.

98. Lommatzsch PK, Kirsch IH. 106Ru/106Rh plaque radiotherapy for malignant melanomas of the choroid. With follow-up results more than 5 
years. Documenta ophthalmologica. Advances in ophthalmology. 68(3-4):22538.

99. Gündüz K, Shields CL, Shields JA, et al. Radiation retinopathy following plaque radiotherapy for posterior uveal melanoma. Archives of ophthalmology. 1999;117(5):609-14.

100. Gragoudas ES, Goitein M, Verhey L, et al. Proton beam irradiation. An alternative to enucleation for intraocular melanomas. Ophthalmology. 1980;87(6):571-81.

101. Zorlu F, Selek U, Kiratli H. Initial results of fractionated CyberKnife radiosurgery for uveal melanoma. Journal of neuro-oncology. 2009;94(1):1117.

102. Papaefthymiou G, Guss H, with Langmann G, Pendl G, Klaus-Müllner. Gamma knife radiosurgery for uveal melanomas: an 8-year experience. Journal of neurosurgery. 2000;93 Suppl 3:184-8.

103. Weber DC, Bogner J, Verwey J, et al. Proton beam radiotherapy versus fractionated stereotactic radiotherapy for uveal melanomas: A comparative study. International journal of radiation oncology, biology, physics. 2005;63(2):373-84.

104. Petersch B, Bogner J, Dieckmann K, Pötter R, Georg D. Automatic realtime surveillance of eye position and gating for stereotactic radiotherapy of uveal melanoma. Medical physics. 2004;31(12):3521-7.

105. Anon. Histopathologic characteristics of uveal melanomas in eyes enucleated from the Collaborative Ocular Melanoma Study. COMS report no. 6. American journal of ophthalmology. 1998;125(6):745-66.

106. Damato B, Lecuona K. Conservation of eyes with choroidal melanoma by a multimodality approach to treatment: an audit of 1632 patients. Ophthalmology. 2004;111(5):977-83.

107. Damato B, Groenewald C, McGalliard J, Wong D. Endoresection of choroidal melanoma. The British journal of ophthalmology. 1998;82(3):213-8.

108. Damato B, Wong D, Green FD, Mackenzie JM. Intrascleral recurrence of uveal melanoma after transretinal "endoresection". The British journal of ophthalmology. 2001;85(1):114-5.

109. Bechrakis NE, Höcht S, Martus P, et al. [Endoresection following proton beam irradiation of large uveal melanomas]. Der Ophthalmologe : Zeitschrift der Deutschen Ophthalmologischen Gesellschaft. 2004;101(4):370-6.

110. Singh AD, Kivelä T, Seregard S, Robertson D, Bena JF. Primary transpupillary thermotherapy of "small" choroidal melanoma: is it safe? The British journal of ophthalmology. 2008;92(6):727-8. 
111. Seregard S, Landau I. Transpupillary thermotherapy as an adjunct to ruthenium plaque radiotherapy for choroidal melanoma. Acta ophthalmologica Scandinavica. 2001;79(1):19-22.

112. Mims JL, Shields JA. Follow-up studies of suspicious choroidal nevi. Ophthalmology. 1978;85(9):929-43.

113. Shields CL, Cater J, Shields JA, et al. Combination of clinical factors predictive of growth of small choroidal melanocytic tumors. Archives of ophthalmology. 2000;118(3):360-4.

114. Singh AD, Mokashi AA, Bena JF, et al. Small choroidal melanocytic lesions: features predictive of growth. Ophthalmology. 2006;113(6):1032-9.

115. Lavinsky D, Belfort RN, Navajas E, et al. Fundus autofluorescence of choroidal nevus and melanoma. The British journal of ophthalmology. 2007;91(10):1299-302.

116. Singh $A D$, Topham A. Incidence of uveal melanoma in the United States: 1973-1997. Ophthalmology. 2003;110(5):956-61.

117. Virgili G, Gatta G, Ciccolallo L, et al. Incidence of uveal melanoma in Europe. Ophthalmology. 2007;114(12):2309-15.

118. Keeney AH, Waddell WJ, Perraut TC. Carcinogenesis and nicotine in malignant melanoma of the choroid. Transactions of the American Ophthalmological Society. 1982;80:131-42.

119. Diener-West M, Reynolds SM, Agugliaro DJ, et al. Second primary cancers after enrollment in the COMS trials for treatment of choroidal melanoma: COMS Report No. 25. Archives of ophthalmology. 2005;123(5):6014.

120. Saornil MA. Iris colour and uveal melanoma. Canadian journal of ophthalmology. Journal canadien d'ophtalmologie. 2004;39(4):448-52.

121. Fernández Sañudo M. [Risk factors of small choroidal melanocytic lesions]. Archivos de la Sociedad Española de Oftalmología. 2000;75(6):40916.

122. Jones R, Gore E, Mieler W, et al. Posttreatment visual acuity in patients treated with episcleral plaque therapy for choroidal melanomas: dose and dose rate effects. International journal of radiation oncology, biology, physics. 2002;52(4):989-95.

123. Lane AM, Egan KM, Kim IK, Gragoudas ES. Mortality after diagnosis of small melanocytic lesions of the choroid. Arch Ophthalmol. 2010 Aug;128(8):996-1000. 
Modelo de consentimiento informado. 


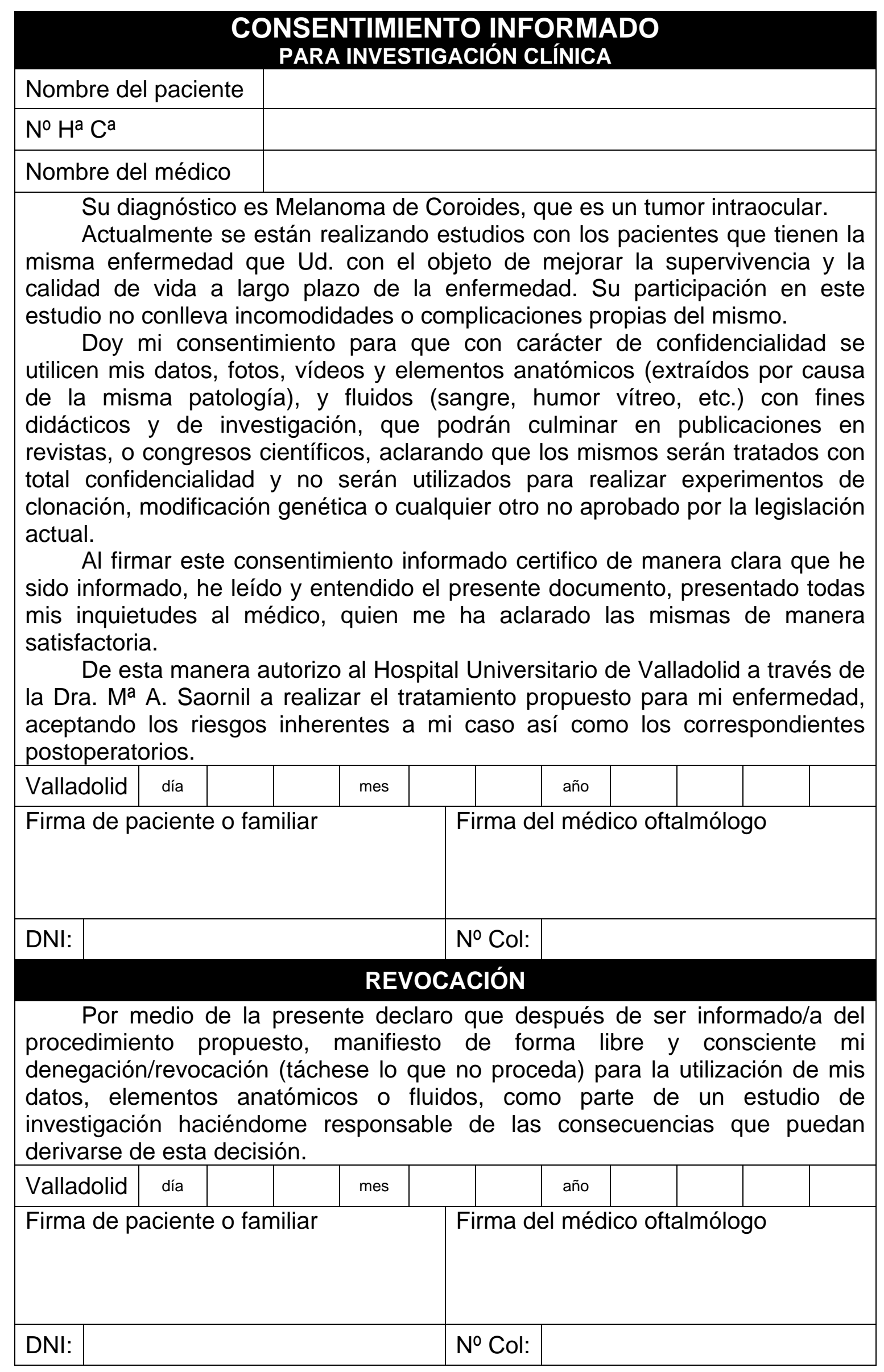


Modelo de formulario de recogida de datos. 


\section{PROTOCOLO DE MELANOMA UVEAL - HCUV}

$\mathrm{N}^{0}$ de registro

$\mathrm{N}^{0}$ de $\mathrm{H}^{\mathrm{a}}$ Clínica

\section{DATOS PERSONALES}

\section{Apellidos}

Nombre

Fecha Nacimiento

Dirección

Prov.

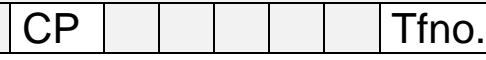

\section{ANTECEDENTES GENERALES}

Exposición solar

Cáncer cutáneo

Otros cánceres

Inmunosupresión

Depresión (activa en tto)

A. familiares de melanoma

Tabaco

No (0)

$<10(1)$

$10-20(2)$

\begin{tabular}{|l|l|l|} 
Sexo & V (0) & M (1) \\
\hline
\end{tabular}

ANTECEDENTES OFTALMOLOGICOS QUE AFECTAN A AV

\begin{tabular}{|l|c|c|c|c|c|c|}
\hline Patología & \multicolumn{2}{|c|}{ Afecto } & \multicolumn{2}{c|}{ Adelfo } & Af. & Ad. \\
\hline Ambliopía & $\mathrm{Si}(1)$ & No (0) & $\mathrm{Si}(1)$ & No (0) & & \\
\hline DMAE & $\mathrm{Si}(1)$ & No (0) & $\mathrm{Si}(1)$ & No (0) & & \\
\hline Glaucoma & $\mathrm{Si}(1)$ & No (0) & $\mathrm{Si}(1)$ & No (0) & & \\
\hline Catarata & $\mathrm{Si}(1)$ & No (0) & $\mathrm{Si}(1)$ & No (0) & & \\
\hline Ret. Diabética & $\mathrm{Si}(1)$ & No (0) & $\mathrm{Si}(1)$ & No (0) & & \\
\hline Otros & \multicolumn{7}{|l|}{} \\
\hline
\end{tabular}

\section{DATOS CLINICOS}

Inicio Síntomas

Fecha diagnóstico

\begin{tabular}{|l|l|l|l|l|l|l}
\hline Día & & & Mes & & & \\
\hline & Día & & & Mes & & \\
\hline
\end{tabular}

Motivo del diagnóstico

Tumor recidivado

Tratamiento previo

Cirugia (1) $\quad$ Protones (2) $\quad$ Enuclea. (3)

\begin{tabular}{|l|l|l}
\hline Año & \\
\hline Año &
\end{tabular}

Rev. Rutin.(1)

Sint. Visual(2)

Si (1) $\quad$ No (0)

\section{EXPLORACION}

Lateralidad

OD (1)

Agudeza visual(afecto) (0,1- 2; 0.01: contar dedos; 0.005: mov manos; 0.001: luz; 0: nada)

Agudeza visual(adelfo) (0,1- 2; 0.01: contar dedos; 0.005: mov manos; 0.001: luz; 0: nada)

PIO (afecto)

PIO (adelfo)

BPA

Color del iris Marrón (1) $\quad$ Verd-avell (2) Invasión iris

Rubeosis

Afectación cristalino

Hemovítreo

Otras

Gonioscopia

Invasión angular

Si (1) $\mathrm{No}(0)$ 


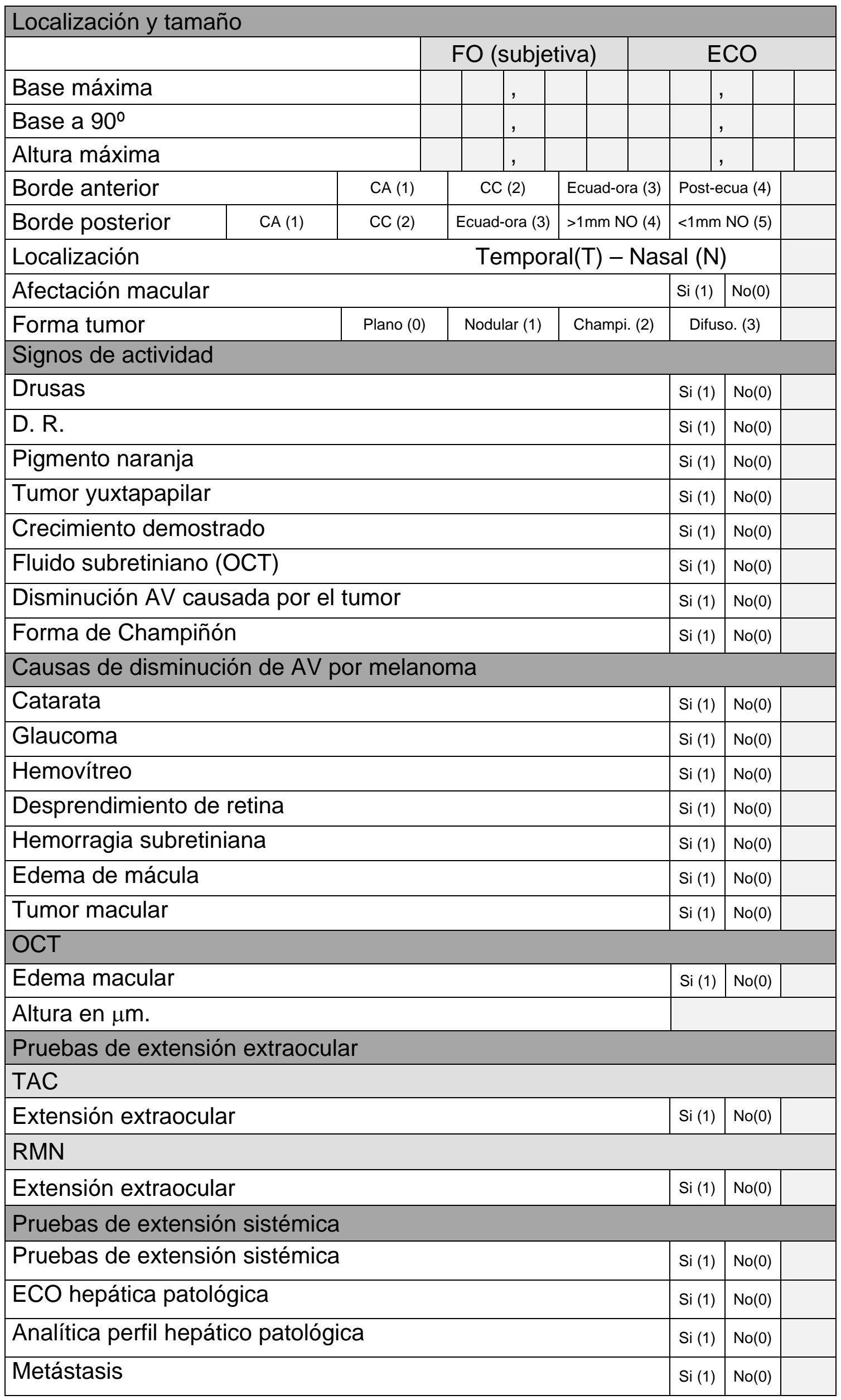


Tamaño

Localización

Actividad

Extensión extraocular

Extensión sistémica

Melanótico

Clasificación TNM

\begin{tabular}{|c|c|c|c|c|c|}
\hline Pequeño (0) & Mediano (1) & \multicolumn{2}{|c|}{ Grande (2) } & \\
\hline Coroides (0) & CC (1) & \multicolumn{2}{|c|}{ Iris (2) } & \\
\hline & & Si (1) & No(0) & \\
\hline & Si (1) & No(0) & \\
\hline & Si (1) & No(0) & \\
\hline
\end{tabular}

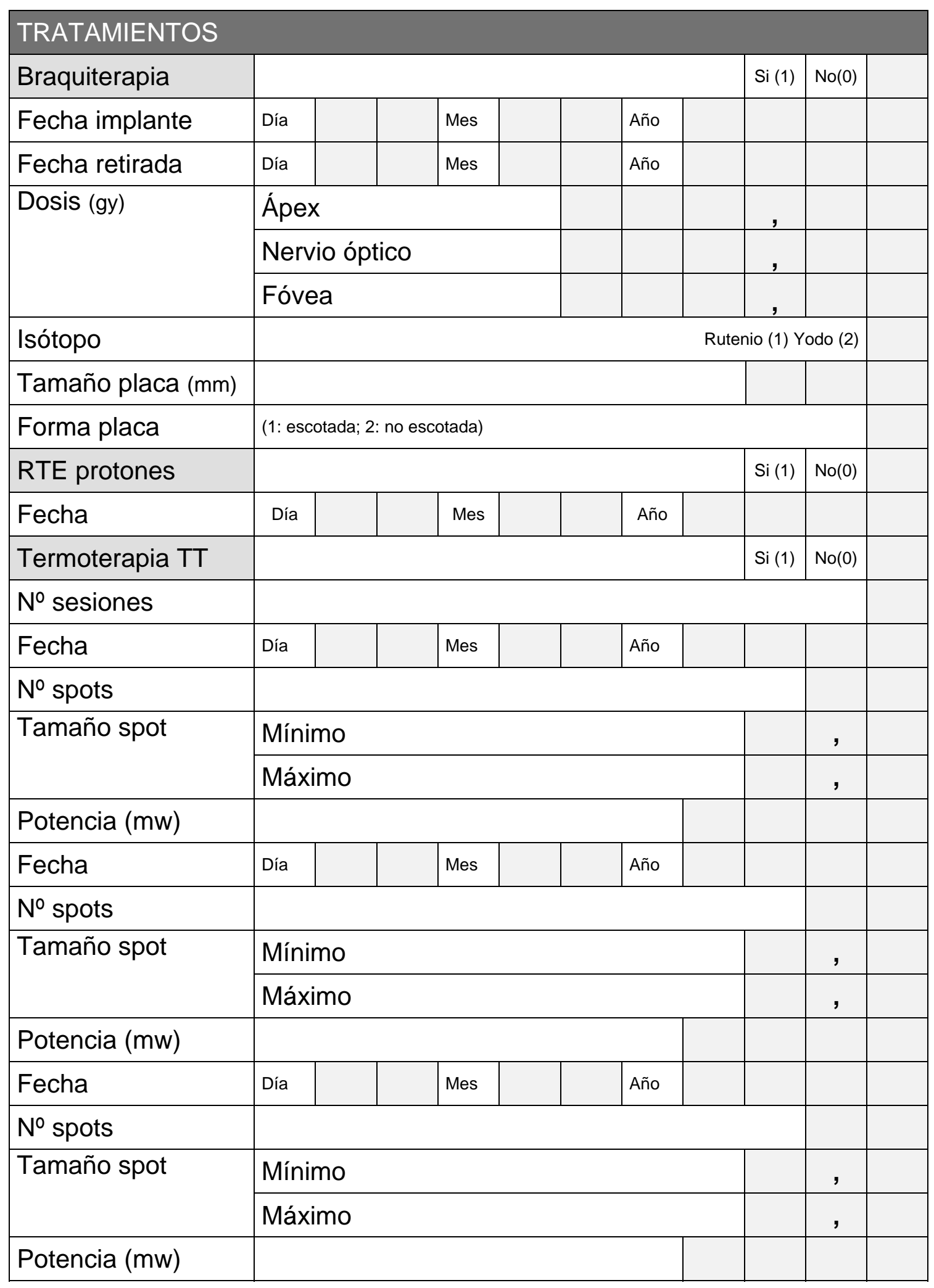




\begin{tabular}{|c|c|c|c|c|c|c|}
\hline Resección Qca. & & & & & $\mathrm{Si}(1)$ & No(0) \\
\hline Fecha & Día & $\mathrm{Me}$ & & Año & & \\
\hline Enucleación & & No(0) & $\operatorname{Sin} \mathrm{RT}$ & Con & \multicolumn{2}{|c|}{$\begin{array}{l}\text { Centro de } \\
\text { origen(3) }\end{array}$} \\
\hline Fecha & Día & $\mathrm{Me}$ & & Año & & \\
\hline Observación & & & & & Si (1) & No(0) \\
\hline Fecha & Día & $\mathrm{Me}$ & & Año & & \\
\hline Causa & Pequ & v (1) Rechaz & o (2) Edad a & zada ( & $\mathrm{o}(4) \mathrm{N}$ & EG (5) \\
\hline
\end{tabular}

\begin{tabular}{|l|l|l|l|l|l|l|l|l|l|l|l|}
\hline RECIDIVA \\
\hline Fecha & Día & & & Mes & & & Año & & & & \\
\hline
\end{tabular}

\begin{tabular}{|l|c|c|c|c|c|c|c|c|c|c|c|}
\hline ENUCLEACION SECUNDARIA \\
\hline Fecha & Día & & & Mes & & & Año & & & & \\
\hline Motivo & \multicolumn{7}{|c|}{ Recidiva (1) Efectos secundarios (2) } & \\
\hline
\end{tabular}

\section{METASTASIS}

\begin{tabular}{|l|l|l|l|l|l|l|l|l|l|l|l|}
\hline Fecha & Día & & & Mes & & & Año & & & & \\
\hline
\end{tabular}

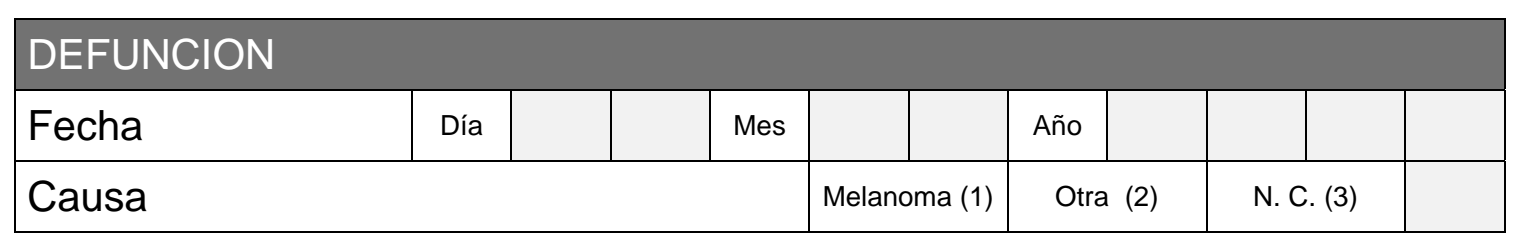


ANATOMIA PATOLOGICA

$\mathrm{N}^{\circ}$ de biopsia

Tamaño

Descripción macroscópica

Diámetro basal

Altura

Preparación

Base

Altura

Localización

Del tumor

Iris

Malla trabecular

Cuerpo ciliar

Entre ora y ecuador

Ecuador

Entre ecuador y papila

Del margen anterior

Tipo celular (\%)

Névicas

Fusiforme A

Fusiforme B

Epitelioides

Clasificación

Fusifor. (1)

Mixto (2)

Epitel. (3)

N.C. (4)

Mitosis

$\mathrm{N}^{\circ}$ en $10 \mathrm{HPF} \times 40$

Indice Proliferativo (Mib-1)

Otras características

Tipo infiltrativo/difuso

Membrana de Bruch rota

Invasión de retina

Desprendimiento de retina

Células tumorales en vítreo

Invasión de venas vorticosas

Invasión en canal emisario

Localización yuxtapapilar

\begin{tabular}{|l|l|l|l|l|l|l|l|l|l|l|l|l|}
\hline \multicolumn{2}{|l|}{} & & \\
\hline
\end{tabular}

Invasión del nervio óptico
(0) No
(1) Anterior a lámina cribosa
(2) Lámina cribosa
(3) Detrás de lámina cribosa
(9) No determinable

\section{Extensión extraescleral}

(0) No

(1) Esclera sin llegar a superficie

(2) Superficie escleral

(3) Extensión extraescleral sin transección

(4) Extensión extraescleral con residuo orbitario presumible

\begin{tabular}{|c|c|c|c|c|}
\hline Inflamación & No o mínima (0) & Moderada (1) & \multicolumn{2}{|c|}{ Marcada (2) } \\
\hline Pigmentación & No o mínima (0) & \multicolumn{2}{|c|}{ Moderada (1) } & rcada (2) \\
\hline Necrosis & No (0) & $<10 \%(1)$ & $10-50 \%(2)$ & $>50 \%(3)$ \\
\hline
\end{tabular}




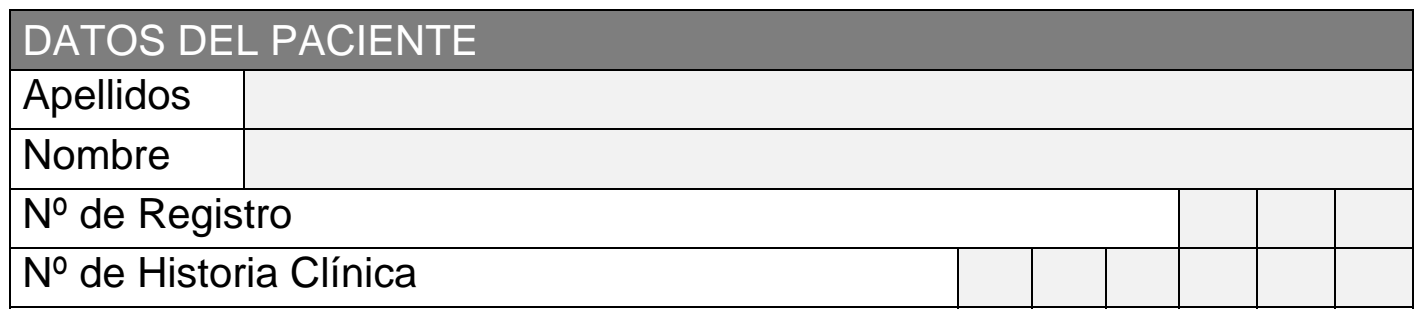

\begin{tabular}{|l|l|l|}
\hline DOSIMETRIA \\
\hline Dosis en PTV y órganos de riesgo & Tasa de dosis (cGy/h) & Dosis (Gy) \\
\hline & & \\
\hline Ápex & & \\
\hline Esclera & & \\
\hline Nervio óptico & & \\
\hline Cristalino & & \\
\hline Centro del globo & \\
\hline Mácula & \\
\hline COMS & \\
\hline Datos del PTV & \\
\hline Tamaño radial (mm) & \\
\hline Tamaño transversal (mm) & \\
\hline Altura (mm) & \\
\hline Superficie ocupada (mm $\left.{ }^{2}\right)$ & \\
\hline Volumen (cm $\left.{ }^{3}\right)$ & \\
\hline Posición radial ( $\left.{ }^{\circ}\right)$ & \\
\hline Posición transversal (hh:mm) & \\
\hline Distancia mácula-tumor (mm) & \\
\hline Distancia nervio óptico-tumor (mm) & \\
\hline Datos de la aplicación & \\
\hline Isotopo & \\
\hline Tipo de aplicador & \\
\hline Nombre del aplicador & \\
\hline Tamaño & \\
\hline$N^{0}$ de fuentes & \\
\hline Actividad & \\
\hline Duración del implante & \\
\hline
\end{tabular}




\begin{tabular}{|c|c|c|c|c|c|c|c|c|c|c|c|c|}
\hline ô & $\frac{\widehat{O}}{\mathrm{O}}$ & $\begin{array}{l}\widehat{\mathrm{o}} \\
\mathrm{o}\end{array}$ & 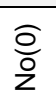 & $\begin{array}{l}\widehat{O} \\
\text { o }\end{array}$ & $\begin{array}{l}\widehat{\mathrm{O}} \\
\mathrm{O}\end{array}$ & $\begin{array}{l}\widehat{o} \\
\text { o }\end{array}$ & $\begin{array}{l}\widehat{\mathrm{o}} \\
\mathrm{o}\end{array}$ & $\begin{array}{l}\widehat{O} \\
\frac{0}{z}\end{array}$ & $\begin{array}{l}\widehat{O} \\
\text { o } \\
z\end{array}$ & $\frac{\widehat{o}}{\mathrm{o}}$ & $\frac{\widehat{o}}{\mathrm{o}}$ & \\
\hline 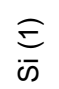 & $\vec{\Xi}$ & $\frac{\Xi}{i n}$ & $\frac{\Xi}{\bar{\omega}}$ & $\underset{\bar{n}}{\bar{a}}$ & $\frac{\Xi}{\bar{\omega}}$ & $\frac{\Xi}{\bar{\omega}}$ & $\overrightarrow{\bar{\theta}}$ & $\frac{\vec{E}}{\bar{n}}$ & $\frac{\bar{\theta}}{\bar{n}}$ & $\frac{\Xi}{\bar{n}}$ & $\frac{\Xi}{i n}$ & \\
\hline
\end{tabular}
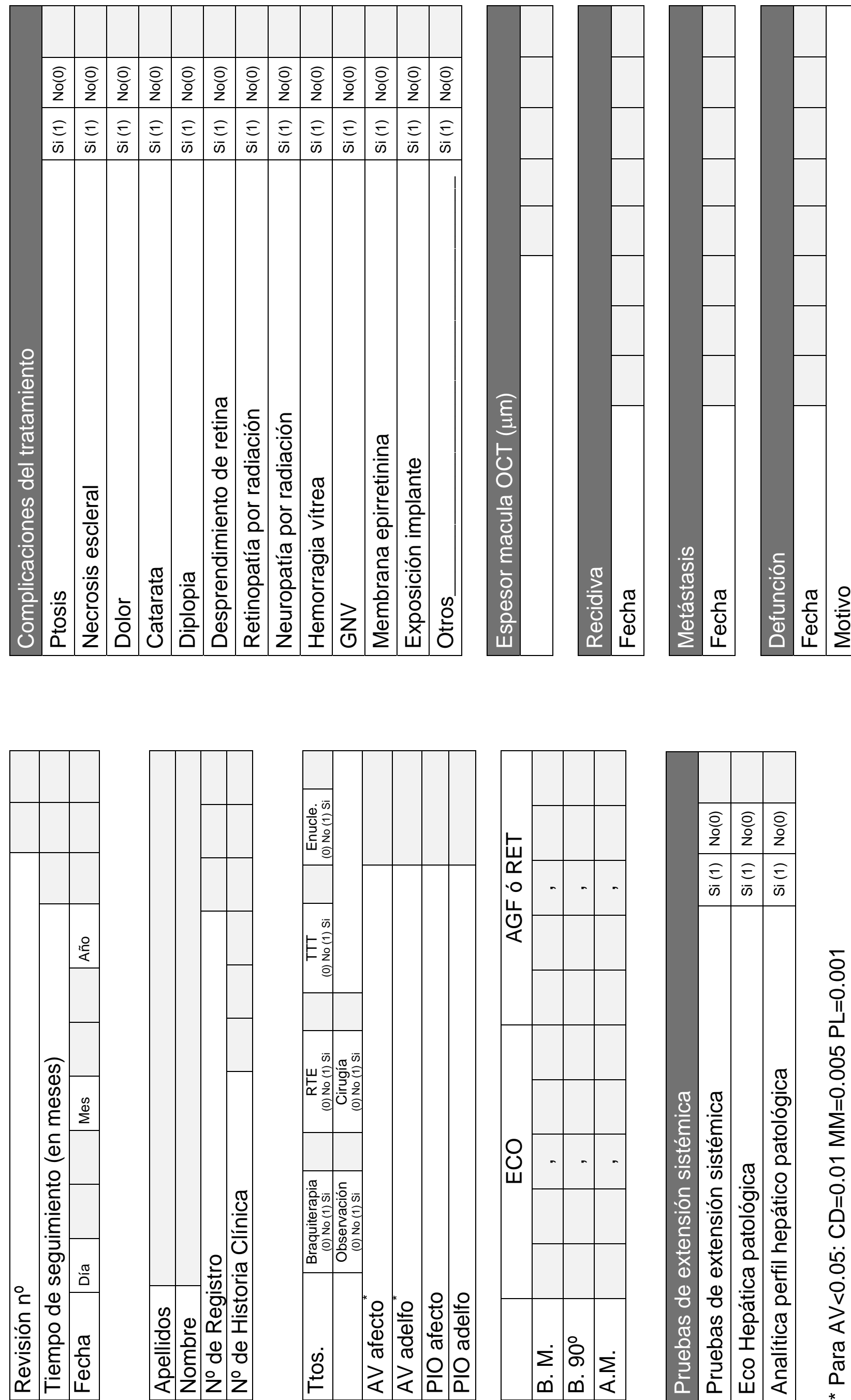

E

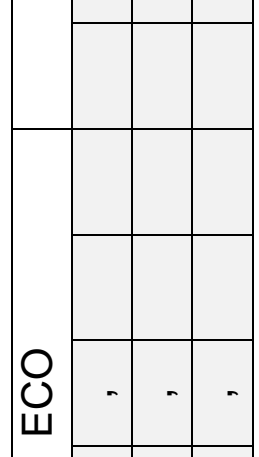

(ָ)
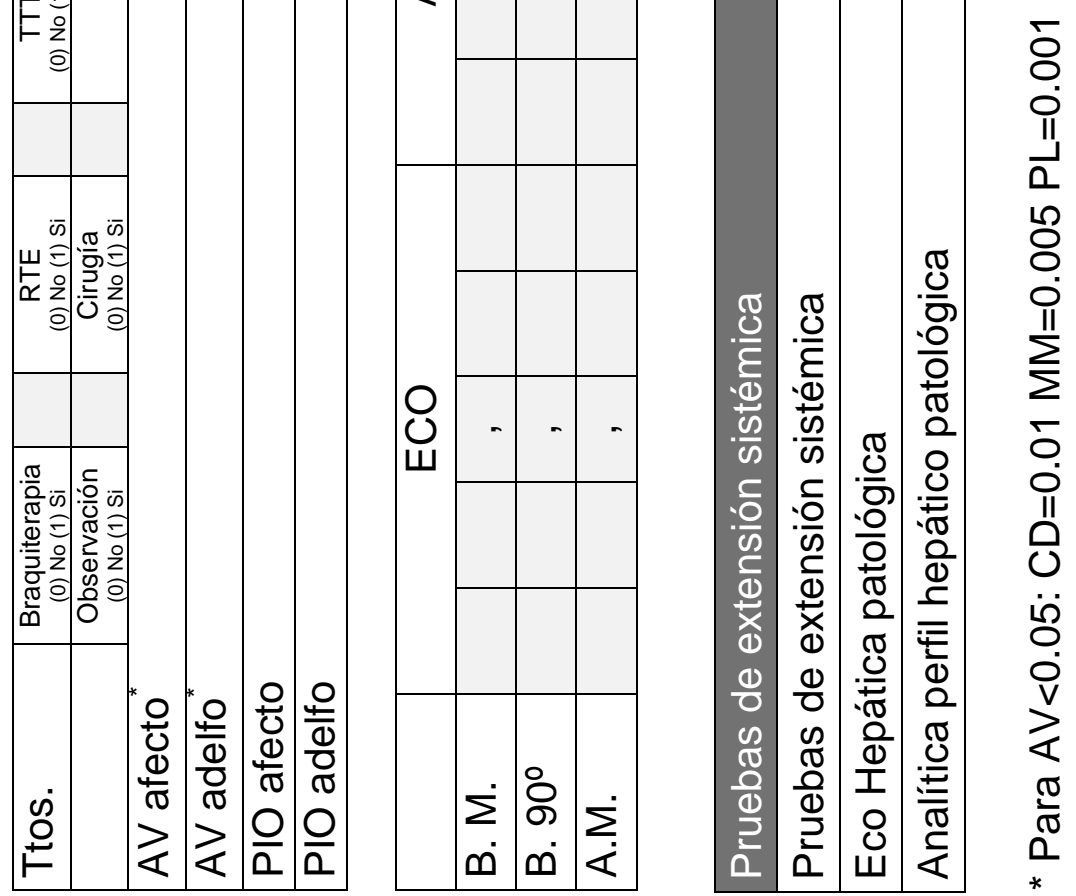



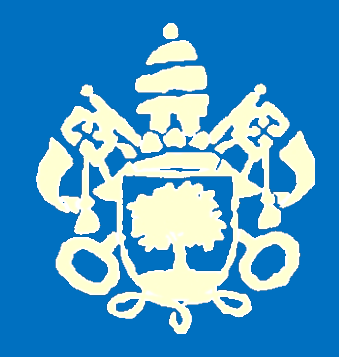

